\title{
AUTOMATED DYNAMIC PROPELLER TESTING AT LOW REYNOLDS NUMBERS
}

\author{
By \\ DUSTIN ELI GAMBLE \\ Bachelor of Science in Mechanical and \\ Aerospace Engineering \\ Oklahoma State University \\ Stillwater, OK \\ 2009
}

Submitted to the Faculty of the

Graduate College of the Oklahoma State University in partial fulfillment of the requirements for the Degree of MASTER OF SCIENCE December, 2009 
COPYRIGHT

BY

Dustin Eli Gamble

December, 2009 


\section{AUTOMATED DYNAMIC PROPELLER TESTING AT LOW REYNOLDS NUMBERS}

Thesis Approved:

Dr. Andrew Arena

Thesis Adviser

Dr. Jamey Jacob

Committee Member

Dr. Gary Young

Committee Member

Dr. A. Gordon Emslie

Dean of the Graduate College 


\section{ACKNOWLEDGMENTS}

I would like to think my family and friends for positively influencing me to continue my research and complete it in a timely manner.

I would also like to think my adviser Dr. Andrew Arena for his support throughout my undergraduate and graduate college career. 


\section{TABLE OF CONTENTS}

Chapter 1. Propeller Introduction .............................................................................. 1

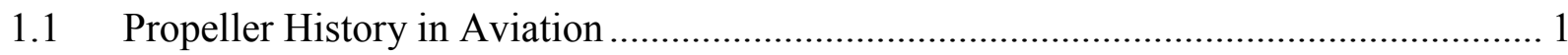

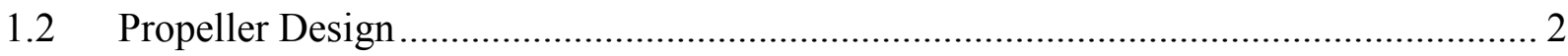

1.3 Overall objectives and goals of Thesis................................................................ 4

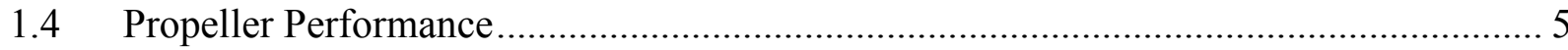

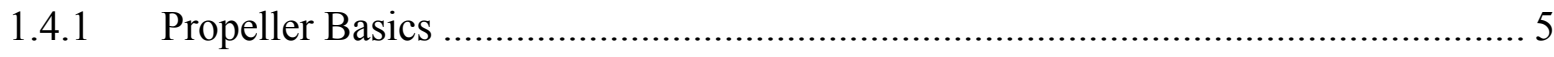

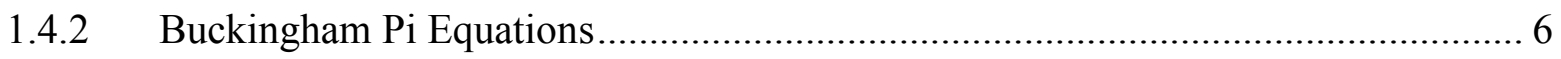

1.4.3 Reynolds number effect on Propellers ...................................................... 10

1.4.4 Unique propeller Reynolds Number Equation............................................. 11

1.5 Previous Work in Low Reynolds number ........................................................... 12

1.5.1 Low Reynolds number........................................................................... 12

1.6 Preliminary analysis of Low Reynolds numbers airfoils .................................... 15

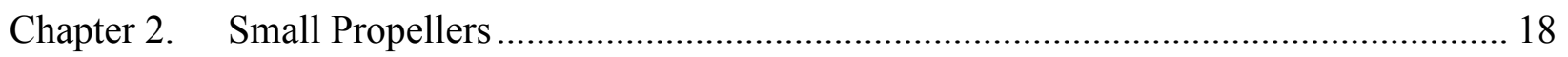

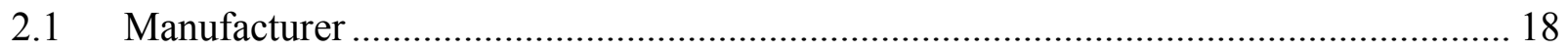

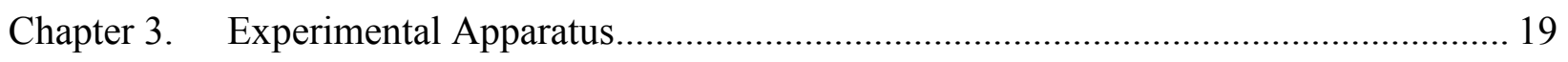

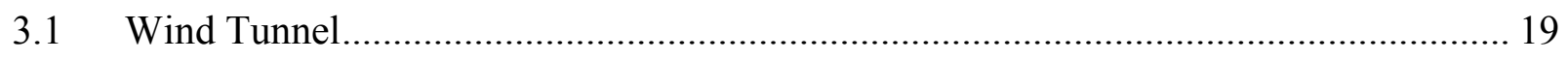

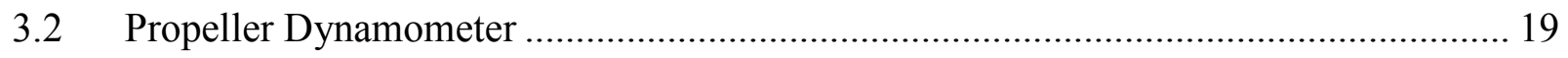




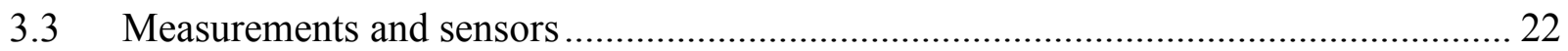

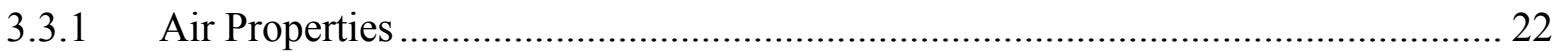

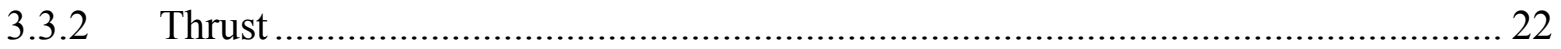

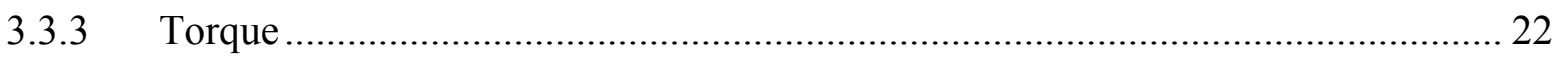

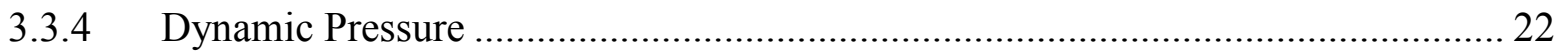

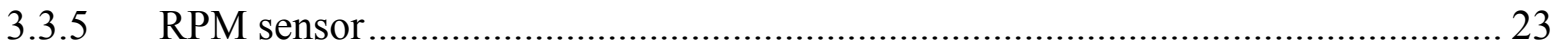

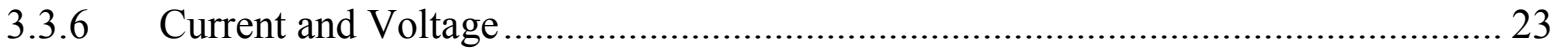

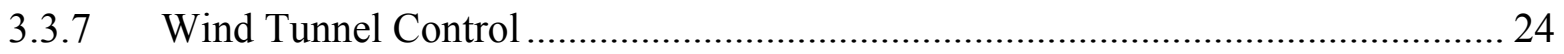

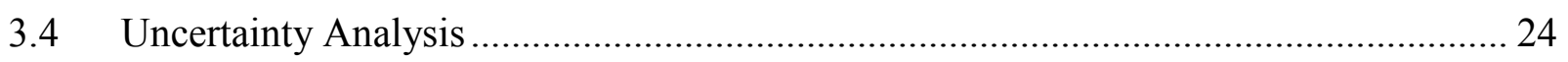

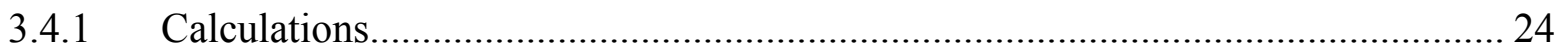

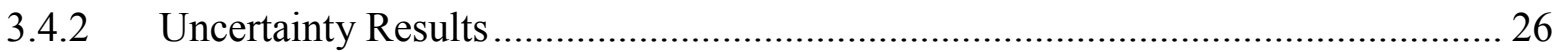

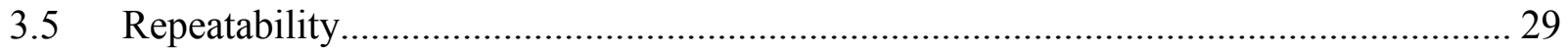

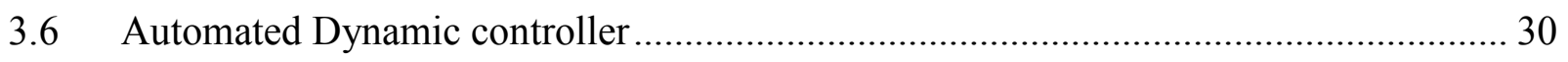

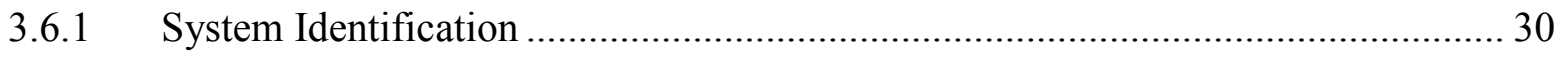

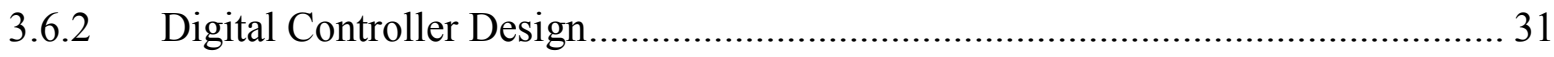

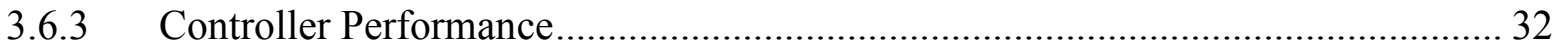

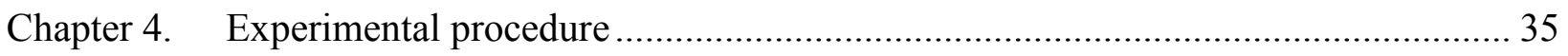

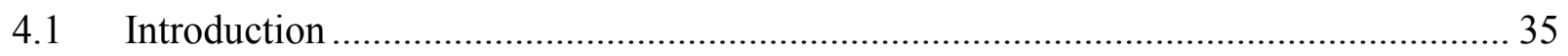

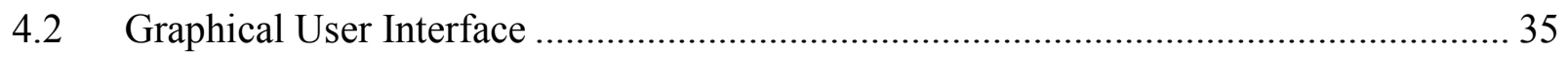

4.3 Dynamometer operations (How to use) …………...................................................... 36 
4.3.1 Data Acquisition System Initialization

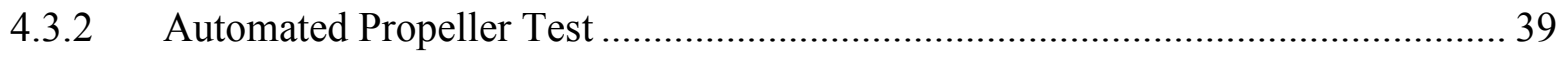

4.3.3 Manual Propeller Test....................................................................................... 41

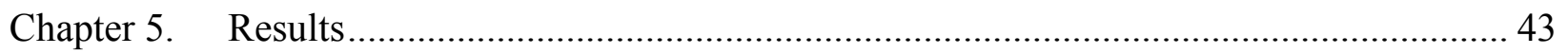

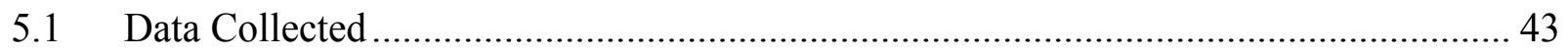

5.2 Low Reynolds Number Effect on Propellers .................................................... 50

5.3 Data Collected on Various pitched Propellers ................................................ 52

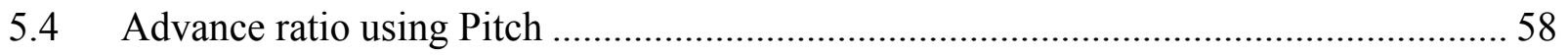

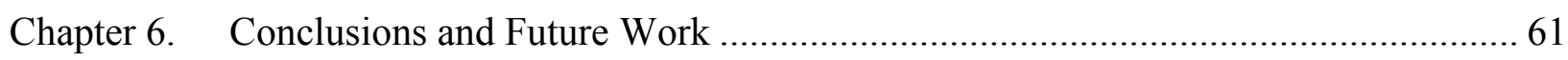

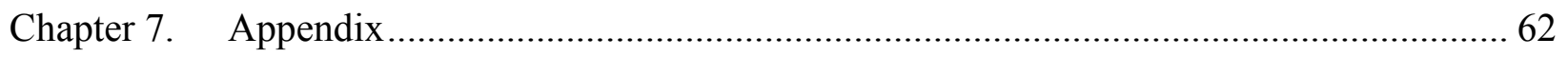

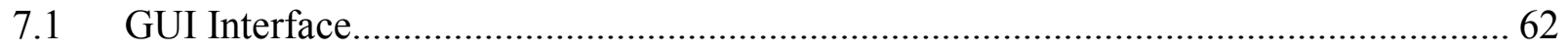

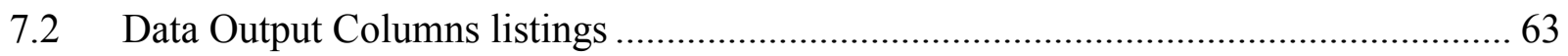

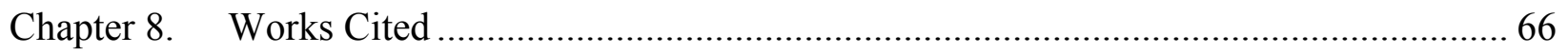




\section{LIST OF TABLES:}

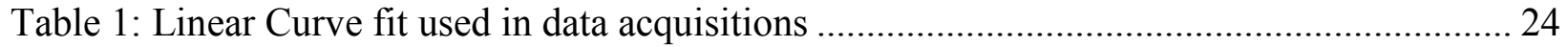

Table 2: Measurement and accuracy for sensors ................................................................ 25

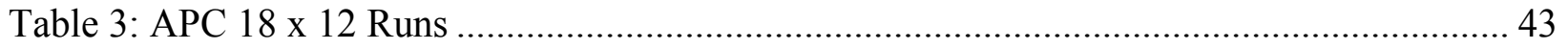

Table 4: APC 18 x 8 Test Runs ..................................................................................... 52

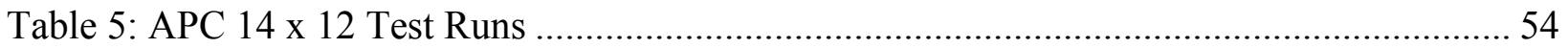




\section{TABLE OF FIGURES}

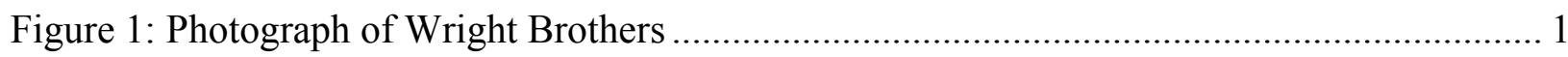

Figure 2: Kettering Bug flying bomb 1918 Courtesy: U.S. AIR FORCE MUSEUM. …………... 2

Figure 3: Propeller trailing helicoidal vortex sheets ............................................................. 3

Figure 4: Comparison of test and calculated propeller efficiency with and without the Reynolds

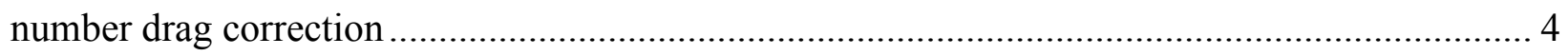

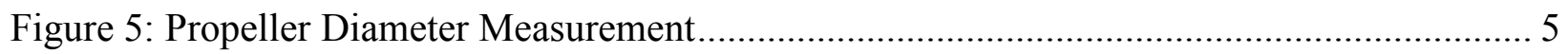

Figure 6: Propeller Pitch Measurement ………………...................................................... 6

Figure 7: Wright Brothers Bend End Propeller Efficiency...................................................... 7

Figure 8: Efficiency Curves for full scale wood propellers at various with various pitches .......... 8

Figure 9: Hartzell Propeller Curves. Courtesy of Hartzell Propeller Inc...................................... 9

Figure 10: Hamilton Standard Propeller Data ……................................................................ 10

Figure 11: Local Low Reynolds number effect on propeller.................................................... 11

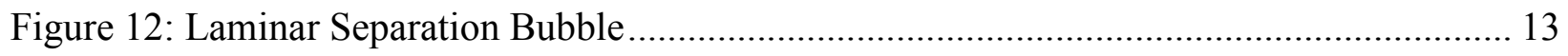

Figure 13: Sectional Lift and Drag showing hysteresis ............................................................. 13

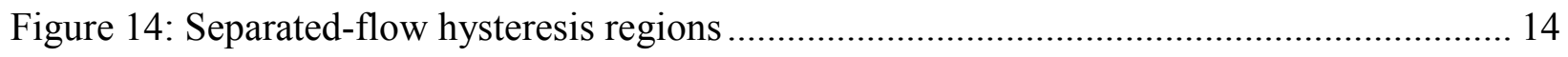

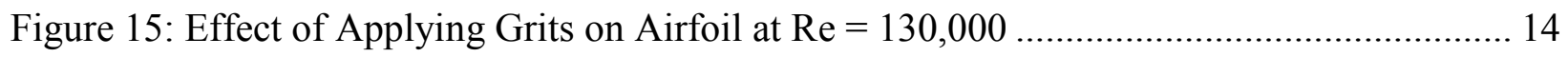

Figure 16: High to Low Reynolds number Comparison, drawn by Profili 2.21 .......................... 15

Figure 17: Cd vs Cl Reynolds number effect, drawn by Profili 2.21 ...................................... 16

Figure 18: L/D vs. Reynolds Number, Computed with XFoil.................................................... 17

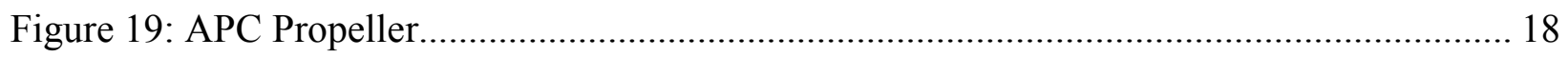

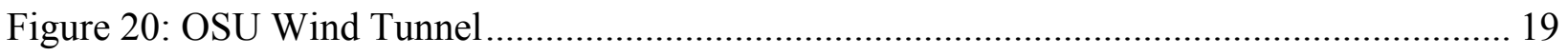

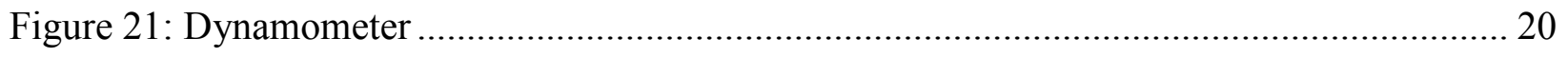




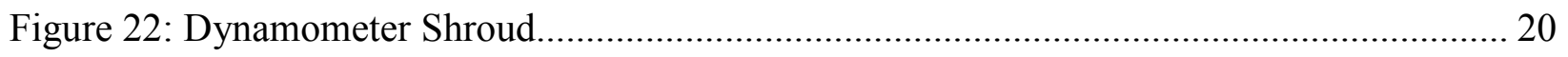

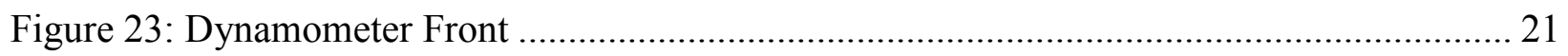

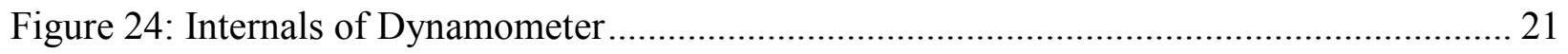

Figure 25: LabVIEW ${ }^{\mathrm{TM}}$ module for data acquisition................................................................. 22

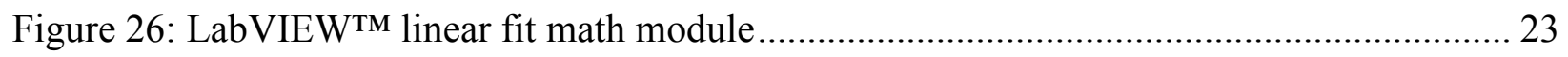

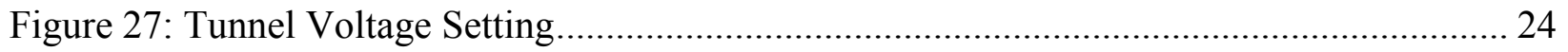

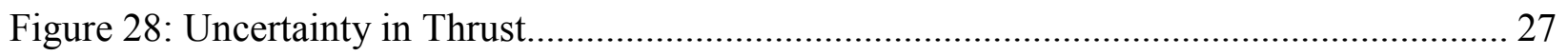

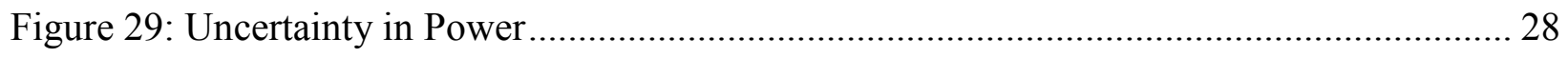

Figure 30: Uncertainty in Efficiency plotted over curve ...................................................... 28

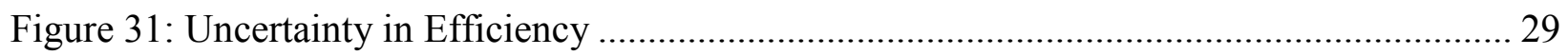

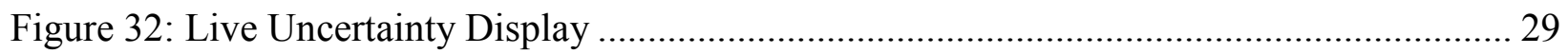

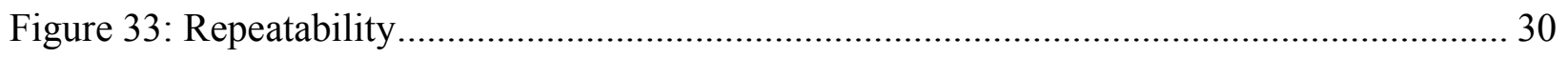

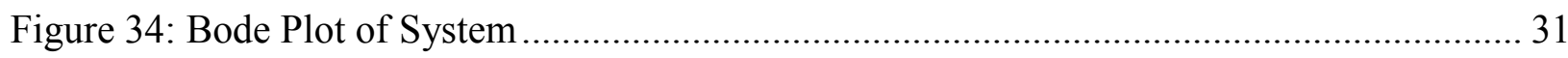

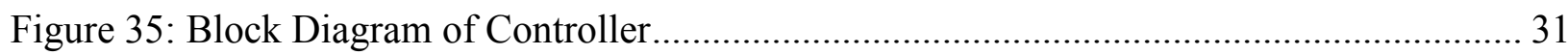

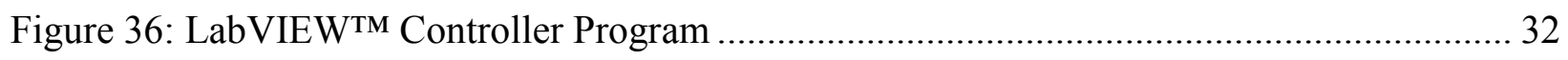

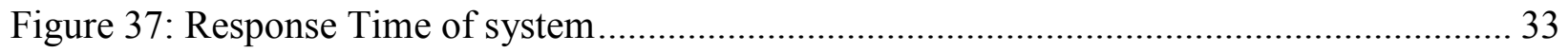

Figure 38: RPM Hold during entire Propeller Experiment........................................................ 33

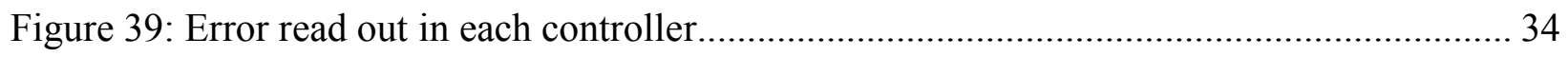

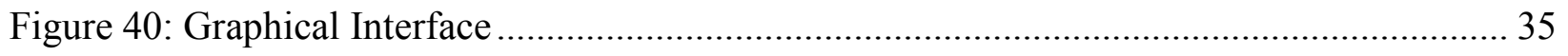

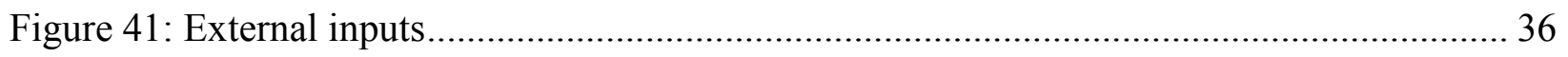

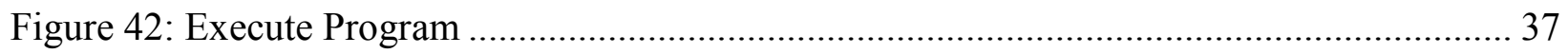

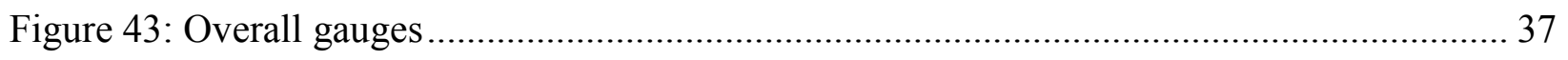

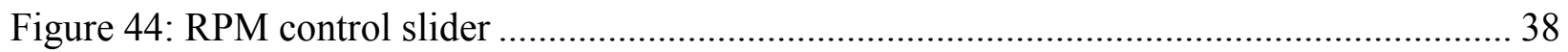




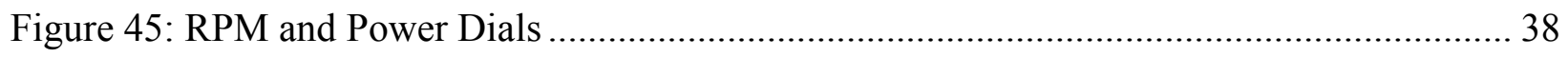

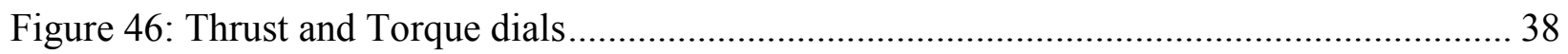

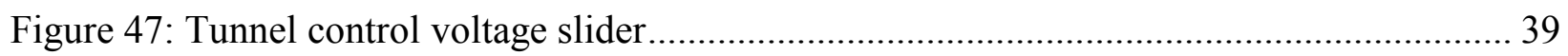

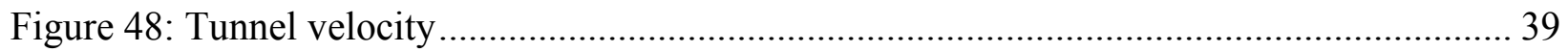

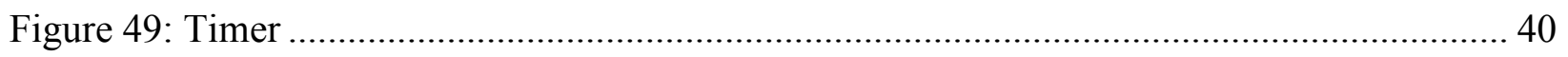

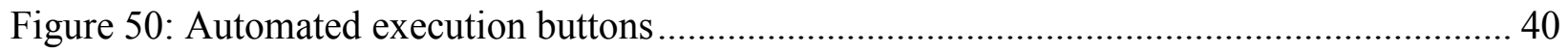

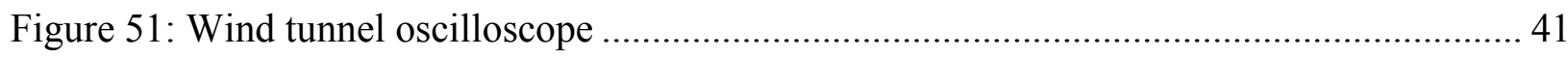

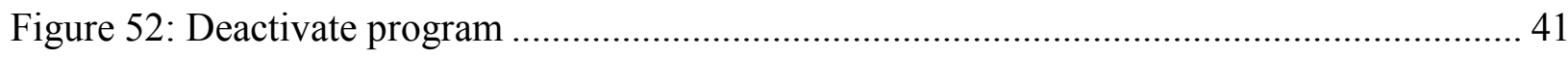

Figure 53: Propeller efficiency dial and advance ratio graph .................................................... 42

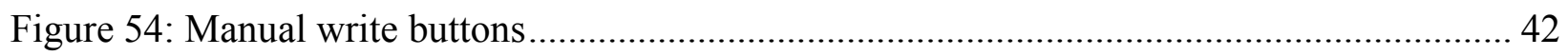

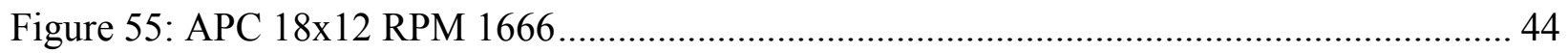

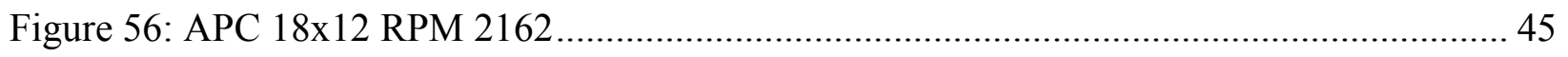

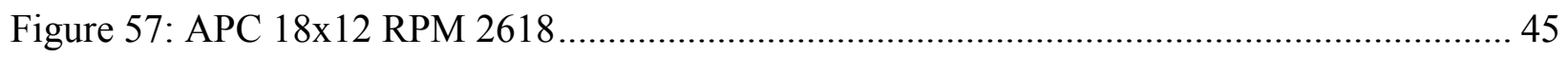

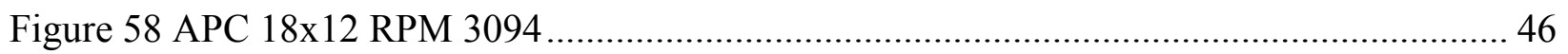

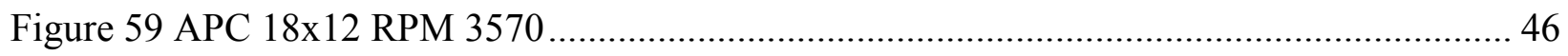

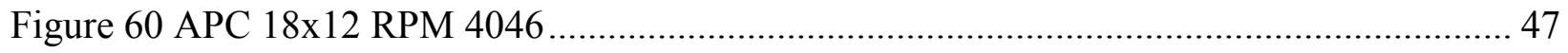

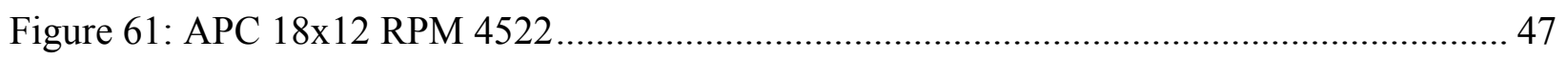

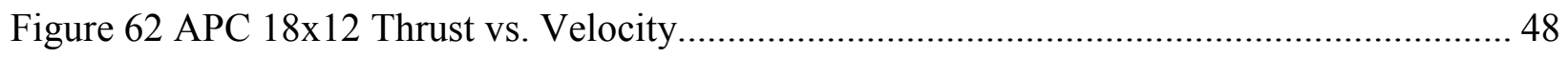

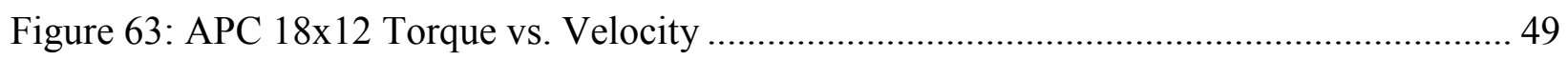

Figure 64: Efficiency Results over Propeller Reynolds number ................................................ 50

Figure 65: Coefficient of Thrust compared to Reynolds Number ................................................. 51

Figure 66: Coefficient of Power compared to Reynolds Number ............................................... 51

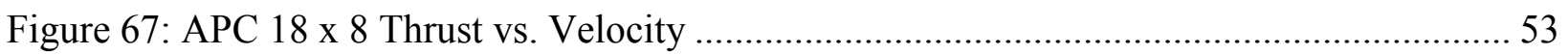




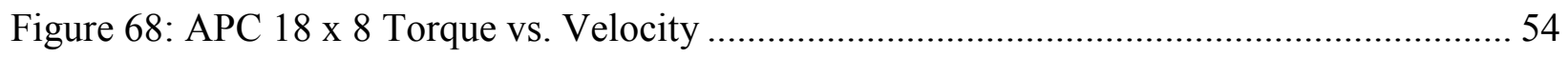

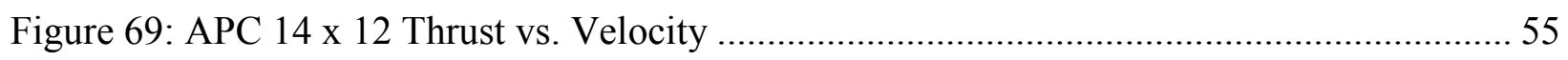

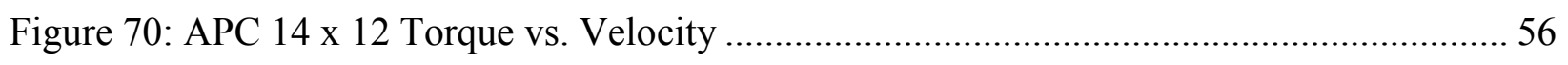

Figure 71: Low Reynolds Number Propeller Pitch Effect........................................................... 57

Figure 72: Reynolds effect on Propeller efficiency and pitch ................................................... 58

Figure 73: Propeller efficiency vs. advance ratio using pitch................................................... 59

Figure 74: Propeller efficiency vs. advance ratio using pitch with 3 bladed Feudenthaler ........... 60 


\section{TABLE OF EQUATIONS}

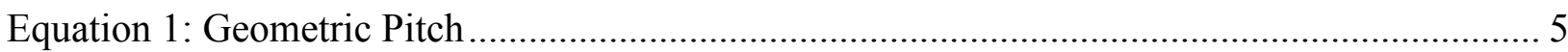

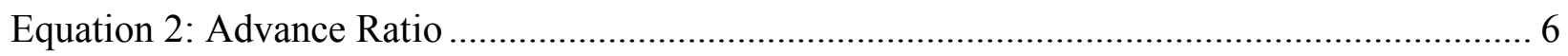

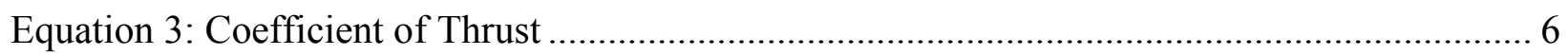

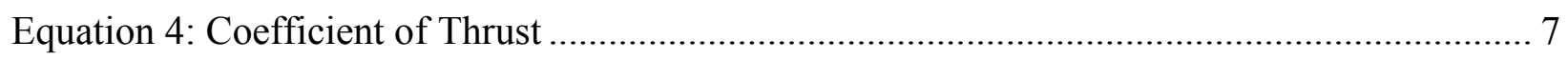

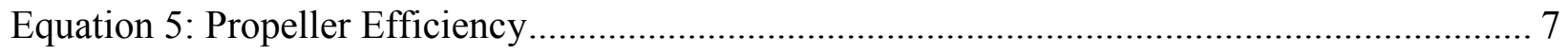

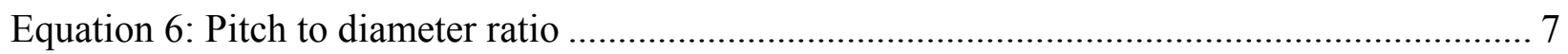

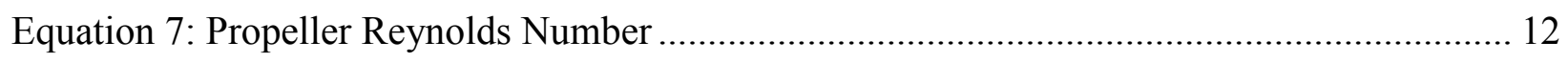

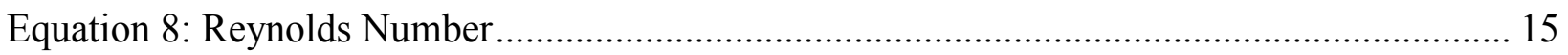

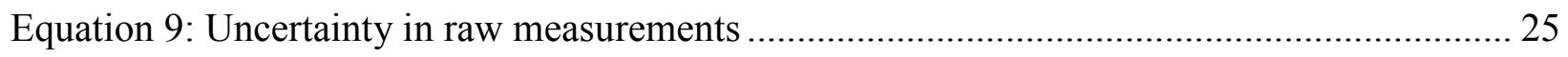

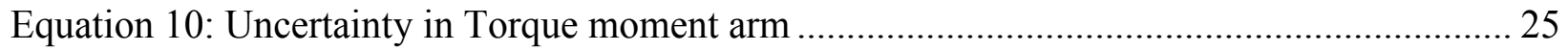

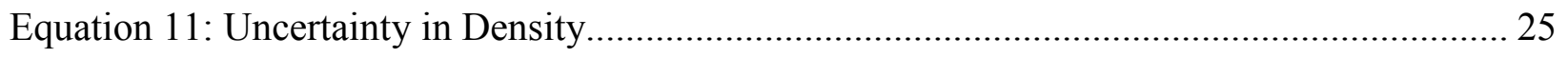

Equation 12: Uncertainty in Free Stream Velocity .................................................................. 25

Equation 13: Uncertainty in the Advance Ratio Calculation......................................................... 26

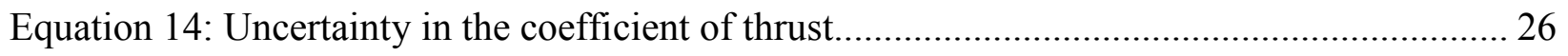

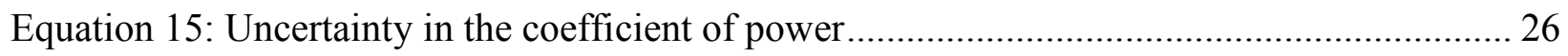

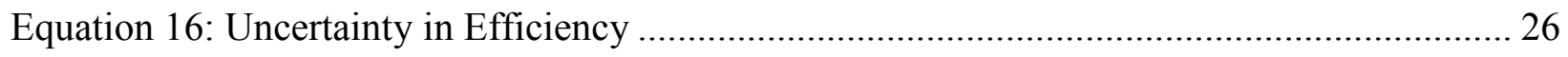




\section{NOMENCLATURE/ LIST OF SYMBOLS}

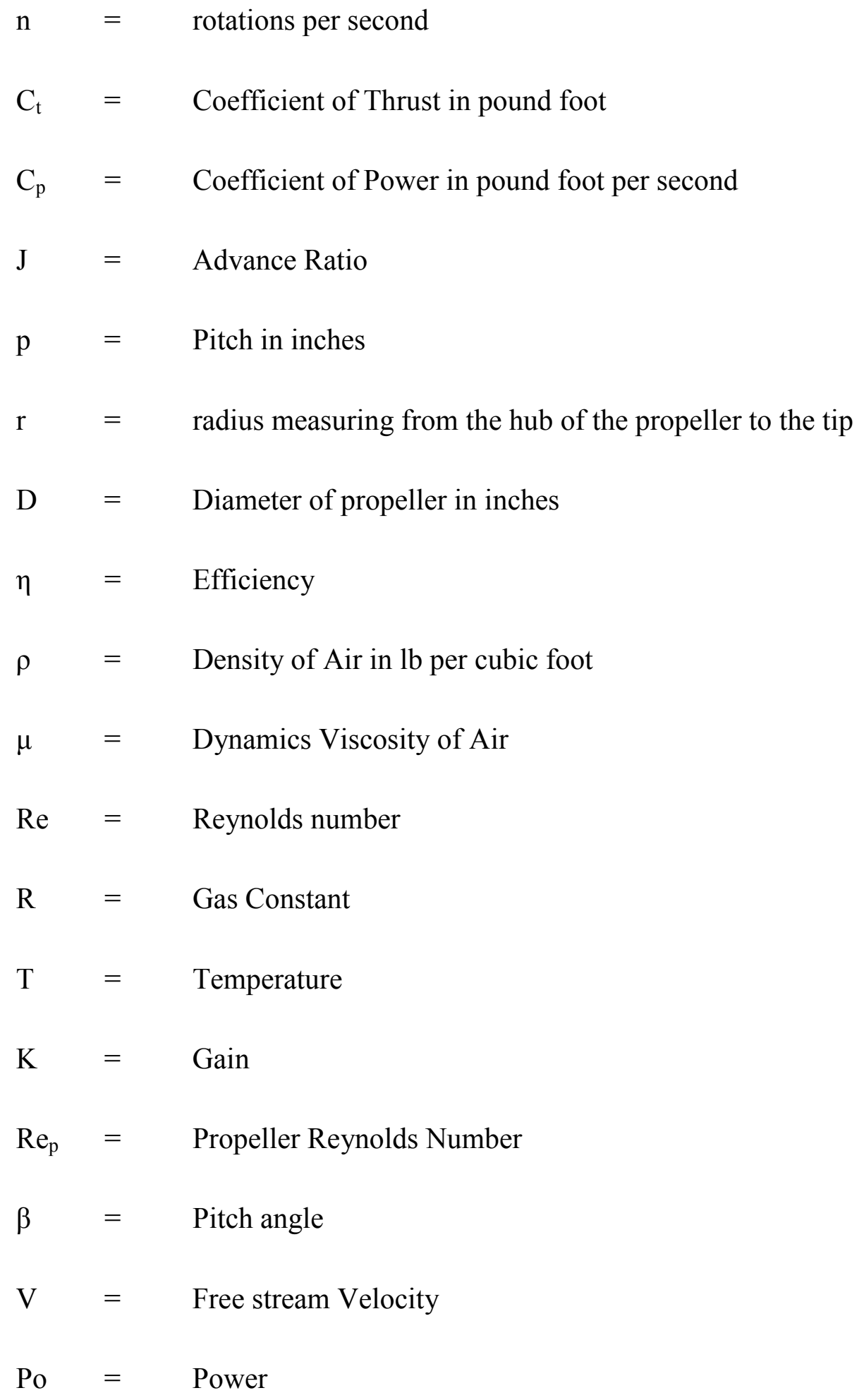




$$
\begin{array}{lll}
\mathrm{L} & = & \text { Chord length } \\
\mathrm{h} & = & \text { height measurement } \\
\varepsilon_{\mathrm{n}} & = & \text { Uncertainty in RPM } \\
\varepsilon_{\mathrm{F}} & = & \text { Uncertainty in Torque Load Cell } \\
\varepsilon_{\mathrm{T}} & = & \text { Uncertainty in Thrust load cell } \\
\varepsilon_{\mathrm{P}} & = & \text { Uncertainty in pressure } \\
\varepsilon_{\mathrm{D}} & = & \text { Uncertainty in Diameter } \\
\varepsilon_{\mathrm{H}} & = & \text { Uncertainty in Moment arm measurement } \\
\varepsilon_{\rho} & = & \text { Uncertainty in air density } \\
\varepsilon_{\mathrm{n}} & = & \text { Uncertainty in RPM } \\
\varepsilon_{\mathrm{V}} & = & \text { Uncertainty in Free Stream Velocity } \\
\mathrm{n}_{\mathrm{m}} & = & \text { Uncertainty in the coefficient of thrust } \\
\sigma_{\mathrm{D}} & = & \text { Accuracy in Diameter } \\
\varepsilon_{\mathrm{cp}} & = & \text { Uncertainty in the coefficient of power } \\
\varepsilon_{\mathrm{\eta}} & = & \text { Uncertainty in efficiency } \\
\sigma_{\mathrm{n}} & = & \text { Accuracy in RPM } \\
\sigma_{\mathrm{P}} & = & \text { Accuracy in Torque Load Cell } \\
& &
\end{array}
$$




$\mathrm{F}_{\mathrm{m}}=$ Maximum measurement of torque load cell
$\mathrm{T}_{\mathrm{m}}=$ Maximum measurement of thrust load cell
$\mathrm{D}_{\mathrm{m}}=$ Maximum measurement of diameter




\section{CHAPTER 1. PROPELLER INTRODUCTION}

Propellers have a long history from the beginning of aviation to their applications in modern aircraft.

\subsection{Propeller History in Aviation}

Propellers have been the keystone of aviation since the Wright Brothers completed the first sustained powered flight on December 17, 1903; the flight, which was made possible by the propeller the Wright brothers designed and built. The propeller has a deeper history, however, starting from 250 B.C. when Archimedes used the screw to advance water uphill. Leonardo daVinci then used the screw idea to create lift in his drawings of flying machines in the 1700s. Later work was done by David Bushnell in the Revolutionary War of 1776. Bushnell developed the first effective use of a screw propeller, which was used in a primitive submarine. The next leap in propellers came in the 1800 s when balloonists modified the airscrew to produce more power. This was done by collapsing the screw into a straight blade. ${ }^{1}$

The Wright Brothers completed several tests in their bicycle shop by running the propeller designs with their shop tools. But, they soon realized that static thrust alone would not give them the information they needed. Using momentum theory, Newton's Second law, and an estimate for air density of $0.075 \mathrm{lb} / \mathrm{ft}^{3}$, they were able to design a propeller with minimal loss. The Wrights first propeller used for flight had a maximum efficiency of $66 \%{ }^{2}$ After a few modifications to the design incorporating "bend-ends" the Wrights increased their propeller efficiency to $81.5 \%$ in $1905 .^{3}$

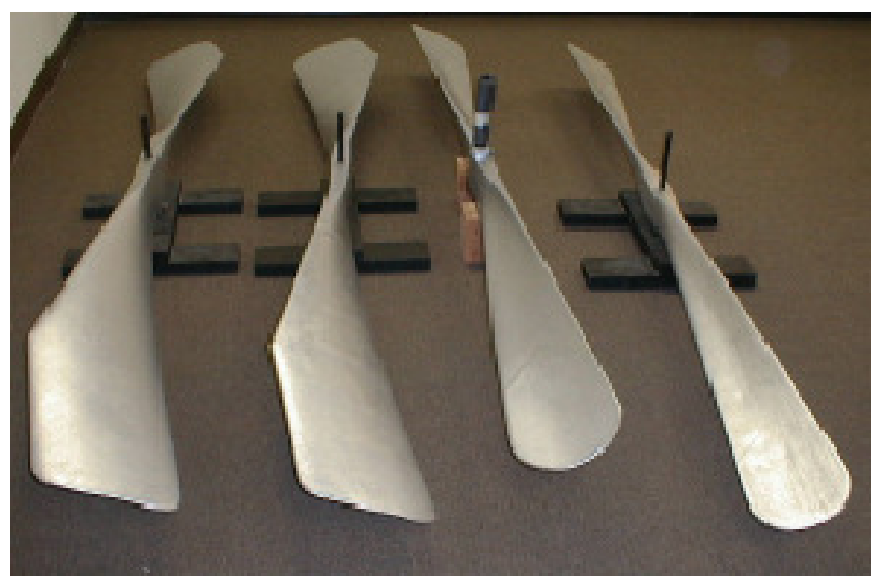

Figure 1: Photograph of Wright Brothers propeller reproductions between 1911 (left) and 1903 (right). Propeller lengths are 8 ft. 6 inches. ${ }^{4}$

\footnotetext{
${ }^{1}$ (Carroll \& Carroll, January-February 2005)

${ }^{2}$ Ibid

${ }^{3}$ (Kochersberger, Wald, \& Hyde, 2000)

4 (Ash, Miley, \& Landman, 2001)
} 
Propellers continued to make powered flight possible through the $2^{\text {nd }}$ World War until the dawn of the jet age. Quickly propellers lost popularity in modern air travel. The jet was a much higher performer with higher flight speeds and higher altitudes making travel times shorter. Jets were used to push humans to the upper limits of what is possible for aircraft with the record setting speeds of the Mach 3.2 with the Lockheed SR-71. An average citizen could fly like a fighter pilot in a Concord at twice the speed of sound in the jet.

Less than fifteen years after the Wright Flyer took flight, the Army Signal Corps flew its first Unmanned Aerial Vehicle (UAV) named the Kettering Bug flying bomb. This UAV was gyroscope controlled and would fall to the earth and explode after the propeller turned a preset number of times. This was just the beginning for UAVs. Later, ballistic missiles and then target drones used by the Air Force and Navy in the 1950s were forms that followed. ${ }^{5}$ Modern uses of UAVs are in areas of intelligence by providing the aerial eyes and ears of an operation. Top level government officials make decisions based on intelligence gathered from a UAV, and even a man on the ground can obtain the information he needs to know from a backpack deployable vehicle.

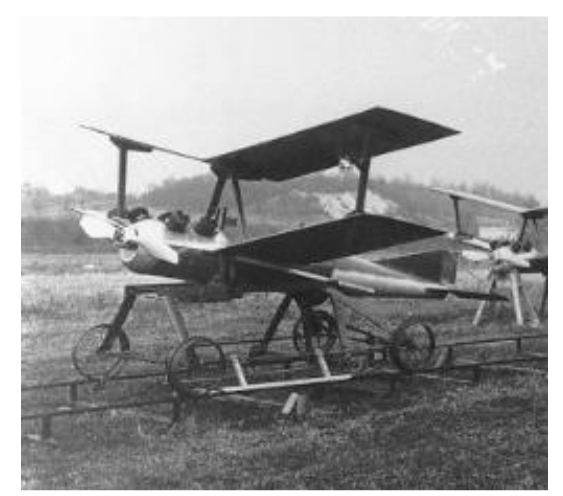

Figure 2: Kettering Bug flying bomb 1918 courtesy: U.S. AIR FORCE MUSEUM.

These types of UAV's are made possible by batteries. To convert the battery energy into thrust, a propulsions sting must be designed which includes a motor and a propeller. Brushless motors in this range have efficiencies in the low 90 percents. $^{6}$ Propellers in this class have a range of efficiencies from $50 \%$ to $80 \%$ depending on the manufacturer. ${ }^{7}$ The reason for this high range of efficiency is due to the Reynolds number that the propeller is operating at. The propeller on a UAV propulsion sting is the place where the highest loss of energy occurs.

\subsection{Propeller Design}

Original propeller design work began in the $19^{\text {th }}$ century with Rankine and Froude on marine propulsion systems. They developed the fundamental momentum relationship for a propulsive

\footnotetext{
${ }^{5}$ (Sullivan, 2005)

${ }^{6}(\mathrm{Neu})$

${ }^{7}$ (Merchant, 2004)
} 
thrust in a fluid medium. By the end of the century Drzewiecki theorized that a blade element works as if it is a single lifting surface moving through a medium on a helical path. Yet, he did not take into account the helical wake and its effect on each blade element. And although, Wilbur and Orville Wright made quick efficient propellers, their work did not aid in the development of the propeller theory. They were, however, the first to combine blade element theory and momentum theory. Momentum theory was only used to estimate the relative velocity and angle of attack of blade elements. ${ }^{8}$

The next addition to propeller theory was from Prandtl's lifting line theory of wings. Betz showed that a regular helicoidal vortex sheet moves backward un-deformed behind a propeller. Prandtl used this work to approximate a solution to the flow around the helicoidal sheet by linking the flow around the edges to the two-dimensional flow around a cascade of semi-infinite straight lamina. ${ }^{9}$

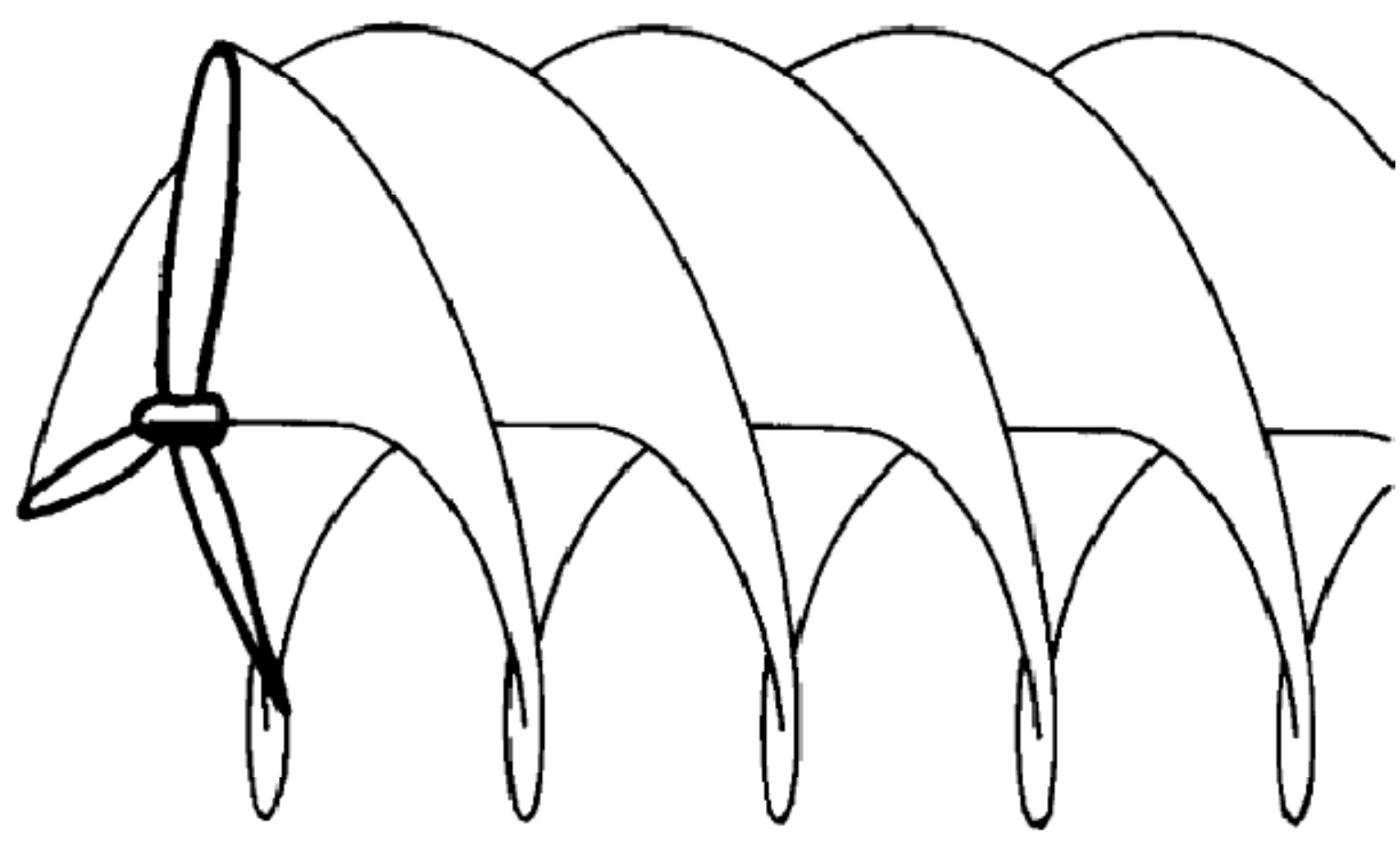

Figure 3: Propeller trailing helicoidal vortex sheets ${ }^{10}$

Goldstein followed this work and solved the problem of the potential field and distribution of circulation for a helicoidal vortex system for low advance ratios. Theodorsen then showed that underforming helicoidal sheet models of the shed vorticity should not be limited to lightly loaded propellers. This can be done if attention is drawn to the vortex system far behind the propeller

\footnotetext{
${ }^{8}$ (Wald, 2006)

${ }^{9}$ Ibid

${ }^{10}$ Ibid
} 
rather than at the propeller. The use of Goldstein's tabulated values has been viable with the mathematical efforts by Tibery and Wrench Jr. ${ }^{11}$

These mathematical models have proven very successful for designing large propellers, but it is a very different issue when designing propellers for UAV. In 1977, Borst was aware of the issues that propeller designers for remotely piloted vehicles were encountering. He showed the effect of not taking the Reynolds number into account; which was, if a correct factor was not taken into account, the propeller approximation could be off by up to $30 \%$. This error becomes more significant if the propeller was lightly loaded.

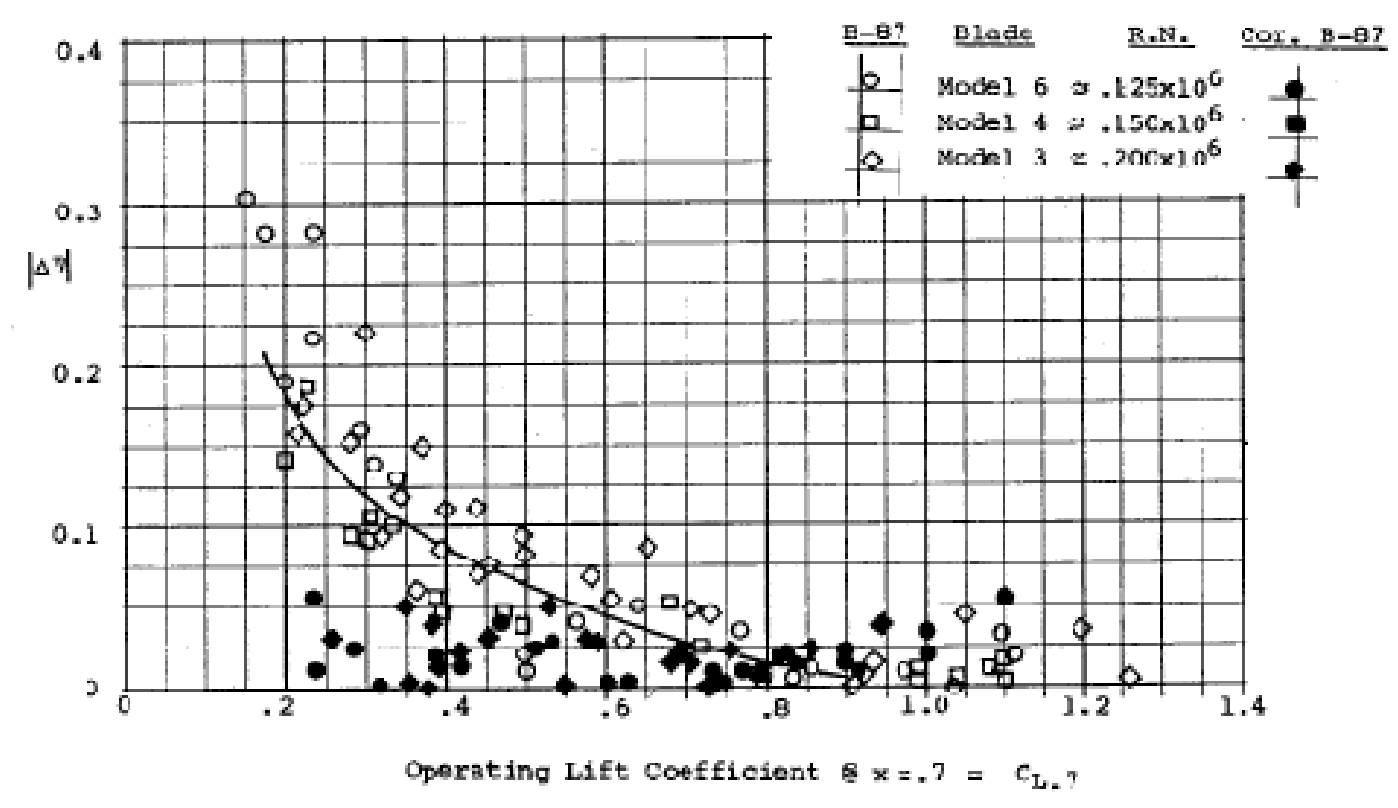

Figure 4: Comparison of test and calculated propeller efficiency with and without the Reynolds number drag correction ${ }^{12}$

\subsection{Overall objectives and goals of Thesis}

The principal objective of this thesis is to describe variations in small propeller test data and correlate those variations non-dimensionally. The secondary objective is to design a system that can acquire propeller data systematically. Data collected in such a way should be less prone to experimental errors. Before this data can be collected, the dynamometer system must be analyzed to guarantee its data has minimal uncertainty and acceptable repeatability.

The long term goals of this thesis are to generate further interest in the propellers of unmanned aerial vehicles. The level of design for small propellers is not near the design level of larger aircraft, but UAV's are usually designed for long endurance. Therefore, designers should focus on improving the performance of these propellers.

\footnotetext{
11 (Tibery \& Wrench Jr., 1964)

12 (Borst, 1977)
} 


\subsection{Propeller Performance}

Although propellers have been around for a long time, their basic operation and propeller characteristic equation have remained the same. These equations are non-dimensional which allow them to be applied to any case. This is a problem, however, with the classical approach to propellers, and has to do with the properties of air and how air reacts on the surface of the blade. This interaction differs from full scale propellers to small scale propellers.

\subsubsection{Propeller Basics}

Propellers are described by two key measurements, diameter and pitch. The diameter of a propeller is the measurement from tip to tip.

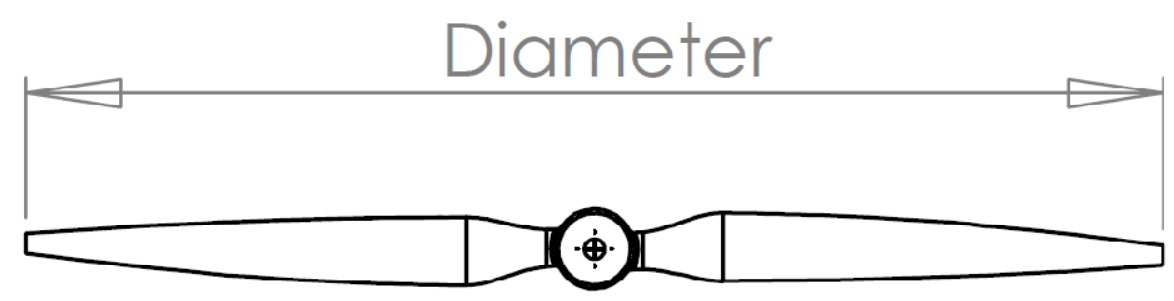

Figure 5: Propeller Diameter Measurement

The pitch of a propeller is the distance the propeller will ideally advance forward with one revolution. The twist distribution is given by the pitch equation. Beta is defined here as the pitch angle along the blade.

$$
p=2 \cdot \pi \cdot r \cdot \tan (\beta)
$$

\section{Equation 1: Geometric Pitch}

Beta can be defined by either the geometric pitch angle or by the zero lift line pitch angle. These angles are measured from a fixed plane of rotation to either the chamber line or the zero life line. If a propeller pitch is defined by the chamber line, the pitch result will vary with the amount of chamber in an airfoil. If the zero lift line is used, the pitch distributions will match any airfoil used. 


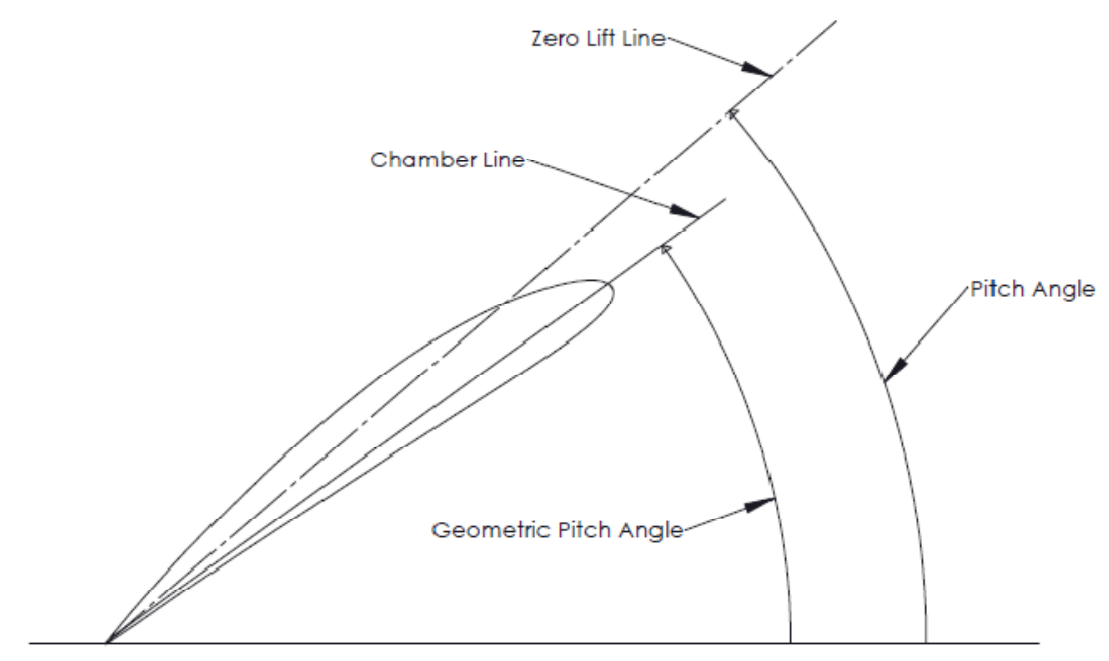

Figure 6: Propeller Pitch Measurement

A propeller is typically stated in the form diameter $\mathrm{x}$ pitch. Propeller manufactures typically list UAV propeller based on the geometric pitch angle.

\subsubsection{Buckingham Pi Equations}

Before low Reynolds number concerns can be addressed and experimentally determined, the overall system must be reevaluated to take into account the traditional understanding of propellers and account for viscosity during the experiment. Using Buckingham $\mathrm{Pi}^{13}$ techniques, along with the other given factors affecting propellers, including air density, propeller diameter, free airstream, propeller angular velocity, thrust, and power, the traditional propeller equations are found. These equation names are advance ratio, coefficient of thrust, and the coefficient of power. Efficiency can also be determined from these ratios as well as the pitch of diameter ratio.

$$
J=\frac{V}{n D}
$$

Equation 2: Advance Ratio

$$
C_{T}=\frac{T}{\rho n^{2} D^{4}}
$$

Equation 3: Coefficient of Thrust

${ }^{13}$ (Buckingham, 1914) 


$$
C_{p}=\frac{P o}{\rho n^{3} D^{5}}
$$

\section{Equation 4: Coefficient of Thrust}

$$
\eta=\frac{c_{t} \cdot J}{c_{p}}
$$

Equation 5: Propeller Efficiency

$$
\frac{\boldsymbol{P}}{\boldsymbol{D}}
$$

\section{Equation 6: Pitch to diameter ratio}

These equations are used in experimental tests to calculate the efficiency of a propeller on a nondimensional basis. One of the first propellers created by the Wright Brothers was tested in 2000 to find its efficiency. The experimental data collected created a fixed pitch propeller curve with a maximum efficiency of $83 \%$ at an advance ratio of 1.2 .

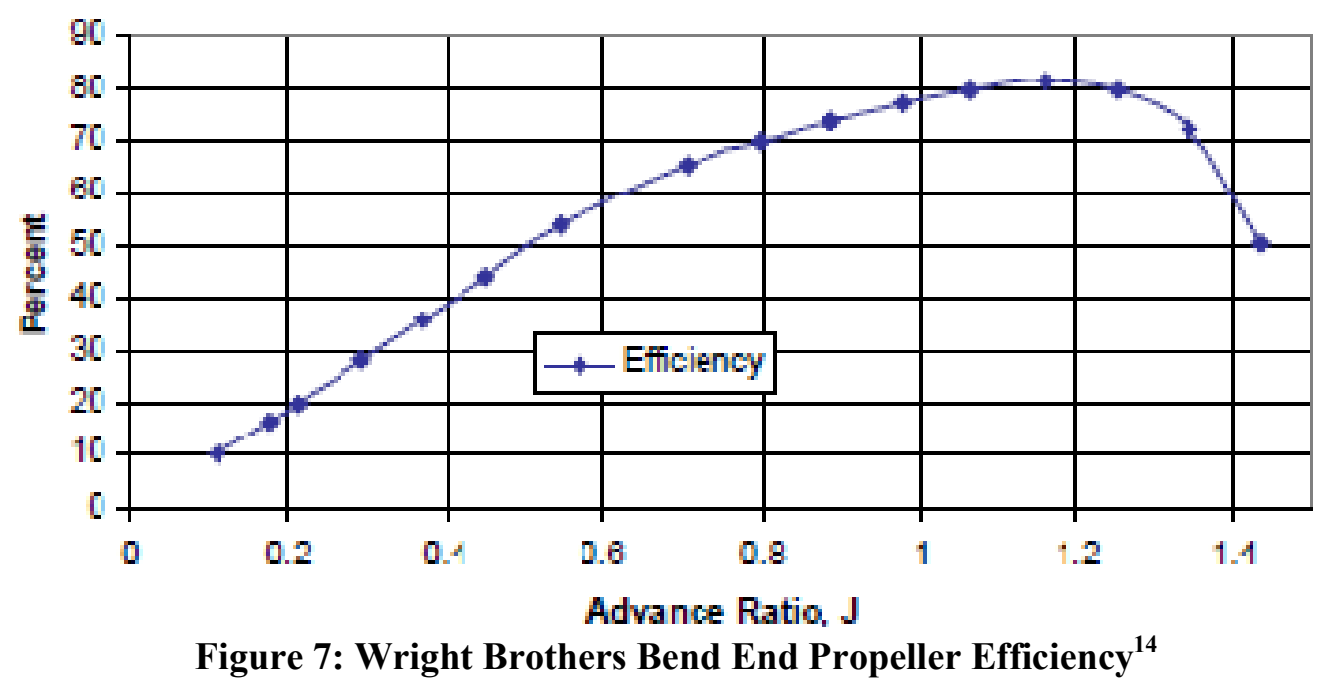

${ }^{14}$ (Kochersberger, Wald, \& Hyde, 2000) 
Later on, wooden propellers' efficiencies were found to be creating efficiencies in the high $83 \%$. These tests were conducted in the 1930s using wooden propellers during the age of bi-planes. But at this time, propellers were pitched to different angles allowing a propeller to be selected for a certain type of vehicle with a corresponding flight speed and motor driven RPM.

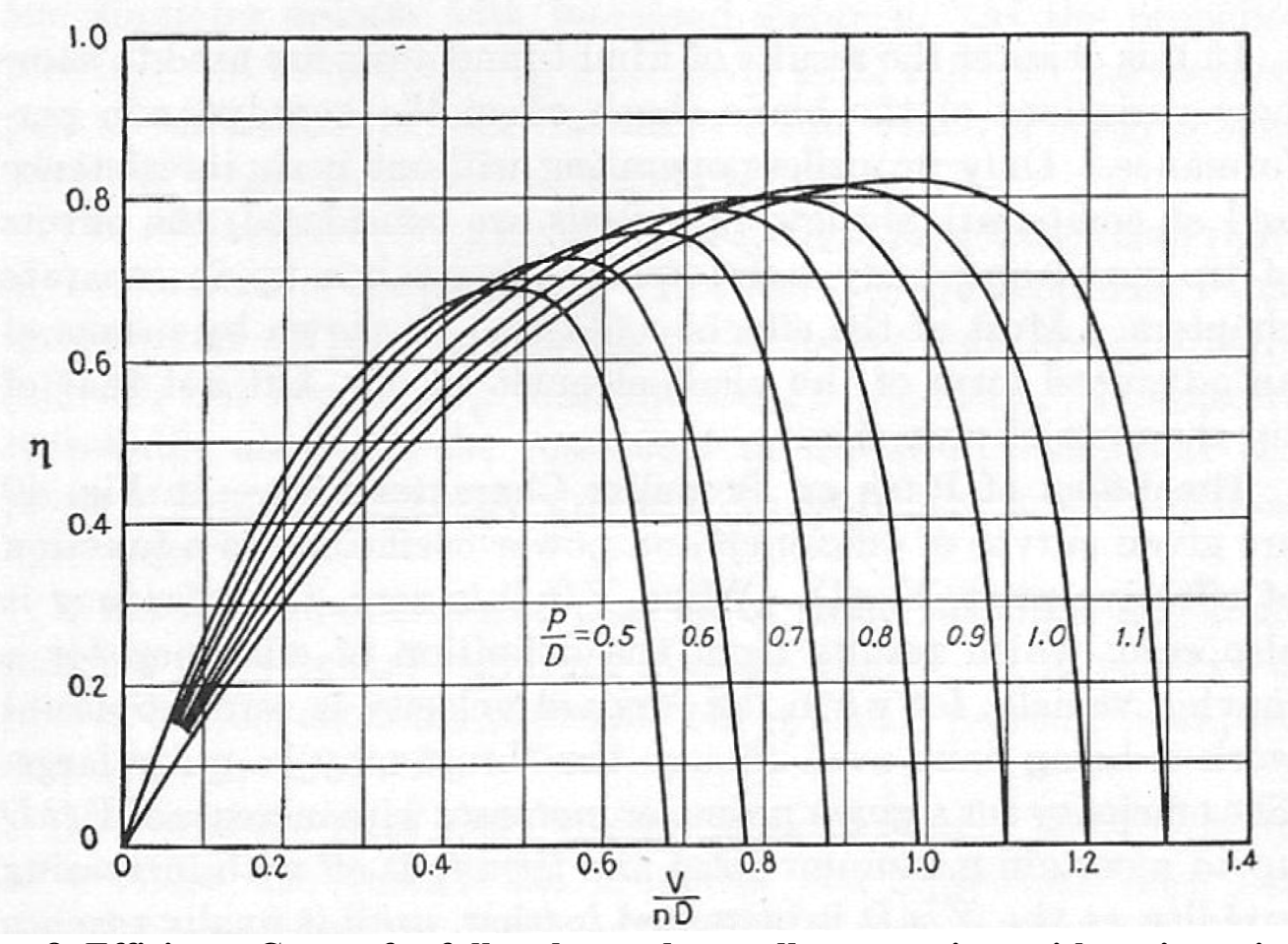

Figure 8: Efficiency Curves for full scale wood propellers at various with various pitches ${ }^{15}$

Modern propellers are constructed from metal and range from fixed pitched propellers to constant speed propellers. These propellers can obtain peak efficiencies near $90 \%$ at cruise. Several propeller manufactures were contacted to obtain their efficiency curves, but the majority of them would not release that data. However, one manufacturer, Hartzell, released data from their constant speed propeller curves. Some data sets were graphed at a couple different sets of constant pitches. These efficiency curves peaked at just under $90 \%$.

${ }^{15}$ (Weick F. E., 1930) 


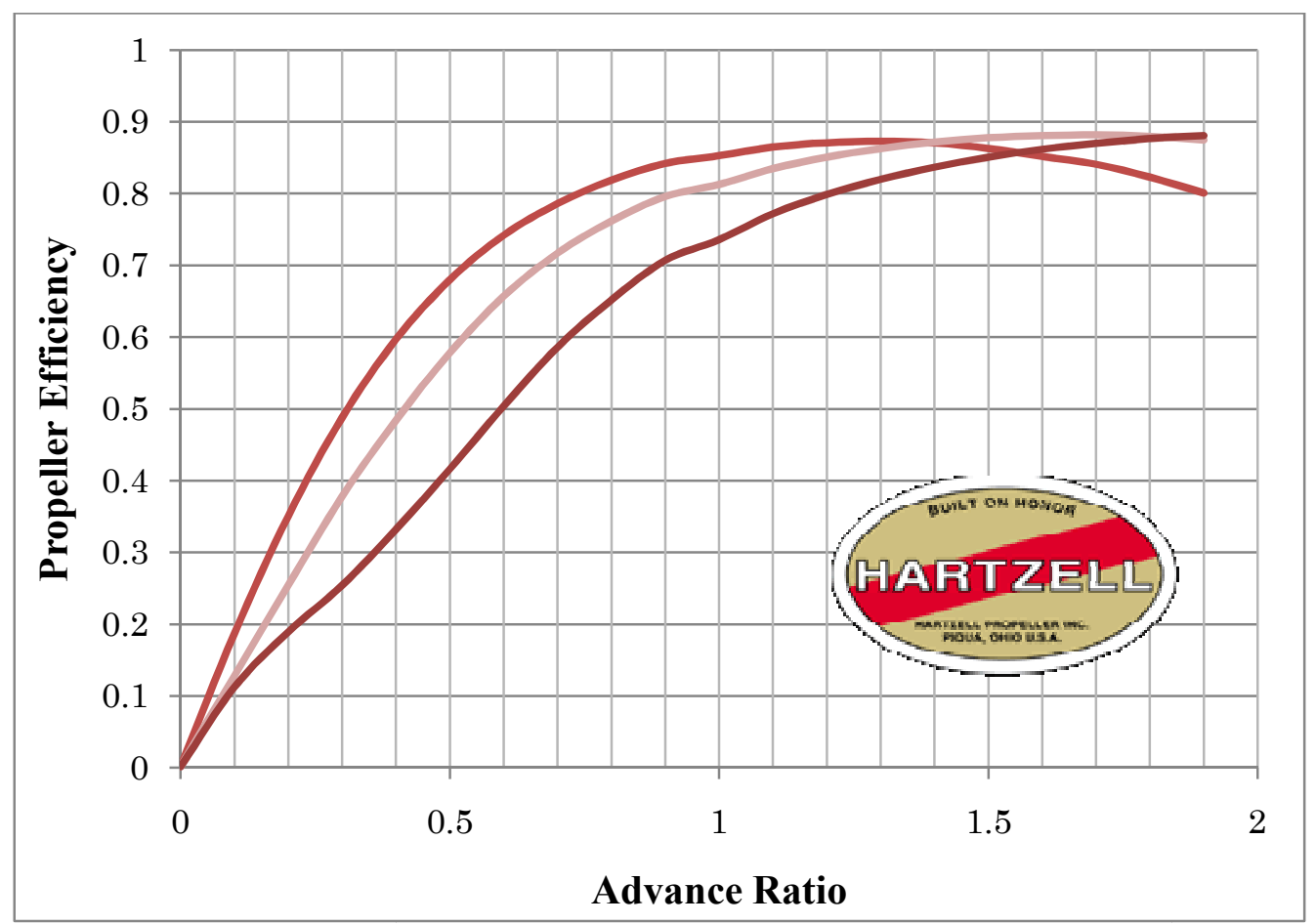

Figure 9: Hartzell Propeller Curves. Courtesy of Hartzell Propeller Inc.

For comparison, Hamilton standard data, from a textbook, is shown below. This graph is also used for a constant speed propeller, but it is a carpet plot. The graphed regions have the efficiencies listed on them. This graph shows that the propeller reaches a peak of $90 \%$ efficiency. 


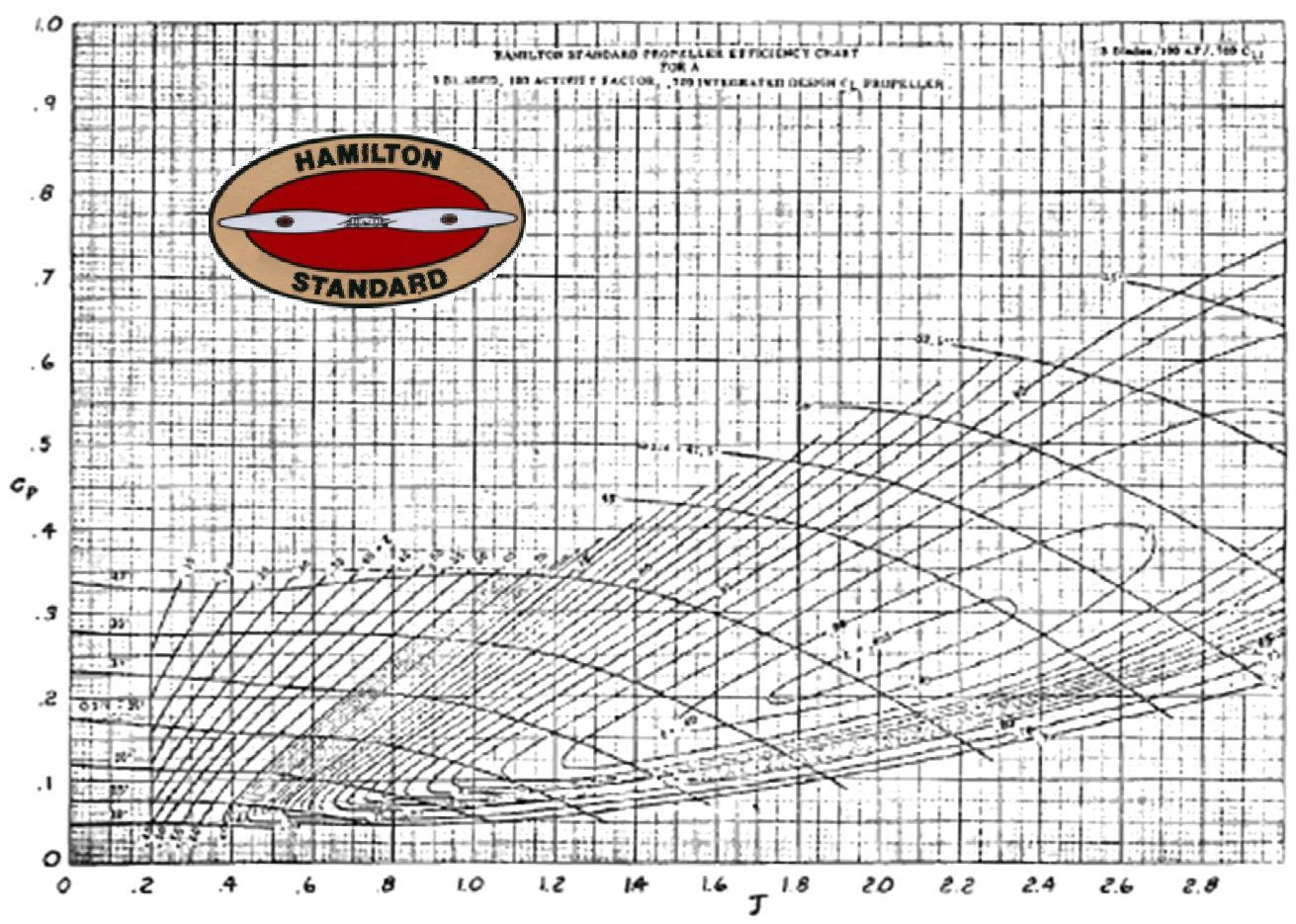

Figure 10: Hamilton Standard Propeller Data ${ }^{16}$

\subsubsection{Reynolds number effect on Propellers}

Small UAV propellers have been tested and shown to perform poorly compared to full scale propellers. Even at different RPMs, these propellers behave differently. Based on how fast the propeller spins, it could increase the efficiency by $10 \%$. Previous assumptions for understanding Reynolds numbers on propellers have been arbitrary because they are usually taken at a random location. As a result, Engineers have typically chosen $75 \%$ of the radius to calculate the Reynolds number using the airfoil cross section chord. These Reynolds numbers are calculated in such a way that the graph clearly shows that low Reynolds numbers are affecting the performance of this propeller. Figure 11 shows the experimental results from a small 16 inch diameter propeller with Reynolds number listings.

\footnotetext{
${ }^{16}$ (Roskam \& Lan, 1997)
} 


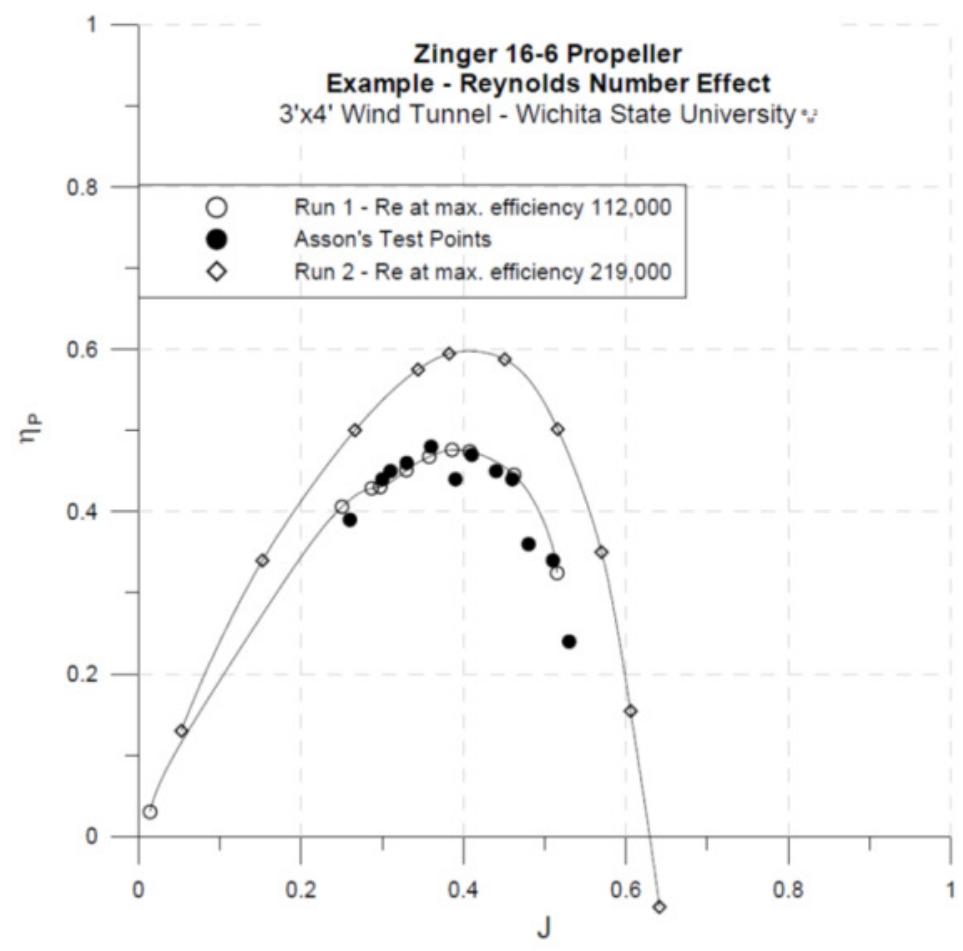

Figure 11: Local Low Reynolds number effect on propeller ${ }^{17}$

\subsubsection{Unique propeller Reynolds Number Equation}

To account for the effects of viscosity, the Buckingham Pi method was used. The first step to this process is to define all the variables to be used.

$$
\text { Function of these variables: } f=f(\rho, \mathrm{n}, \mathrm{D}, \mu)
$$

Next list all the variables available for the calculations.

Variables (Density of air, RPM, Diameter of propeller, Viscosity of air) : $[\rho n D \mu]$

After the variables have been selected, there must be a set of units which should be used.

$$
\text { Type of Units to use (Mass, Length, Time): [MLT] }
$$

Next, use the fundamental units to form the variables.

$$
\text { Fundamental Units: }\left[\frac{M}{L^{3}} \frac{1}{T} \quad L \frac{M}{L \cdot T}\right]
$$

\footnotetext{
${ }^{17}$ (Merchant, 2004)
} 
The Pi terms can be formed at this point, which are built up from the fundamental units.

$$
\text { Pi Term: } \Pi_{1}=\mathrm{n}^{\mathrm{a}} \cdot \rho^{\mathrm{b}} \cdot D^{c} \cdot \mu=\left(\frac{M}{L^{3}}\right)^{a}\left(\frac{1}{T}\right)^{b}(L)^{c}\left(\frac{M}{L \cdot T}\right)=M^{0} L^{0} T^{0}
$$

Next, solve for the Pi term exponents.

$$
\begin{gathered}
M: b+1=0 \\
L:-3 \cdot b+c-1=0 \\
T:-a-1=0 \\
a=-1, b=-1, c=-2
\end{gathered}
$$

Once the Pi exponents have been solved for, the complete Pi equation is created.

$$
\Pi_{1}=\frac{\mu}{\rho \cdot D^{2} \cdot n}
$$

This final Buckingham Pi term can be rearranged to form the propeller Reynolds number equation.

$$
R e_{p}=\frac{\rho n D^{2}}{\mu}
$$

\section{Equation 7: Propeller Reynolds Number}

This equation will allow one to determine the Reynolds number of a propeller without arbitrarily selecting a point on the propeller's blade. However, this equation should be validated by holding all coefficients constant and only changing the Reynolds number to discover the effect.

\subsection{Previous Work in Low Reynolds number}

\subsubsection{Low Reynolds number}

At low Reynolds numbers, 50,000 - 200,000, the flow has a higher interaction from viscous forces than from inertia forces. This viscous interaction can significantly increase the coefficient of drag on a section of an airfoil. In this regime, the flow is transiting from laminar to turbulent. In this transition, a leading edge separation bubble is formed when the laminar boundary layer separates from the surface as a result of strong adverse pressure gradient downstream of the point of minimum pressure. At critical values of Reynolds numbers, the laminar bubble bursts because the turbulent shear layer reattaches much further downstream to form a long bubble. ${ }^{18}$

\footnotetext{
${ }^{18}$ (Mueller \& Batill, 1982)
} 


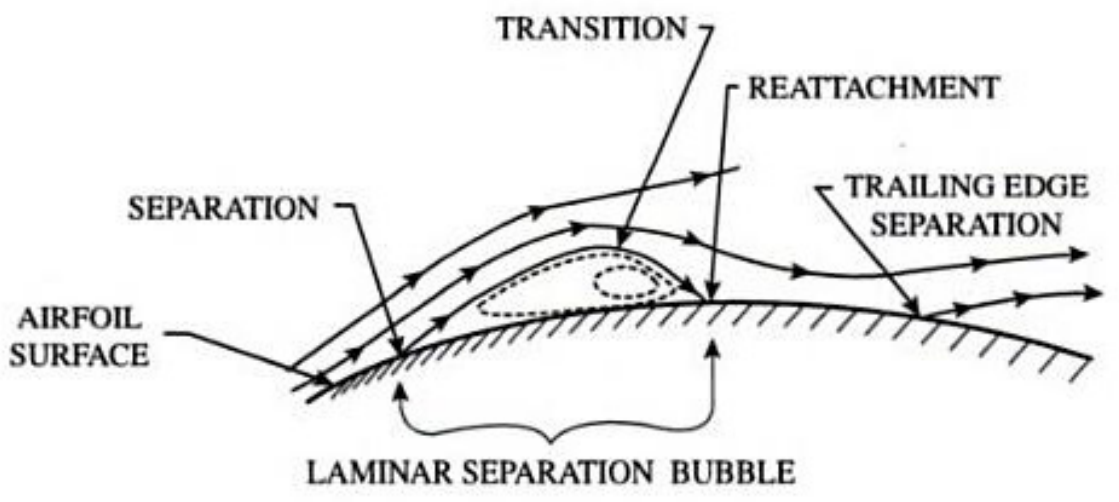

Figure 12: Laminar Separation Bubble ${ }^{19}$

Low Reynolds numbers' airfoil can also exhibit hysteresis when sweeping the angle of attack of an airfoil. The hysteresis occurs because the drag increases more as the angle of attack increases than when the angle of attack decreases from a value beyond stall. ${ }^{20}$ When a propeller spins statically and is pitched for its flight speed, the local airfoil on the propeller blade is stalled. As a propeller accelerates and the flight speed increases, the local airfoil section blade section sweeps from a stalled angle of attack to a lower angle of attack. At this Reynolds number, the propeller could behave non-linearly depending on its sweep direction.

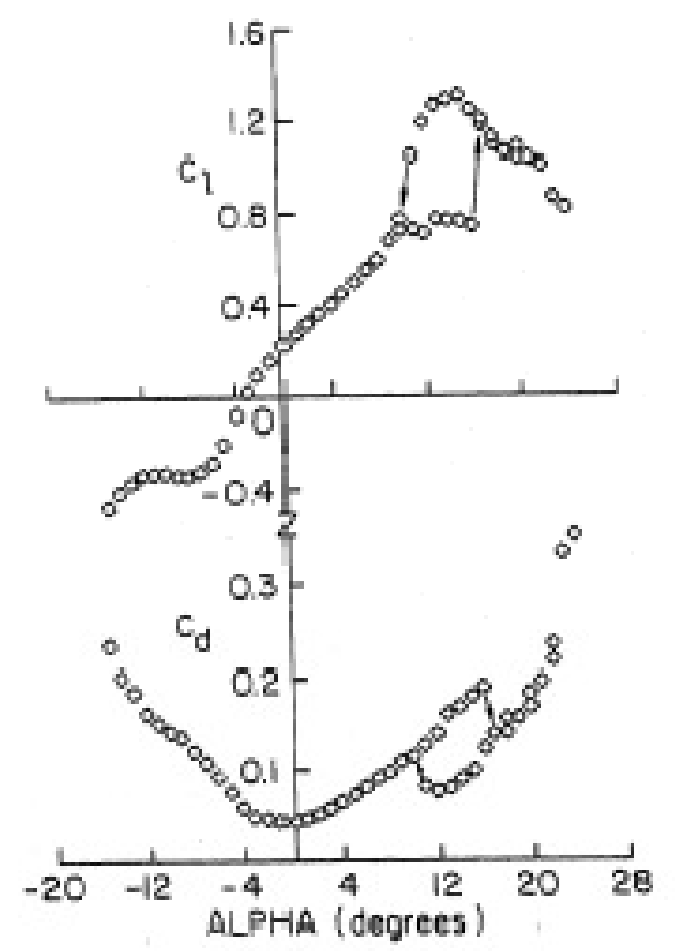

Figure 13: Sectional Lift and Drag showing hysteresis ${ }^{21}$

\footnotetext{
${ }^{19}$ (Mueller, Fixed and Flapping Wind Aerodyanmics for Micro Air Vehicle Applications, 2001)

${ }^{20}$ (Pohlen \& Mueller, 1984)

${ }^{21}$ (Pohlen \& Mueller, 1984)
} 


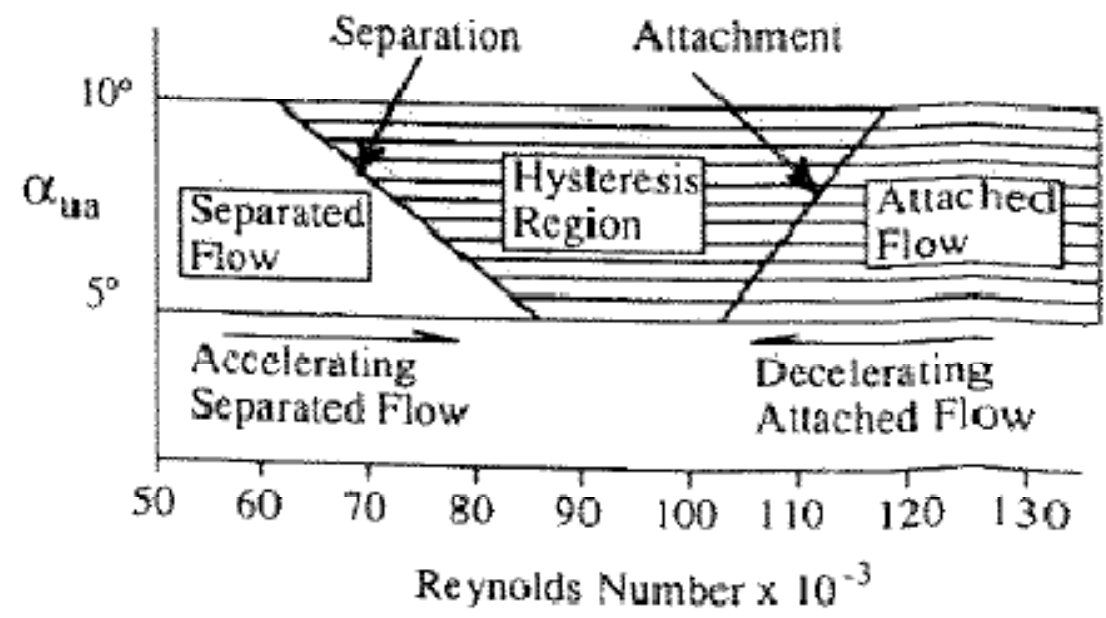

Figure 14: Separated-flow hysteresis regions ${ }^{22}$

Experimental research on applying grits or trip dots to the upper surface of an airfoil section in order to force it to transition to a higher Reynolds number and remove the laminar separation bubble has also been completed. These grits allow for the flow to stay attached at high angles of attack, but increases the coefficient of drag. ${ }^{23}$

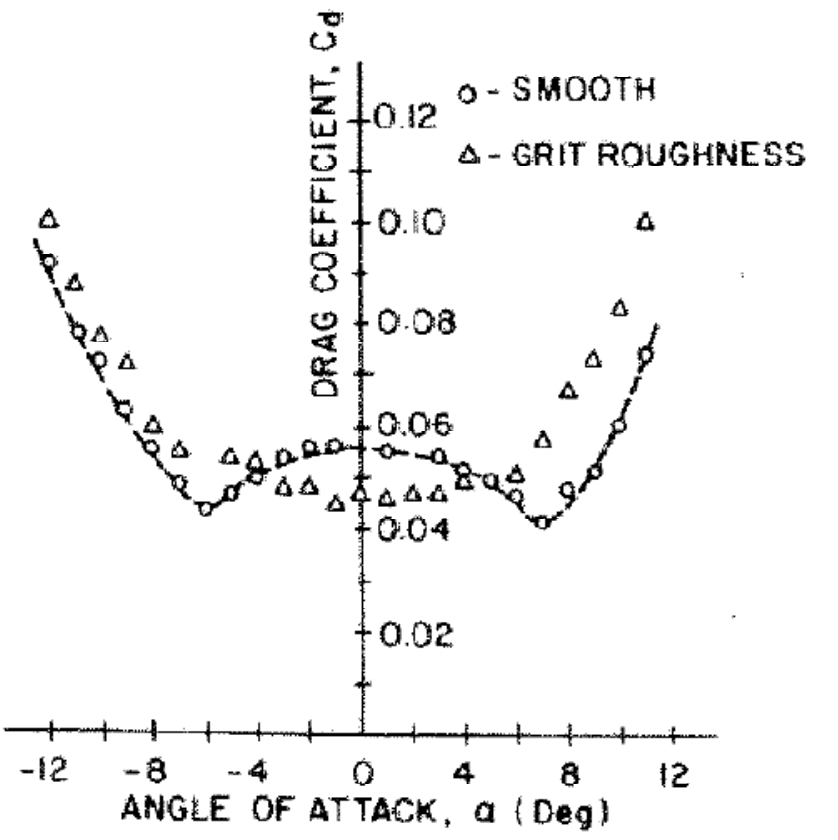

Figure 15: Effect of Applying Grits on Airfoil at $\mathrm{Re}=130,000^{24}$

22 (Scharphf \& Mueller, 1992)

${ }_{23}^{23}$ (Mueller \& Batill, 1982)

${ }^{24}$ (Mueller \& Batill, Experimental Studies of Seperation on a Two-Dimensional Airfoil at Low Reynolds Number, 1982) 


\subsection{Preliminary analysis of Low Reynolds numbers airfoils}

Reynolds numbers locally on an airfoil section can be calculated using the local velocity, chord, density, and viscosity.

$$
R e=\frac{\rho L V}{\mu}
$$

\section{Equation 8: Reynolds Number}

The local Reynolds number on a full scale propeller can be upwards of 1,000,000 or higher. This is because of the high angular velocity of the blade. At that Reynolds number, the airfoil has turbulent flow and has a low coefficient of drag. An example of a full scale propeller size and rotational speed would be, a 78 inch diameter blade spinning at 3,000 RPM. A UAV propeller can have an airfoil section Reynolds number of less than 100,000 because of its small size. A typical size for a UAV propeller is an 18 inch diameter blade spinning at 4,000 RPM.

To compare the Reynolds number effect at the airfoil cross section of each type of blade, an XFoil code was used along with the graphing software Profili. XFoil is a proven code for modeling the effects at low Reynolds numbers. ${ }^{25}$ The difference between the low Reynolds numbers airfoils are typically higher coefficients of drag at all angles of attack. The operating regime is also narrower compared with the high Reynolds number airfoil. This would mean that a propeller would have a very narrow operation area to gain maximum efficiency.

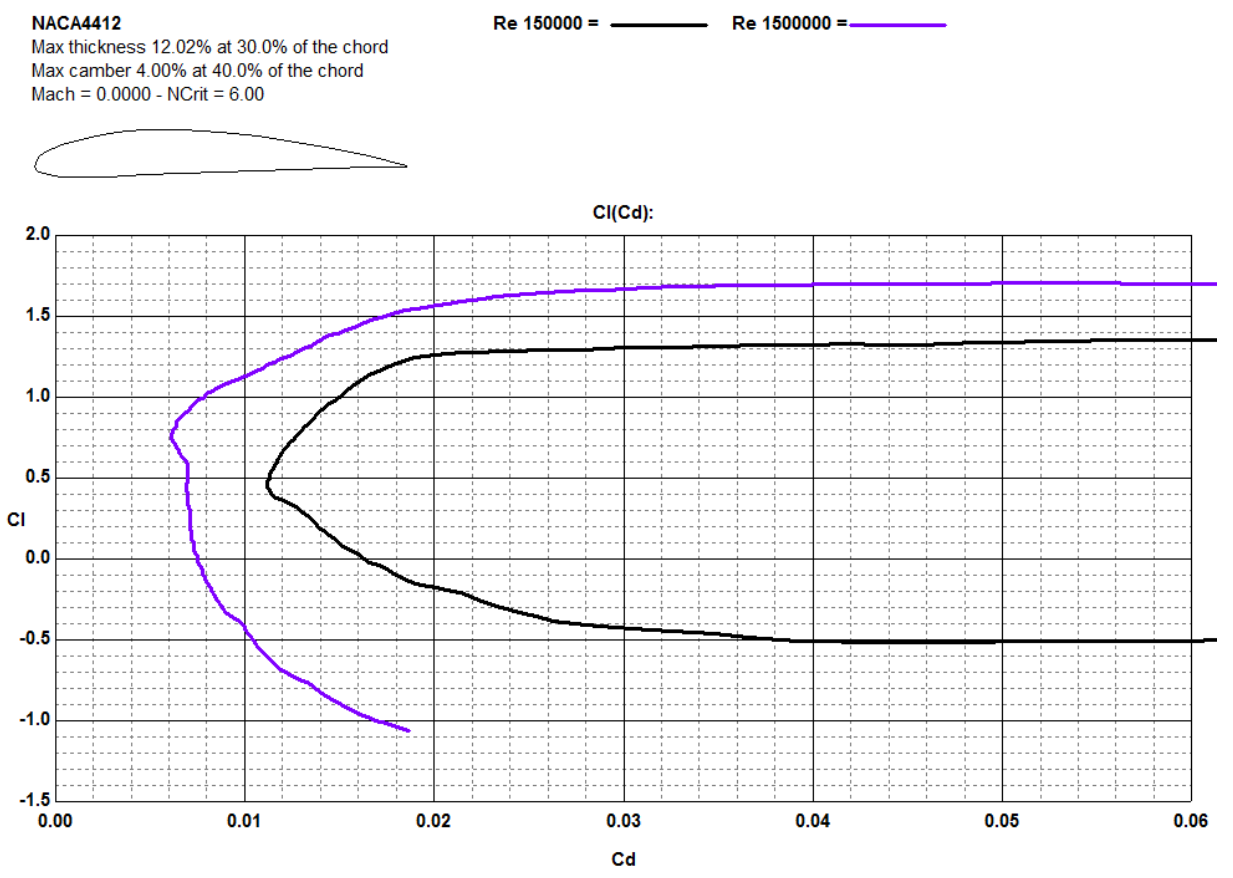

Figure 16: High to Low Reynolds number Comparison, drawn by Profili 2.21

${ }^{25}$ (Drela, 1989) 
The lower the Reynolds number, the larger effect viscosity has on the surface. A UAV propeller with an 18 inch diameter spinning at 3,000 RPM has a local Reynolds number of 150,000 near $75 \%$ of the radius. Common UAV propellers use NACA 4412 airfoils, which have a maximum thickness of $12 \%$ located at $30 \%$ of the chord, and a $4 \%$ camber at $40 \%$ of the chord.

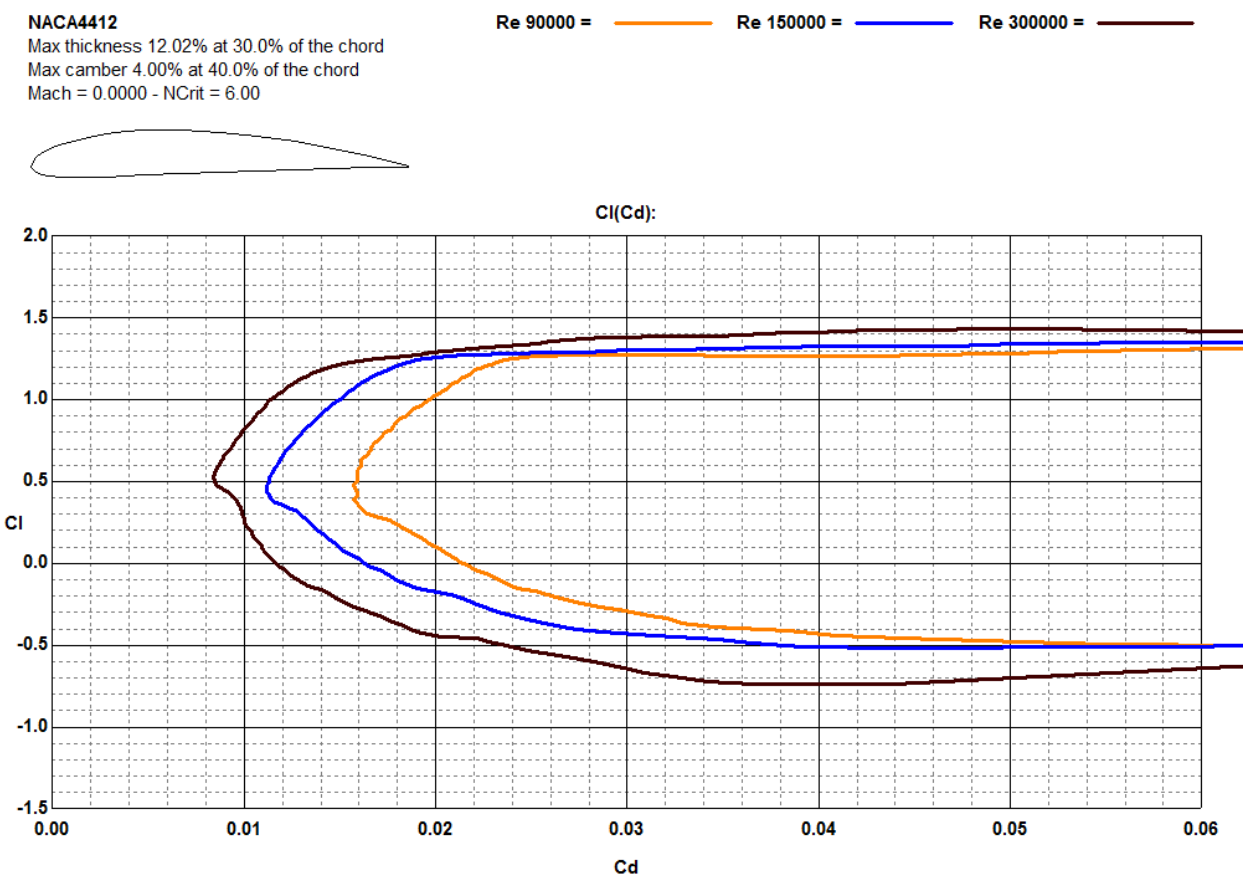

Figure 17: Cd vs Cl Reynolds number effect, drawn by Profili 2.21

The effect of the Reynolds number can increase the drag significantly, which will increase the torque and reduce the efficiency. An airfoil is most efficient at maximum lift over drag. As shown in Figure 18, the lift of drag performance can vary tremendously with a decrease in the Reynolds number. 


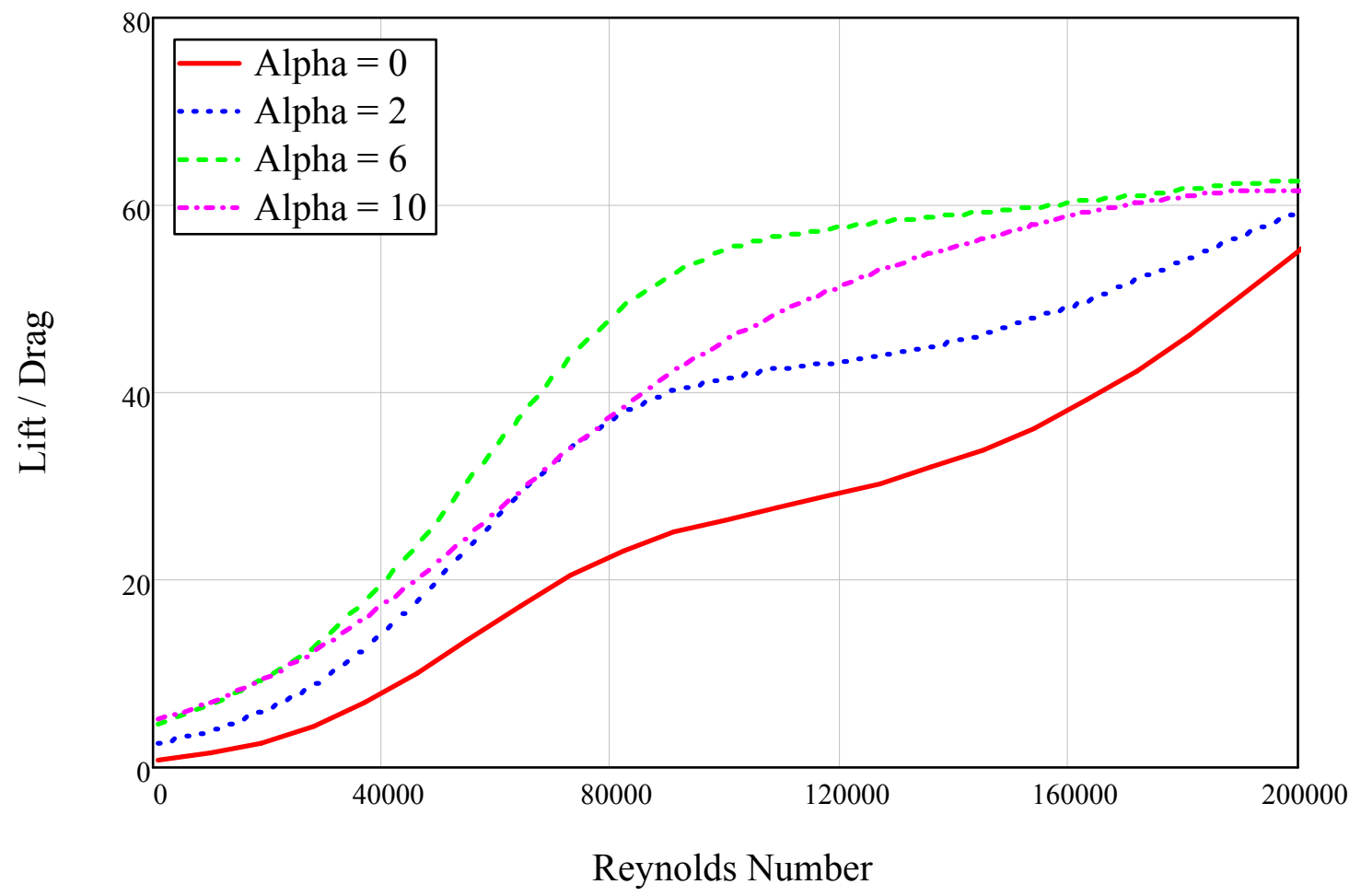

Figure 18: L/D vs. Reynolds Number, Computed with XFoil 


\section{CHAPTER 2. SMALL PROPELLERS}

\subsection{Manufacturer}

The main objective of this experiment is to model the Reynolds effect on propellers, and in order to do this, it is vital that the propeller's shape, twist, and chord be scaled linearly with its diameter. APC propellers were used because they are injection molded propellers made with glass filled epoxy for high torsion strength to reduce deformation under high rotational speeds.

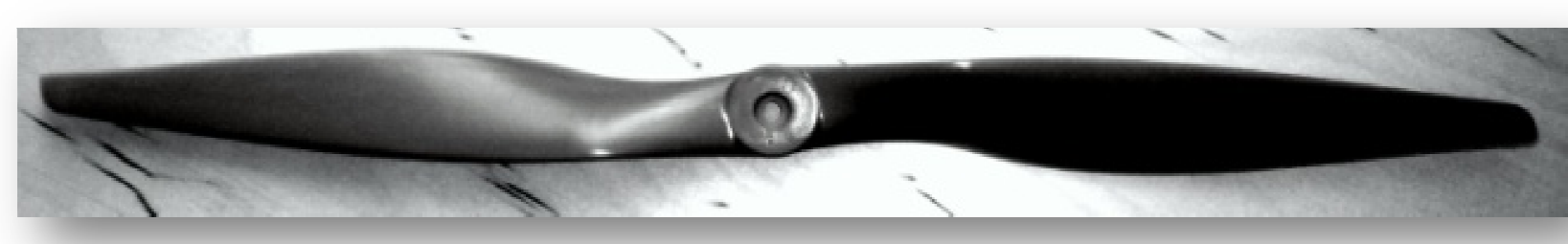

Figure 19: APC Propeller

These propellers feature a NACA 4412 and Clark Y airfoils for added thickness near the hub of the propeller, which adds strength. ${ }^{26}$ The pitch is defined by the manufacture's listed pitch.

${ }^{26}$ (APC Propellers) 


\section{CHAPTER 3. EXPERIMENTAL APPARATUS}

\subsection{Wind Tunnel}

All experiments were performed with a low-turbulence, in-draft open circuit located at Oklahoma State University's Advanced Technology and Research Laboratory. This wind tunnel has a contraction ratio of 15:1 and a rectangular inlet contraction cone. The test section used in all experiments was 6 feet long with a square cross section of 3 feet by 3 feet. The tunnel is driven by a $125 \mathrm{hp}$ electric motor with a maximum dynamics pressure of 26 pounds of force per square foot.

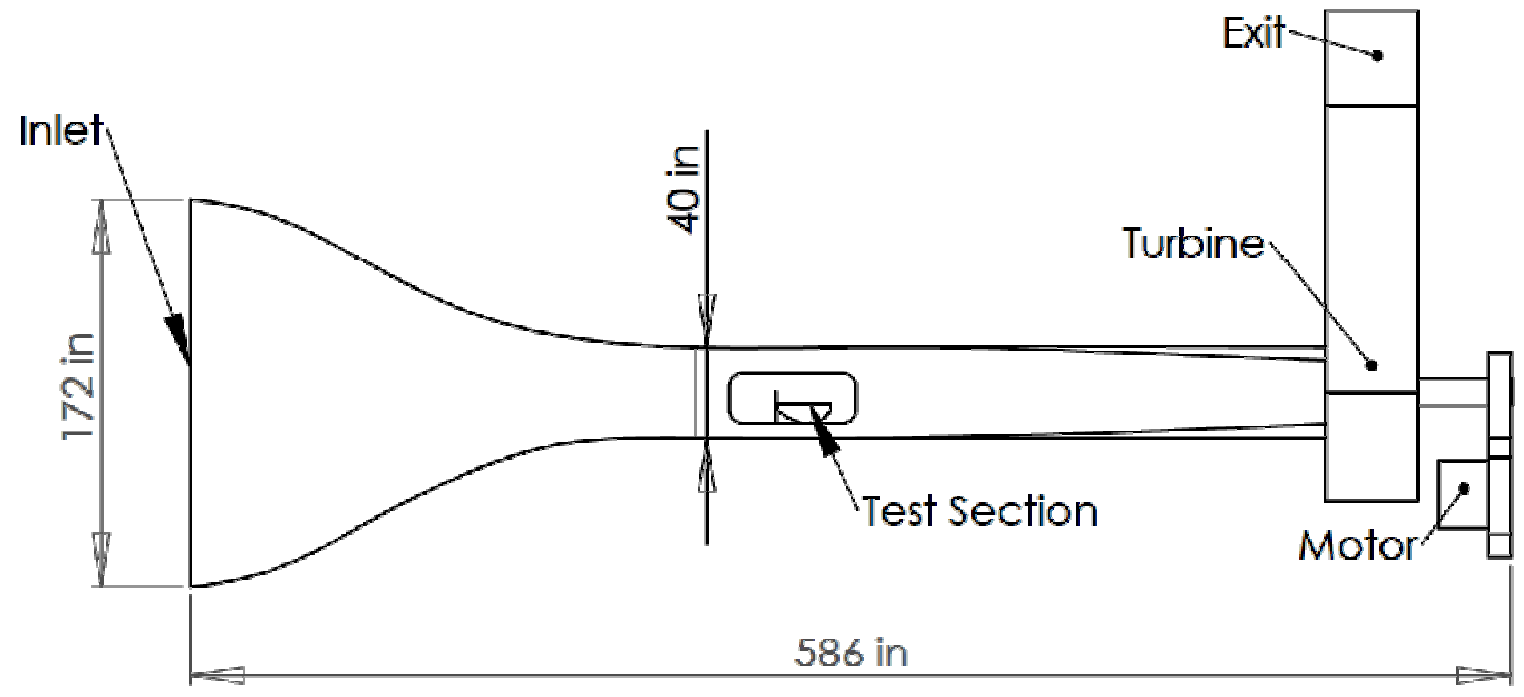

Figure 20: OSU Wind Tunnel

\subsection{Propeller Dynamometer}

The Dynamometer was designed and built at Oklahoma State University to conduct small propeller tests in the wind tunnel. It features two load cells, which measure thrust and torque using a moment arm. The dynamometer also measures the rotational speed of the propeller. 


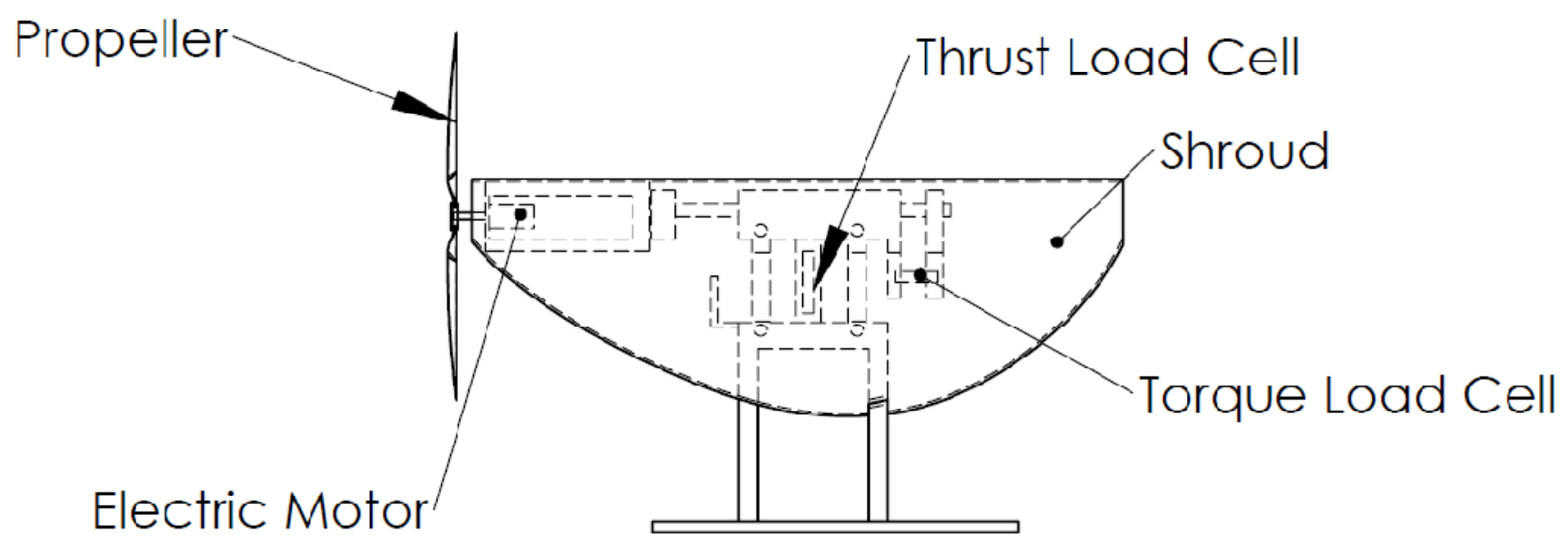

Figure 21: Dynamometer

A shroud covers the entire unit, shielding it from the wind tunnel air which could error the load cells and produce false readings.

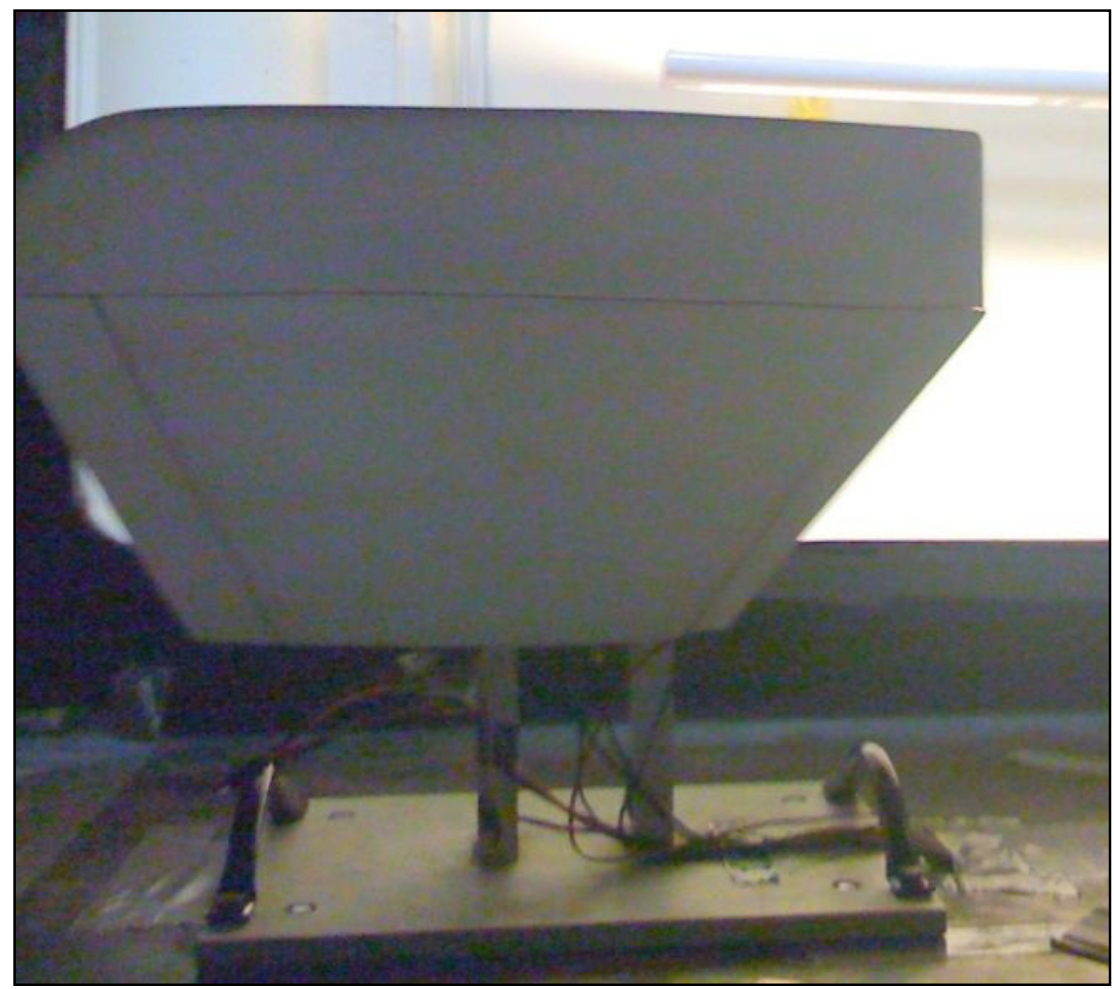

Figure 22: Dynamometer Shroud

The motor extends out the front of the shroud. Through the front opening the propeller transmits the thrust and torque. 


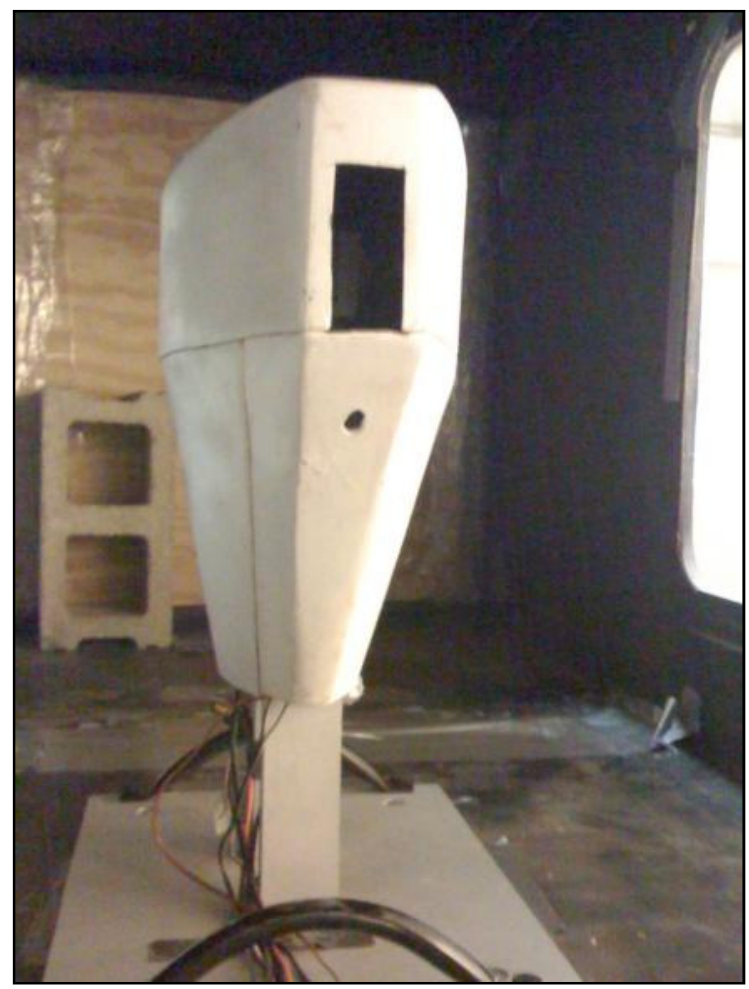

Figure 23: Dynamometer Front

The internal workings of the dynamometer have to be delicately organized to allow the load cell to not come in contact with the propulsions system wiring.

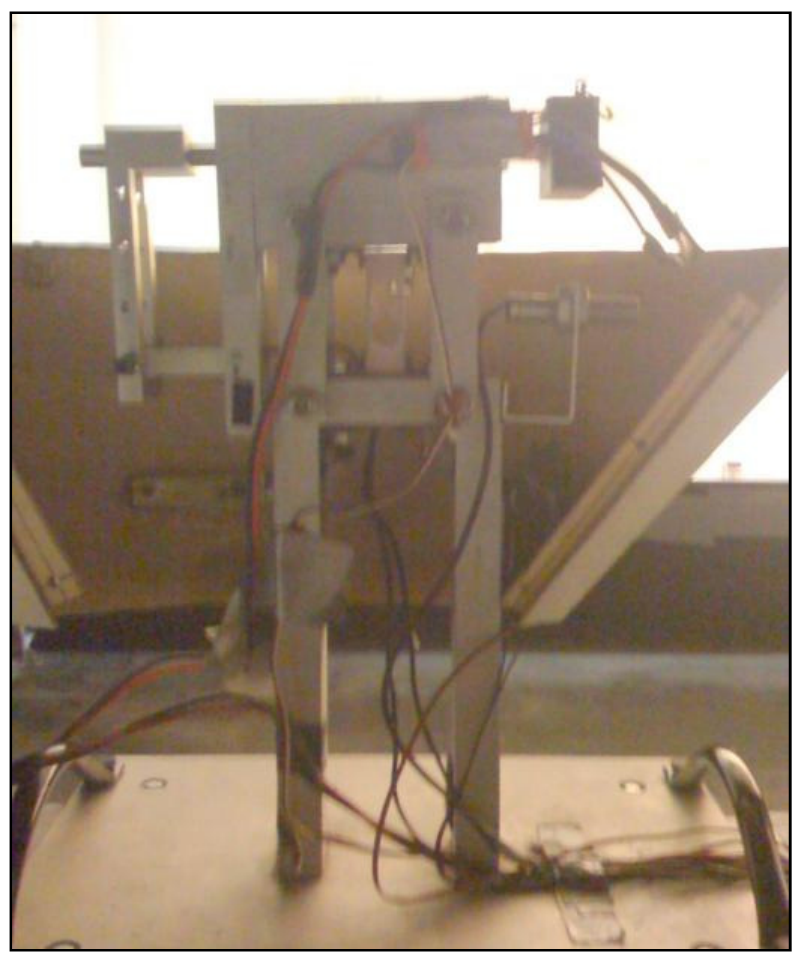

Figure 24: Internals of Dynamometer 
The propeller dynamometer was used only after the load cells were calibrated. The dynamometer was used to discover effects of low Reynolds numbers on propellers. This thesis will not go into detail on the specific setup and calibration of the dynamometer. Other documents exist which contain the setup and calibration of the dynamometer including documents by Kotcherlakota. ${ }^{27}$

\subsection{Measurements and sensors}

The propeller dynamometer uses a number of measuring instruments to collect the required data for propeller control as well as propeller data for plotting of efficiency curves. These instruments will be discussed in the appropriate following sections.

\subsubsection{Air Properties}

The air properties are gathered from using two different instruments. A mercury manometer is used to gather the local pressure in the wind tunnel room outside of the wind tunnel section itself. The local temperature is also gathered from a bulb thermometer located next to the manometer.

\subsubsection{Thrust}

The thrust measurement is read from a low capacity single point load cell mounted between the sway bars. The resistance measurement from the load is then read by a load cell meter made by Transducer Techniques. The meter has an analog output board installed which outputs 0-10 volts. That output voltage is connected to a Measurement Computing Data Acquisitions PCI board. LabVIEW processes the data from the data acquisitions board using the analog in-module and converts it to engineering units. Once the data is acquired, it is corrected using a curve fit line found in Table 1.

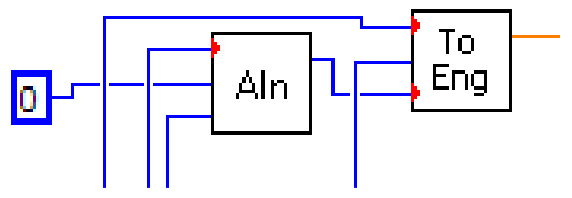

Figure 25: LabVIEWTM module for data acquisition

\subsubsection{Torque}

The torque measurement is read from a low capacity single point load cell mounted at the rear end of the dynamometer. The load cell is pinned to a moment arm, which is directly connected to the motor along a rod. The rod can freely rotate inside of the bearings. The resistance measurement from the load is then read by a load cell meter made by Transducer Techniques. The meter has an analog output board installed which outputs $0-10$ volts. That output voltage is connected to a Measurement Computing Data Acquisitions board. LabVIEW ${ }^{\mathrm{TM}}$ processes the data from the data acquisitions board using the analog in-module and converts it to engineering units. Once the data is acquired, it is corrected using curve fit line found in Table 1.

\subsubsection{Dynamic Pressure}

The wind tunnel's dynamic pressure is measured from a Pitot tube located ahead of the propeller stream and mounted 1 foot from the base of the wind tunnel wall. The pressure tube is connected

${ }^{27}$ (Kotcherlakota, 2006) 
to an Omega low pressure laboratory transducer which reads pressure from 0-3 inches of water and will output $0-5$ volts. That output voltage is connected to a Measurement Computing Data Acquisitions board. LabVIEW ${ }^{\text {TM }}$ processes the data from the data acquisitions board using the analog in-module and converts it to engineering units. Once the data is acquired, it is corrected using curve fit line found in Table 1.

\subsubsection{RPM sensor}

The rotations the propeller makes are counted using a Monarch Instrument optical counter. The counter is mounted under the thrust cell, in front of the dynamometer and omits a laser onto the propeller blade. The propeller blade has an omi-directional piece of tape placed on it which reflects the laser back to the counter. The counter is directly connected to a Monarch Instruments panel tachometer. The tachometer outputs an analog voltage from 0-5 volts. That output voltage is connected to a Measurement Computing Data Acquisitions board. LabVIEW ${ }^{\mathrm{TM}}$ processes the data from the data acquisitions board using the analog in-module and converts it to engineering units. Once the data is acquired, it is corrected using curve fit line found in Table 1.

\subsubsection{Current and Voltage}

The current and voltage going into the system are also monitored for safety and in order to process the motor efficiency. The power supply is connected to a red lion voltage meter and a red lion current meter before they connect to the propulsion system. Both meters output an analog voltage which is read by the computer data acquisition system.

The math module for applying the linear curve fits for the data are shown in Figure 26. Table 1 listed all of the curve fit information.

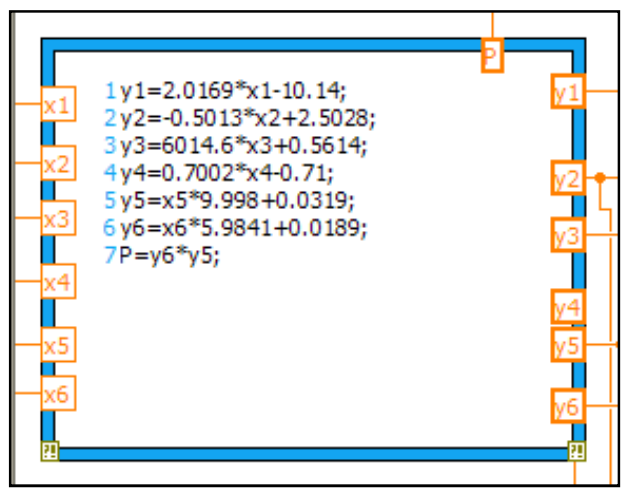

Figure 26: LabVIEWTM linear fit math module 


\begin{tabular}{|l|l|l|}
\hline Input & Linear correction & Output Units \\
\hline Thrust Cell Volts & $2.0169 * \mathrm{x}-10.14$ & Lbs \\
\hline Torque Cell Volts & $-0.5013^{*} \mathrm{x}+2.5028$ & Lbs ${ }^{\mathrm{ft}}$ \\
\hline RPM Volts & $6014.6 * \mathrm{x}+0.5614$ & $\mathrm{RPM}$ \\
\hline Tunnel Pressure Volts & $0.7002 * \mathrm{x}-0.71$ & Inches of Water \\
\hline System Volts in Volts & $9.998^{*} \mathrm{x}+0.0319$ & Volts \\
\hline Current in Volts & $5.9841 * \mathrm{x}+0.0189$ & Ampere \\
\hline
\end{tabular}

Table 1: Linear Curve fit used in data acquisitions

\subsubsection{Wind Tunnel Control}

The tunnel was controlled through the Measurement Computing analog output channel. This channel was connected to the OSU wind tunnel controller terminal through a BNC connector. To control the tunnel pressure the LabVIEW ${ }^{\mathrm{TM}}$ program sent a message to the output board to output a voltage between $0-10$ volts. A display of the output voltage being sent to the control can be observed from a dial on the LabVIEW ${ }^{\mathrm{TM}}$ program screen.

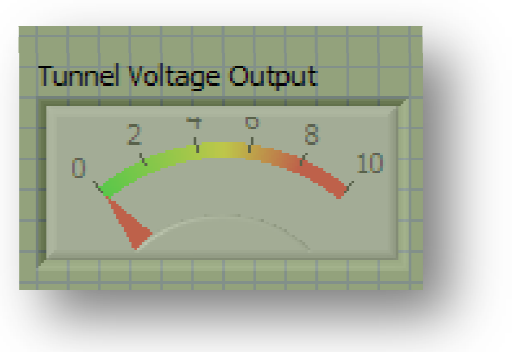

Figure 27: Tunnel Voltage Setting

\subsection{Uncertainty Analysis}

\subsubsection{Calculations}

The dynamometer uses several sensors, all of which have different accuracies. To analyze the uncertainty of the full system, an uncertainty analysis was completed on the full system using the Smith and Kline technique. ${ }^{28}$ The difficulty in performing this study lies in the fact that the uncertainty changes as the load cell is loading more or less than its maximum load. In order to know the uncertainty of the system, LabVIEW ${ }^{\mathrm{TM}}$ was programmed to output the uncertainty at all times as well as to record the data in a file.

${ }^{28}$ (Kline, 1985) 


\begin{tabular}{|ccc|}
\hline Measurement & Uncertainty & $\begin{array}{c}\text { Maximum } \\
\text { Measurement }\end{array}$ \\
\hline RPM & $1 \mathrm{RPM}$ & $20,000 \mathrm{RPM}$ \\
\hline Thrust & $0.002 \mathrm{lb}$ & $11 \mathrm{lb}$ \\
\hline Torque Cell & $0.002 \mathrm{lb}$ & $11 \mathrm{lb}$ \\
\hline Moment Arm & $0.001 \mathrm{inch}$ & 12 inches \\
\hline Diameter & 0.001 inch & 12 inches \\
\hline Pressure & $0.05 \mathrm{~mm}$ of $\mathrm{Hg}$ & $10,000 \mathrm{~mm}$ of $\mathrm{Hg}$ \\
\hline Dynamic Pressure Q & 0.01 in of $\mathrm{H} 2 \mathrm{O}$ & 3 inches of H2O \\
\hline Temperature & $0.05 \mathrm{C}$ & $100 \mathrm{C}$ \\
\hline
\end{tabular}

Table 2: Measurement and accuracy for sensors

Based on the fundamental measurements and the accuracy of each measurement, uncertainty can be calculated. Note: uncertainty changes based on how the measurement device is loaded. Uncertainty is most commonly the lowest when the measurement is taken near its maximum measurement point. The first step of calculating uncertainty is to use all the raw measurements and to find their uncertainty given their accuracy.

$$
\varepsilon_{\mathrm{n}}\left(\mathrm{n}_{\mathrm{m}}\right):=\frac{\sigma_{\mathrm{n}}}{\mathrm{n}_{\mathrm{m}}} \quad \varepsilon_{\mathrm{F}}\left(\mathrm{F}_{\mathrm{m}}\right):=\frac{\sigma_{\mathrm{F}}}{\mathrm{F}_{\mathrm{m}}} \quad \varepsilon_{\mathrm{T}}:=\frac{\sigma_{\mathrm{T}}}{\mathrm{T}_{\mathrm{m}}} \quad \varepsilon_{\mathrm{P}}:=\frac{\sigma_{\mathrm{P}}}{\mathrm{P}_{\mathrm{m}}} \quad \varepsilon_{\mathrm{D}}\left(\mathrm{D}_{\mathrm{m}}\right):=\frac{\sigma_{\mathrm{D}}}{\mathrm{D}_{\mathrm{m}}}
$$

Equation 9: Uncertainty in raw measurements

For any calculations needed in the required results then the uncertainty must be solved for. First the equation to solve for the calculation must be analyzed. Then the uncertainty can be calculated. The first calculation here is the moment arm used to calculate torque.

$$
\mathrm{H}\left(\mathrm{h}_{1}, \mathrm{~h}_{2}, \mathrm{~h}_{3}\right):=\mathrm{h}_{1}-\frac{1}{2} \cdot \mathrm{h}_{2}-\frac{1}{2} \cdot \mathrm{h}_{3} \quad \varepsilon_{\mathrm{H}}(\mathrm{arm}):=3 \cdot \frac{\sigma_{\mathrm{D}}}{\operatorname{arm}}
$$

\section{Equation 10: Uncertainty in Torque moment arm}

Density is solved for using another calculation. Using another uncertainty analysis method, the uncertainty is solved for using the exponents in the equation.

$$
\rho(\mathrm{P}, \mathrm{T}):=\frac{\mathrm{P}}{\mathrm{R} \cdot \mathrm{T}} \quad \varepsilon_{\rho}:=\sqrt{1^{2} \cdot \varepsilon_{\mathrm{P}}{ }^{2}+1^{2} \cdot \varepsilon_{\mathrm{T}}{ }^{2}}
$$

\section{Equation 11: Uncertainty in Density}

The free stream velocity in the wind tunnel was solved for using the same method.

$$
\mathrm{V}(\mathrm{h}, \rho):=\sqrt{\frac{2 \cdot \mathrm{h} \cdot \rho_{\mathrm{W}} \cdot \mathrm{g}}{\rho}} \varepsilon_{\mathrm{V}}\left(\mathrm{h}_{\mathrm{m}}\right):=\sqrt{\left(\frac{1}{2}\right)^{2} \cdot(0)^{2}+\left(\frac{1}{2}\right)^{2} \cdot \varepsilon_{\mathrm{h}}\left(\mathrm{h}_{\mathrm{m}}\right)^{2}+\left(-\frac{1}{2}\right)^{2} \cdot \varepsilon_{\rho}}
$$

Equation 12: Uncertainty in Free Stream Velocity

That uncertainty is carried over to the calculation of the advance ratio. 


$$
\mathrm{J}(\mathrm{V}, \mathrm{n}, \mathrm{D}):=\frac{\mathrm{V}}{\mathrm{n} \cdot \mathrm{D}} \quad \varepsilon_{\mathrm{J}}\left(\mathrm{h}_{\mathrm{m}}, \mathrm{n}_{\mathrm{m}}, \mathrm{D}_{\mathrm{m}}\right):=\sqrt{\varepsilon_{\mathrm{V}}\left(\mathrm{h}_{\mathrm{m}}\right)^{2}+\varepsilon_{\mathrm{n}}\left(\mathrm{n}_{\mathrm{m}}\right)^{2}+\varepsilon_{\mathrm{D}}\left(\mathrm{D}_{\mathrm{m}}\right)^{2}}
$$

\section{Equation 13: Uncertainty in the Advance Ratio Calculation}

The coefficient of thrust is one of the primary results from the experiment.

$$
\mathrm{C}_{\mathrm{T}}(\mathrm{F}, \mathrm{n}, \mathrm{D}, \rho):=\frac{\mathrm{F}}{\rho \cdot \mathrm{n}^{2} \cdot \mathrm{D}}{ }^{4} \varepsilon_{\mathrm{ct}}\left(\mathrm{F}_{\mathrm{m}}, \mathrm{n}_{\mathrm{m}}, \mathrm{D}_{\mathrm{m}}\right):=\sqrt{1^{2} \cdot \varepsilon_{\mathrm{F}}\left(\mathrm{F}_{\mathrm{m}}\right)^{2}+(-1)^{2} \cdot \varepsilon_{\rho}{ }^{2}+(-2)^{2} \cdot \varepsilon_{\mathrm{n}}\left(\mathrm{n}_{\mathrm{m}}\right)^{2}+(-4)^{2} \cdot \varepsilon_{\mathrm{D}}\left(\mathrm{D}_{\mathrm{m}}\right)^{2}}
$$

\section{Equation 14: Uncertainty in the coefficient of thrust}

In a similar way, the coefficient of power is calculated. Note: the coefficient of power carries over an extra calculation from the calculation of the moment arm, which is used to calculate the torque.

$$
\begin{gathered}
\mathrm{C}_{\mathrm{p}}(\mathrm{T}, \mathrm{H}, \mathrm{Q}, \mathrm{n}, \mathrm{D}, \rho):=\frac{\mathrm{H} \cdot \mathrm{F}}{\rho \cdot \mathrm{n}^{3} \cdot \mathrm{D}^{5}} \\
\varepsilon_{\mathrm{cp}}\left(\mathrm{arm}, \mathrm{F}_{\mathrm{mq}}, \mathrm{n}_{\mathrm{m}}, \mathrm{D}_{\mathrm{m}}\right):=\sqrt{1^{2} \cdot \varepsilon_{\mathrm{H}}(\mathrm{arm})^{2}+1^{2} \cdot \varepsilon_{\mathrm{F}}\left(\mathrm{F}_{\mathrm{mq}}\right)^{2}+(-1)^{2} \cdot \varepsilon_{\rho}{ }^{2}+(-3)^{2} \cdot \varepsilon_{\mathrm{n}}\left(\mathrm{n}_{\mathrm{m}}\right)^{2}+(-5)^{2} \cdot \varepsilon_{\mathrm{D}}\left(\mathrm{D}_{\mathrm{m}}\right)^{2}}
\end{gathered}
$$

Equation 15: Uncertainty in the coefficient of power

The final calculation, shown below, contains the most uncertainty.

$$
\begin{gathered}
\eta\left(\mathrm{C}_{\mathrm{t}}, \mathrm{C}_{\mathrm{p}}, \mathrm{J}\right):=\frac{\mathrm{C}_{\mathrm{t}} \cdot \mathrm{J}}{\mathrm{C}_{\mathrm{p}}} \\
\varepsilon_{\eta}\left(\mathrm{arm}, \mathrm{h}_{\mathrm{m}}, \mathrm{F}_{\mathrm{m}}, \mathrm{n}_{\mathrm{m}}, \mathrm{D}_{\mathrm{m}}, \mathrm{F}_{\mathrm{mq}}\right):=\sqrt{1^{2} \cdot \varepsilon_{\mathrm{ct}}\left(\mathrm{F}_{\mathrm{m}}, \mathrm{n}_{\mathrm{m}}, \mathrm{D}_{\mathrm{m}}\right)^{2}+1^{2} \varepsilon_{\mathrm{J}}\left(\mathrm{h}_{\mathrm{m}}, \mathrm{n}_{\mathrm{m}}, \mathrm{D}_{\mathrm{m}}\right)^{2}+(-1)^{2} \cdot \varepsilon_{\mathrm{cp}}\left(\operatorname{arm}, \mathrm{F}_{\mathrm{mq}}, \mathrm{n}_{\mathrm{m}}, \mathrm{D}_{\mathrm{m}}\right)^{2}}
\end{gathered}
$$

\section{Equation 16: Uncertainty in Efficiency}

\subsubsection{Uncertainty Results}

The most sensitive areas for uncertainty are in the load cells on the dynamometer itself. The thrust cell is a $5 \mathrm{~kg}$ max cell with accuracy down to 1 gram. The diameter of the propeller was measured to 0.001 of an inch. This was included in the uncertainty calculation for the coefficient of thrust. The RPM sensor is accurate to 1 RPM. The uncertainty in the coefficient was consistently $1 \%$. 


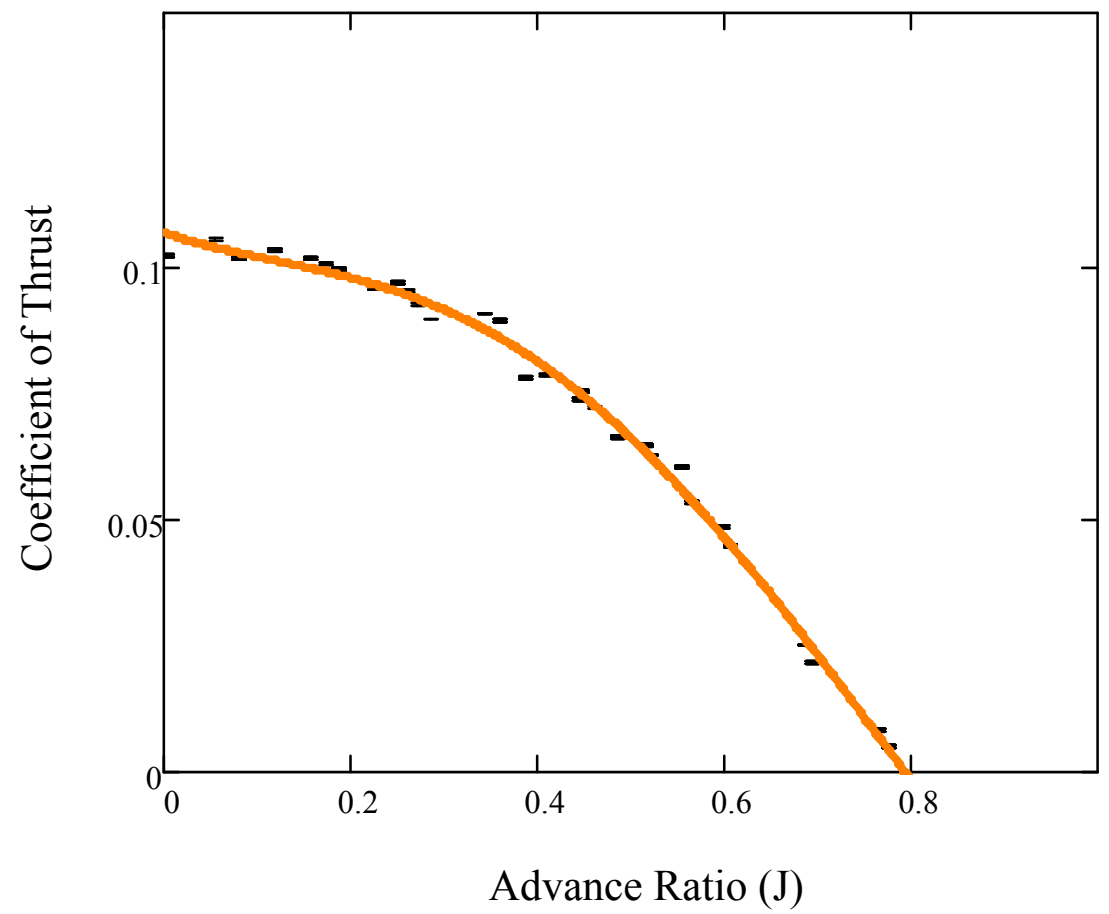

Figure 28: Uncertainty in Thrust

The torque measured to obtain power was from a moment arm pressing on a similar load cell. The measurement of torque must then be extrapolated from the moment arm, which is measured using accuracy to 0.001 inches. Using the most conservative measurements on torque, the uncertainty was found to be $4 \%$.

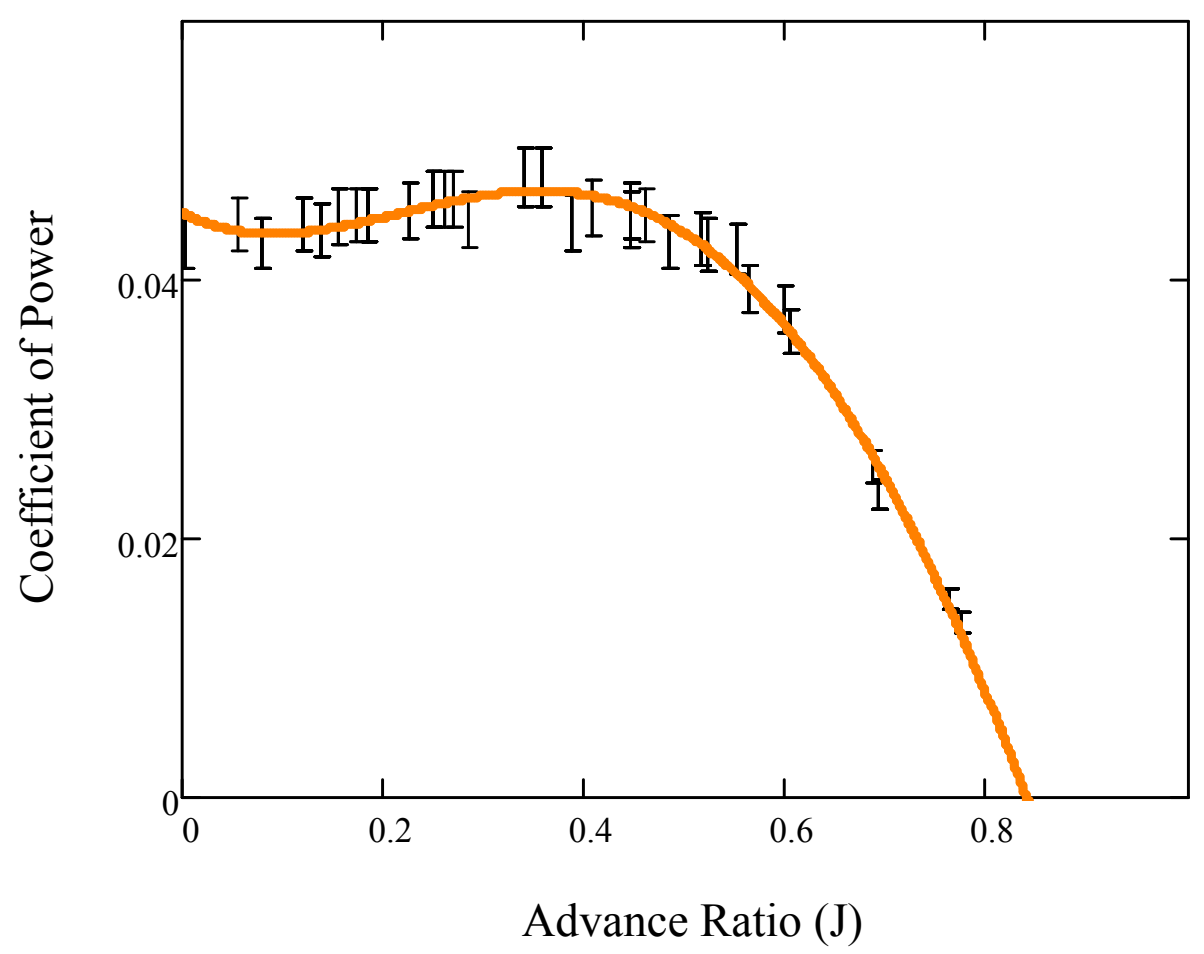




\section{Figure 29: Uncertainty in Power}

The overall uncertainty throughout an experiment can be shown between the bands on the propeller efficiency run. Notice how the efficiency bands increase at high advance ratios. This is because the propeller is not producing as much thrust. The result is that the load cells are not being used to their maximum potential, which means uncertainty increases.

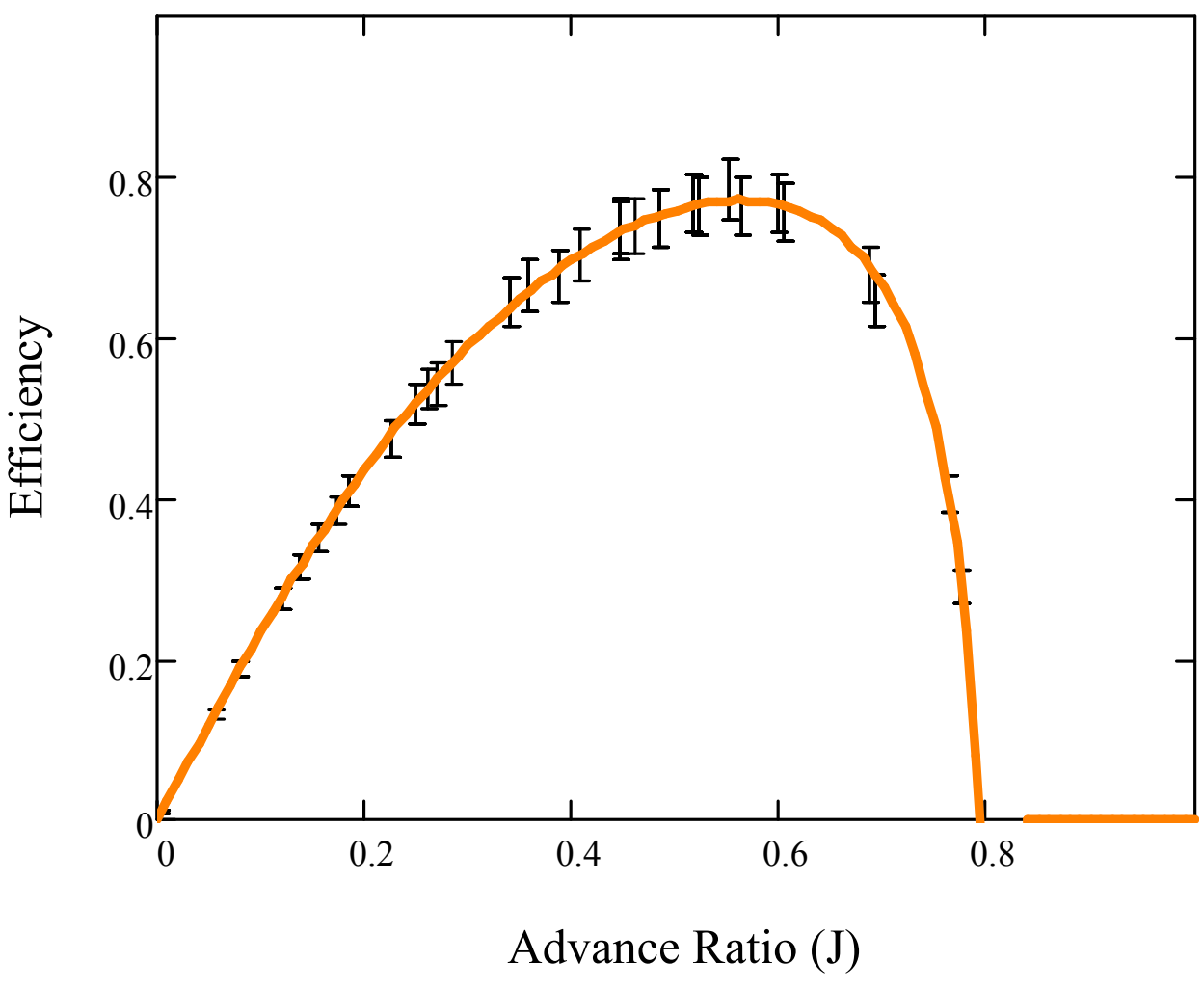

Figure 30: Uncertainty in Efficiency plotted over curve

The increase in uncertainty throughout an entire test is displayed in the following graph. Notice that the uncertainty is highest in the coefficient of power calculation. This is a result of the extra calculation that is used to find the torque, which uses a moment arm. That moment arm is the primary driver for the ultimate uncertainty in the efficiency calculation. 


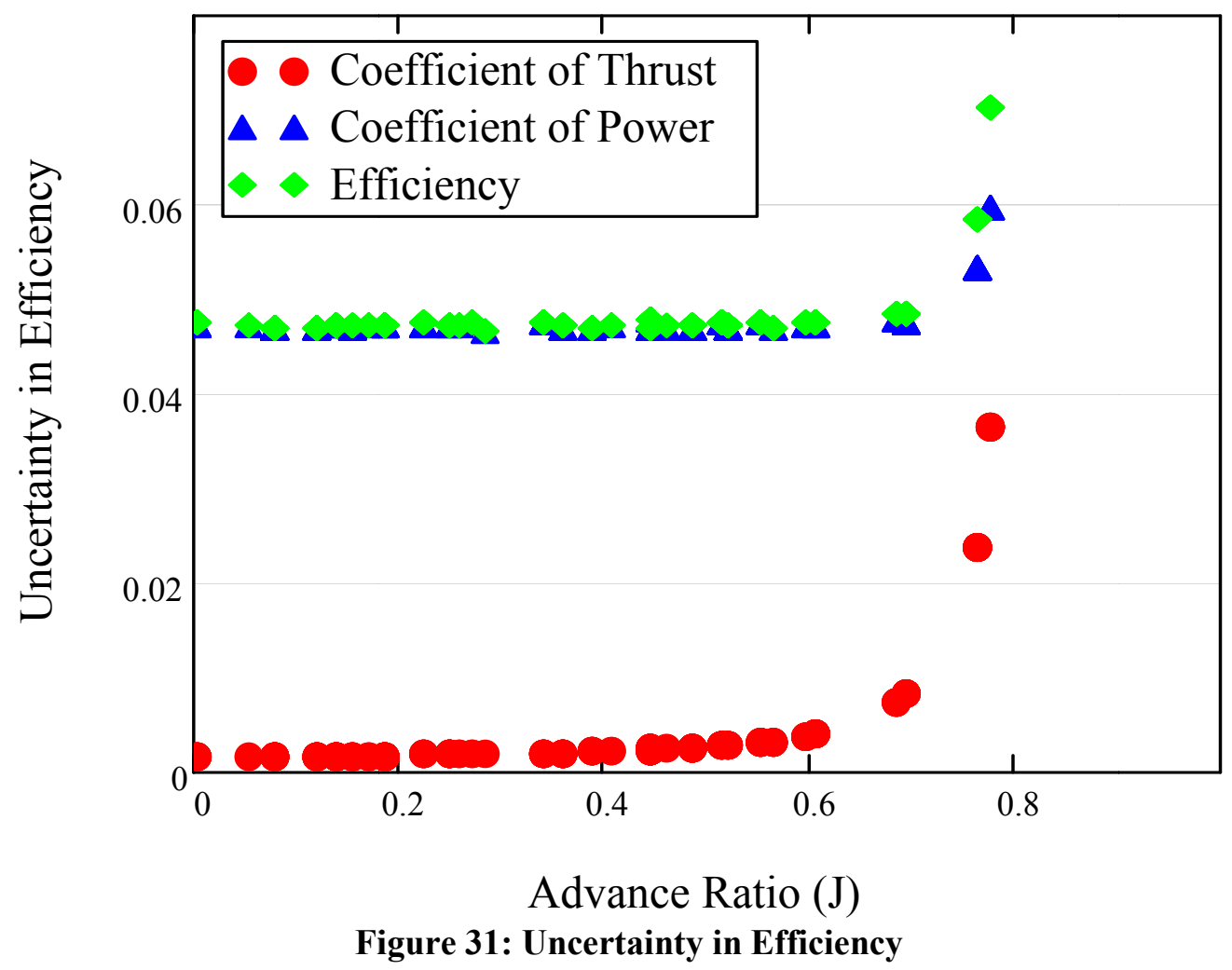

The live uncertainty can also be found when a test is running. The displays show three tanks which increase to show the uncertainty. The tanks show the uncertainty in the coefficient of thrust, power, and efficiency respectively.

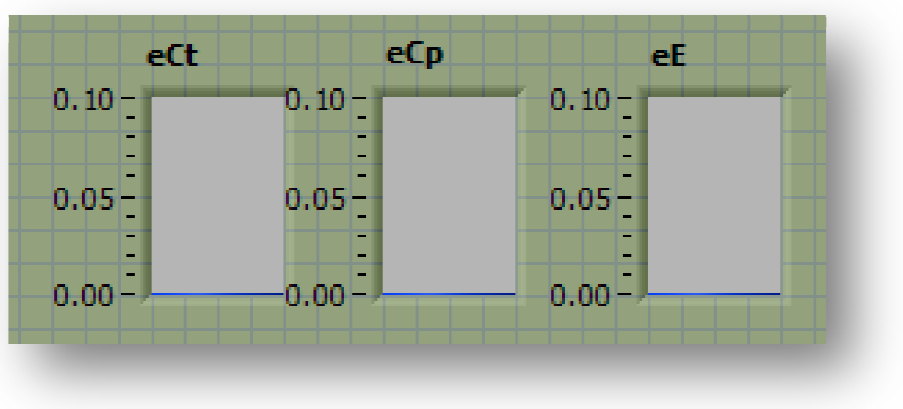

Figure 32: Live Uncertainty Display

\subsection{Repeatability}

To insure the data was repeatable an APC $18 \times 12$ propeller was tested 3 separate days at the same propeller Reynolds number of 866,000. On the last day, a copy of the test propeller was also tested. At low tunnel velocities, the data was nearly identical, and at peak efficiency, the variance from the mean was less than $1 \%$. 


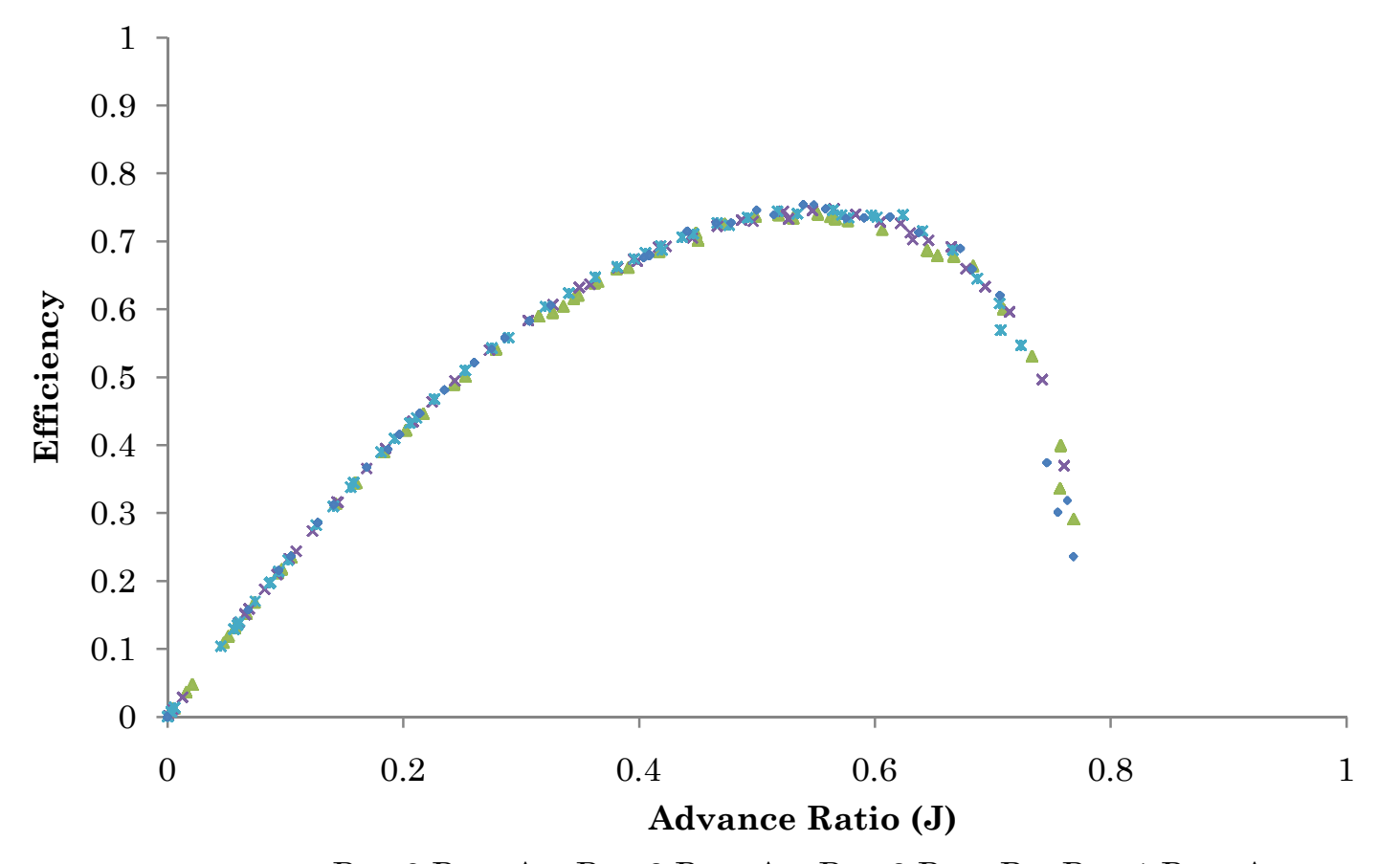

$\triangle$ Day 2 Prop A × Day 3 Prop A * Day 3 Prop B - Day 1 Prop A

Figure 33: Repeatability

\subsection{Automated Dynamic controller}

The purpose of the incorporations of the LabVIEW ${ }^{\text {TM }}$ system and the dynamometer is to obtain data holding a specific Buckingham Pi term constant. From the propeller Reynolds number equation, the RPM is important to keep constant during a test. A digital controller was designed in LabVIEW ${ }^{\mathrm{TM}}$ to hold the RPM. That controller used an input of RPM, from the RPM sensor, read from the Monarch sensor and the Measurements computing data acquisition board for processing. After the signal was processed, LabVIEW ${ }^{\mathrm{TM}}$ controlled the propeller's RPM using a Phidget's USB servo controller board, which was connected to an electronic speed controller. It was then connected to the electric motor.

\subsubsection{System Identification}

Using LabVIEW ${ }^{\mathrm{TM}}$, a sine wave was sent through the system to find its dynamic response. The sine wave was varied over frequencies from $0.01 /$ second to $5 /$ second. 


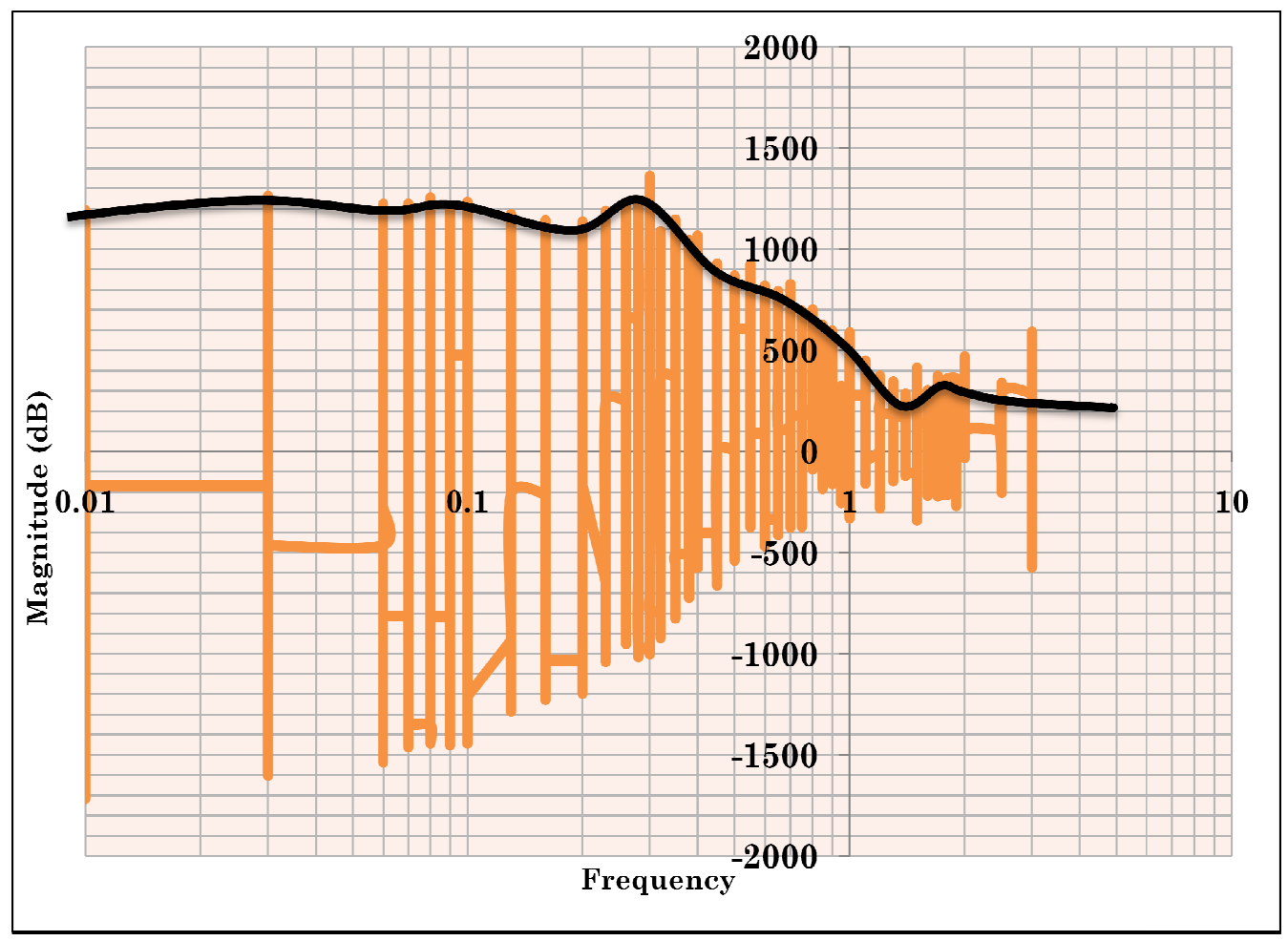

Figure 34: Bode Plot of System

The system has a quick rate of decay of over $1000 \mathrm{~dB}$ per decade, which shows that the system is slow to respond. And, at a certain limit, it will not respond. From the bode plot, the system has a zero and a pole based on its response, as well as, possibly being at least a second order system with a $\delta<0.4$.

\subsubsection{Digital Controller Design}

In order to maintain the desired RPM, a proportional gain algorithm was used along with an integral gain controller. The integral gain controller was applied to reduce steady state error because maintaining a constant RPM and Reynolds number is important.

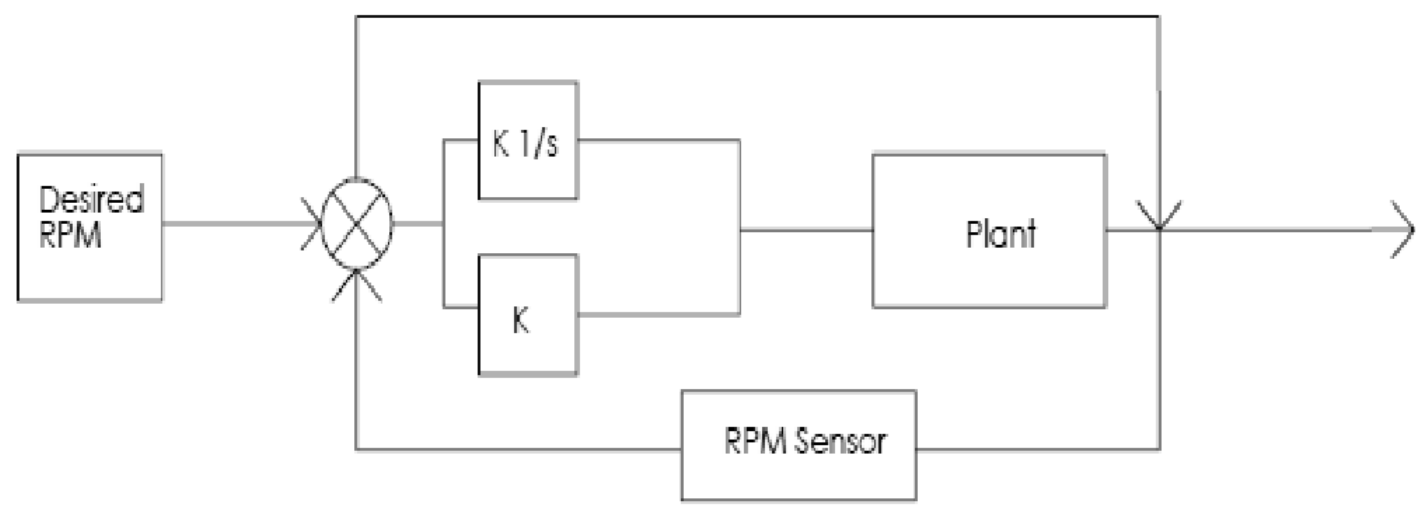

Figure 35: Block Diagram of Controller 
A feed forward loop was also used in the system to give the system an artificial inertia due to LabVIEW'TM's delayed response time. The feed forward loop was key when using LabVIEW ${ }^{\mathrm{TM}}$ in the control loop.

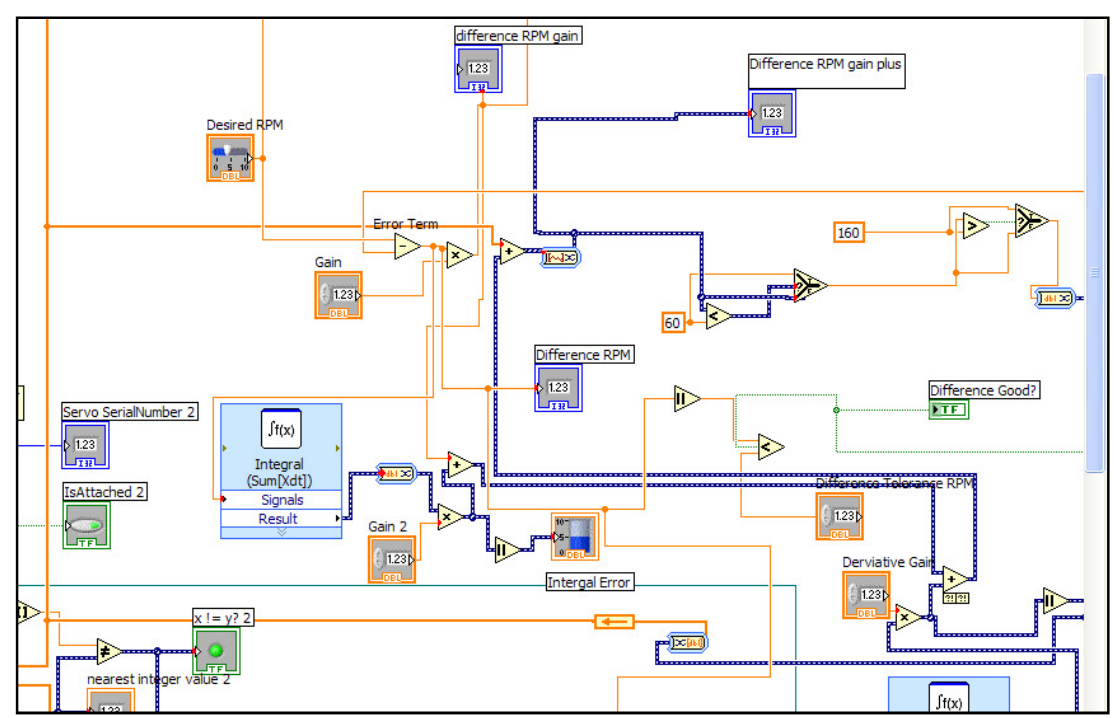

Figure 36: LabVIEWTM Controller Program

\subsubsection{Controller Performance}

Through trial and error, the gain on the proportional was found to be 0.00034 , and the gain on the integral error was found to be 0.000006 . The initial response of the system has a settling time of $\sim 10$ seconds with a maximum over shoot of $35 \%$. These performance qualities were acceptable because the main design of the controller is to hold the RPM constant against slight changes that can occur when the electric motor spins up because the blades are unloading from an increase in the tunnel velocity. 


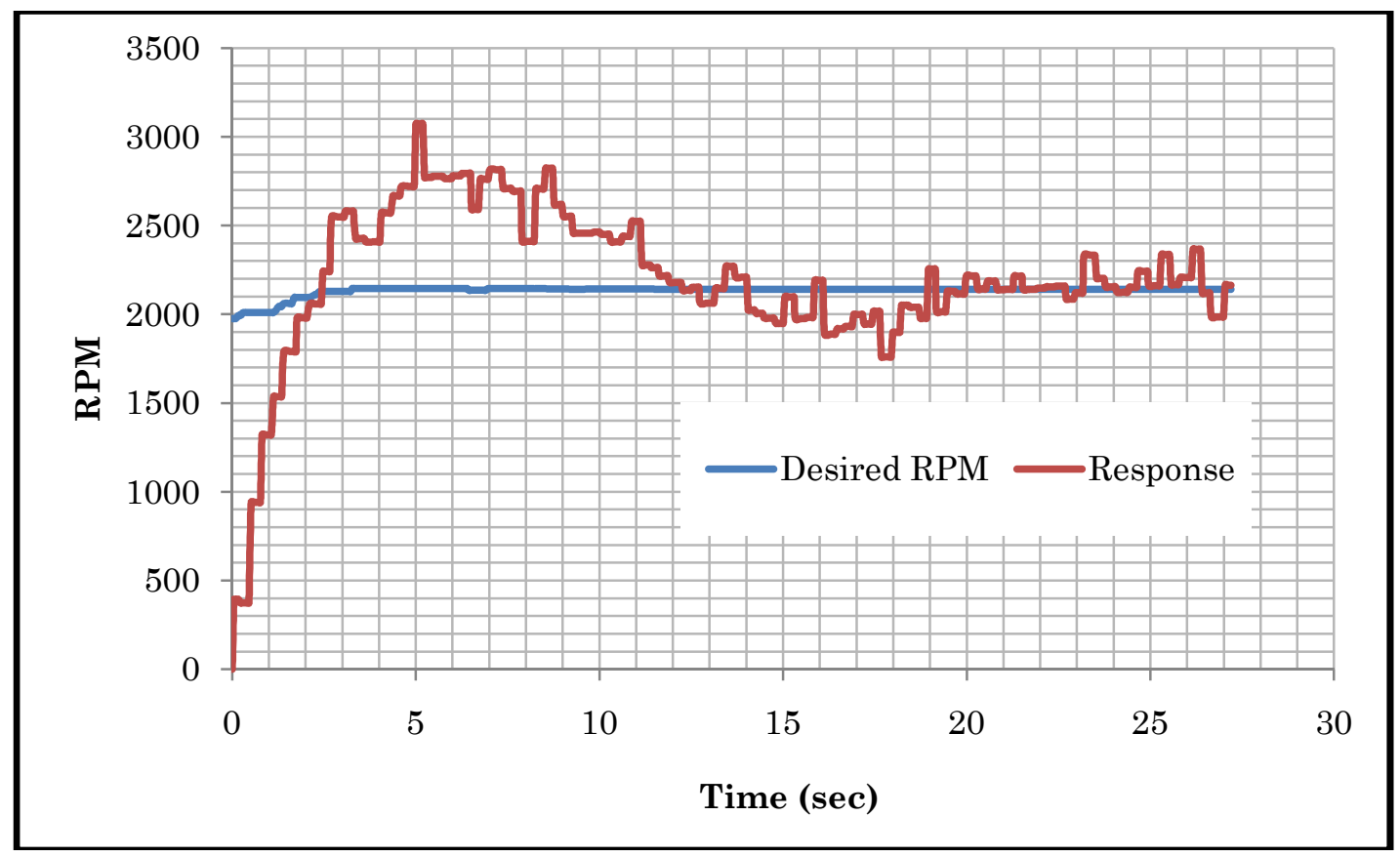

Figure 37: Response Time of system

This gain gave the controller the ability to hold the RPM of the propeller constant through an entire propeller test. A few noise spikes in the RPM channel where observed, but the slow response of the system allowed these to be ignored.

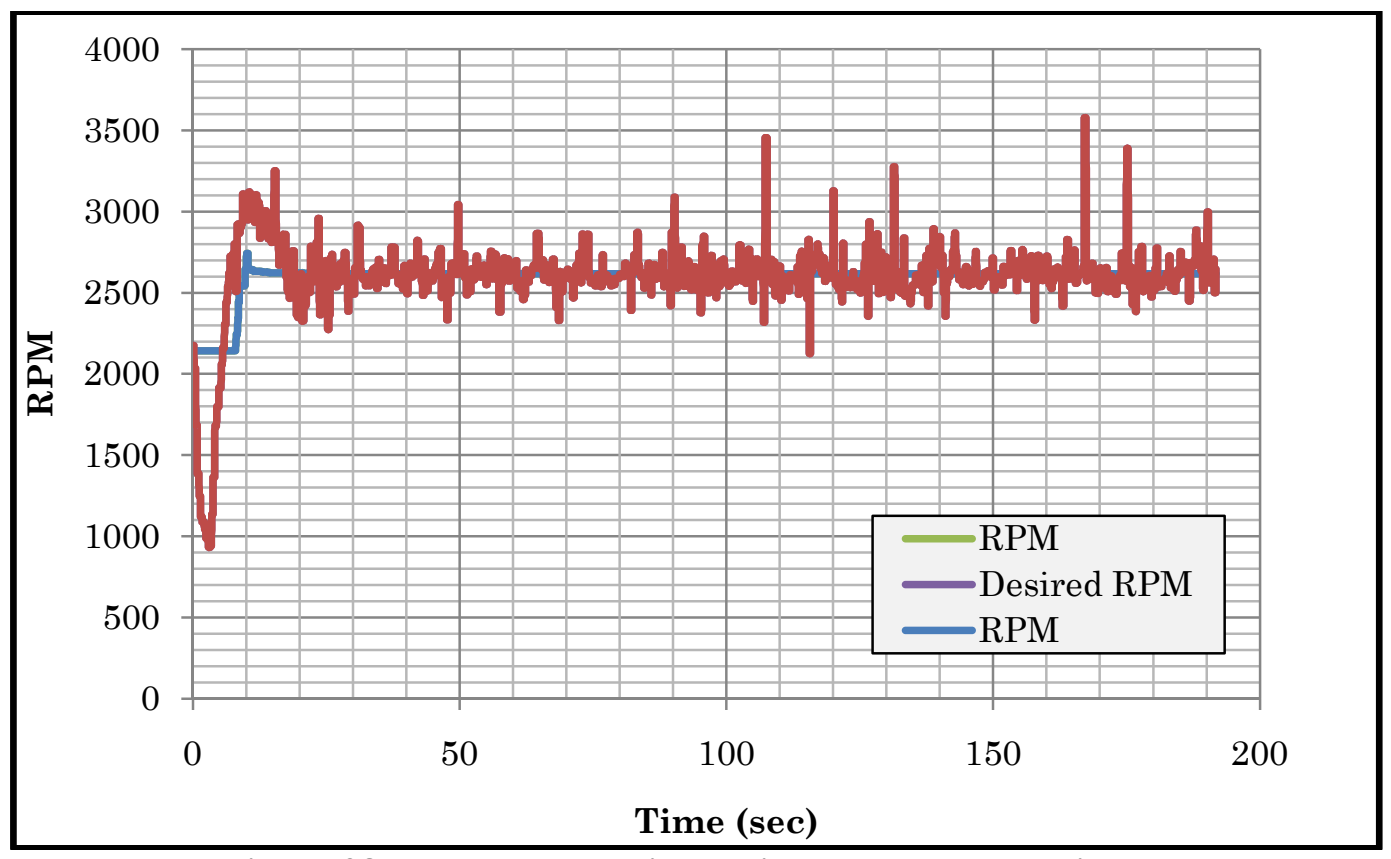

Figure 38: RPM Hold during entire Propeller Experiment

A live controller readout was included on the LabVIEW ${ }^{\mathrm{TM}}$ screen. This readout shows the error in each controller. The goal of the controller is to make all of the error tanks empty. As the 
propeller test is running, one can observe the integral error grow and then empty as it corrects the RPM from minor offsets.

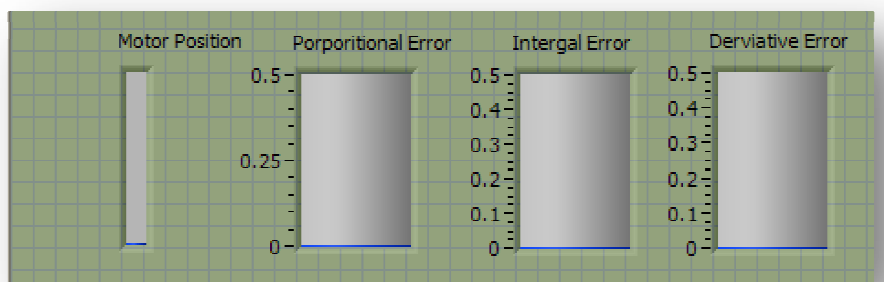

Figure 39: Error read out in each controller 


\section{CHAPTER 4. EXPERIMENTAL PROCEDURE}

\subsection{Introduction}

The OSU propeller dynamometer was designed in house and was used to conduct all of the propeller experiments. These sections will provide an overview of how to use the data acquisition program and the automated system. It is assumed that to follow these tests one should already be familiar with the system and the basic operation. For the detailed basic setup of the dynamometer please use other references.

\subsection{Graphical User Interface}

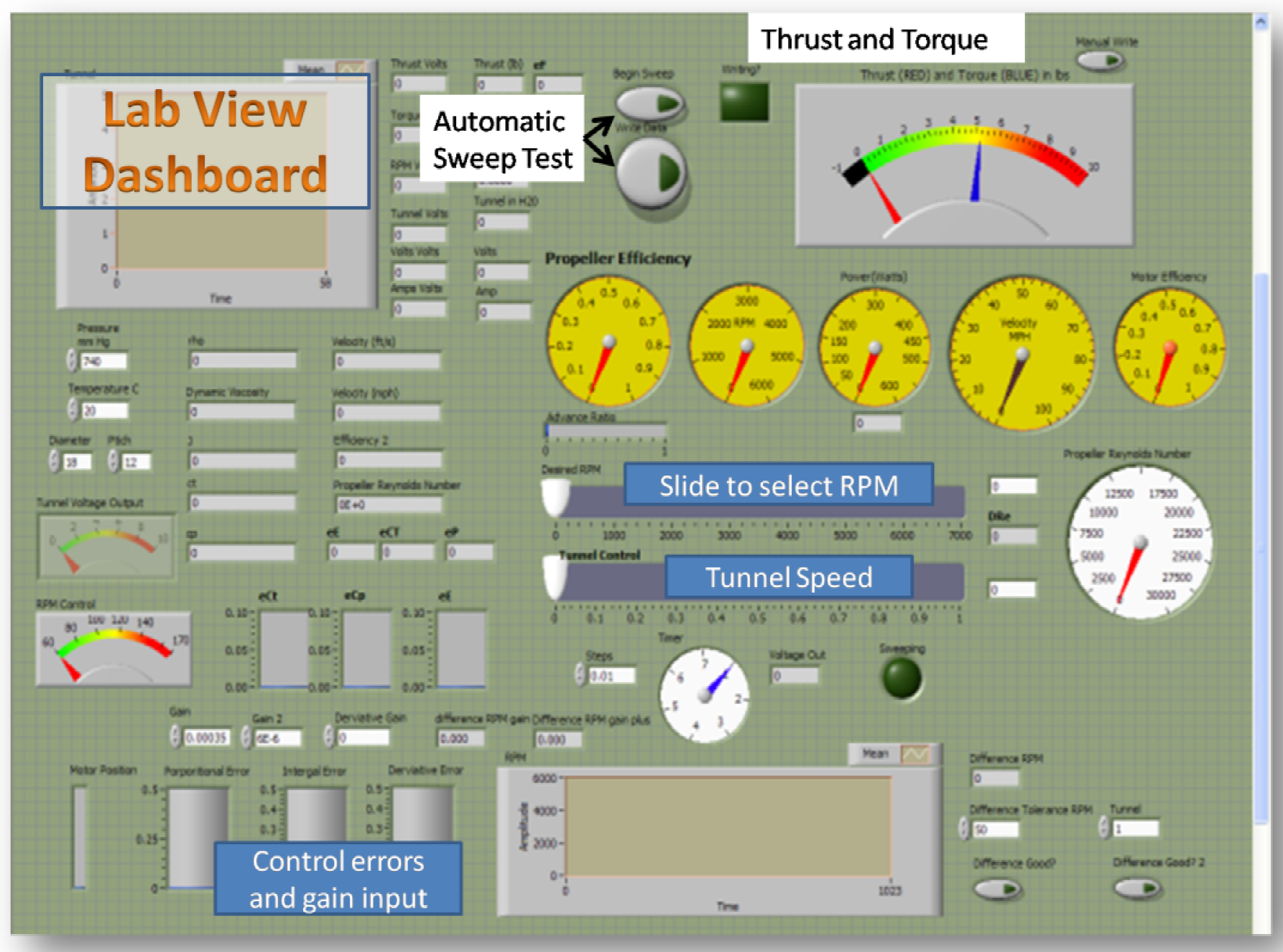

Figure 40: Graphical Interface 


\subsection{Dynamometer operations (How to use)}

This section describes the operation and use of the program which was created to complete accurate and consistent propeller experiments. Perquisites for the user include: knowledge of the general use and operation of the propeller dynamometer, as well as, of the electric motors and the OSU wind tunnel. This includes knowing the limits of the load cell in the dynamometer and the power limitations of the power supply. The user should have already completed the calibration checklist for the dynamometer. The wind tunnel should be prepped and running and the user should make sure the computer is connected to the tunnel controller and the switch is set to BNC.

\subsubsection{Data Acquisition System Initialization}

The program, designed to run the propeller experiments, was created in LabVIEW ${ }^{\mathrm{TM}}$. To run the software, all digital readouts from the dynamometer should be connected to the Measurements Computing ${ }^{\mathrm{TM}}$ data acquisitions terminal. The computer and all equipment should be powered up as well. It is important to always clear the propeller when the system is powered on. Also, one should carefully observe the load cells to make sure they do not go above their limit. The user should always be able to quickly switch the power supply and/or the wind tunnel off if any problems occur. It is also important that reflective tape has been placed on the propeller and that the optical sensor flashes when it crosses the tapes path. If this tape is not in place, the system will spin out of control because it will lose its feedback loop.

To begin the experiments, first start LabVIEWTM on the computer and open the program, "OSU Wind Tunnel Dyno."

Before running the program, the user should obtain the local barometric pressure in millimeters of mercury and the local temperature in the room in degrees Celsius. This can be done from the wall mounted mercury manometer and the temperature gauges. The diameter and the pitch of the propeller to be tested should be noted before the test. Once this information is obtained, it can be entered into the program as shown below.

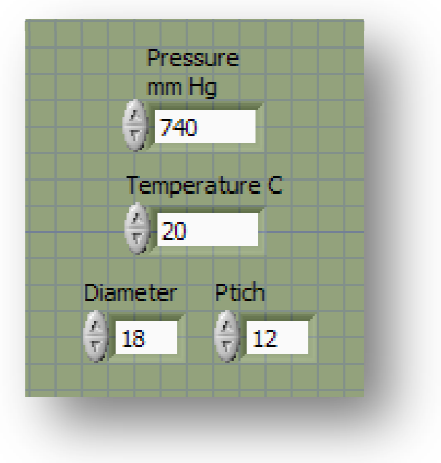

Figure 41: External inputs

Once the document has opened, make sure all equipment is on and connected. To execute the program, click on the white arrow. 


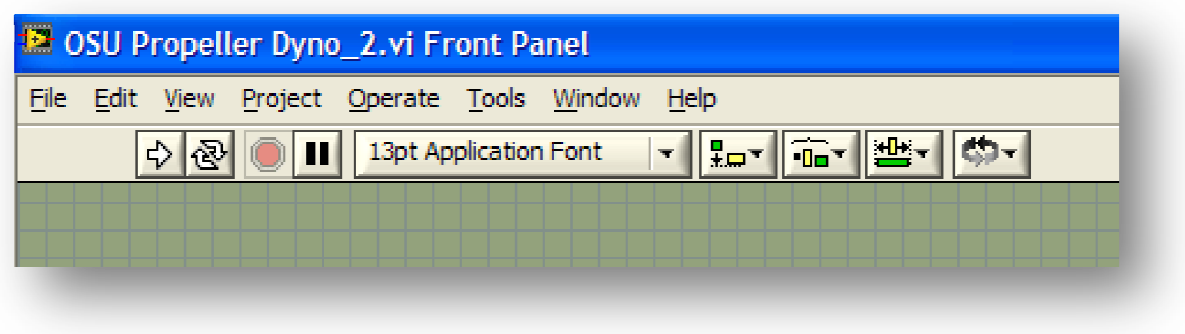

Figure 42: Execute Program

When the program becomes active, a quick check can be done by looking at the thrust and torque gauges. The needles should both be at zero.

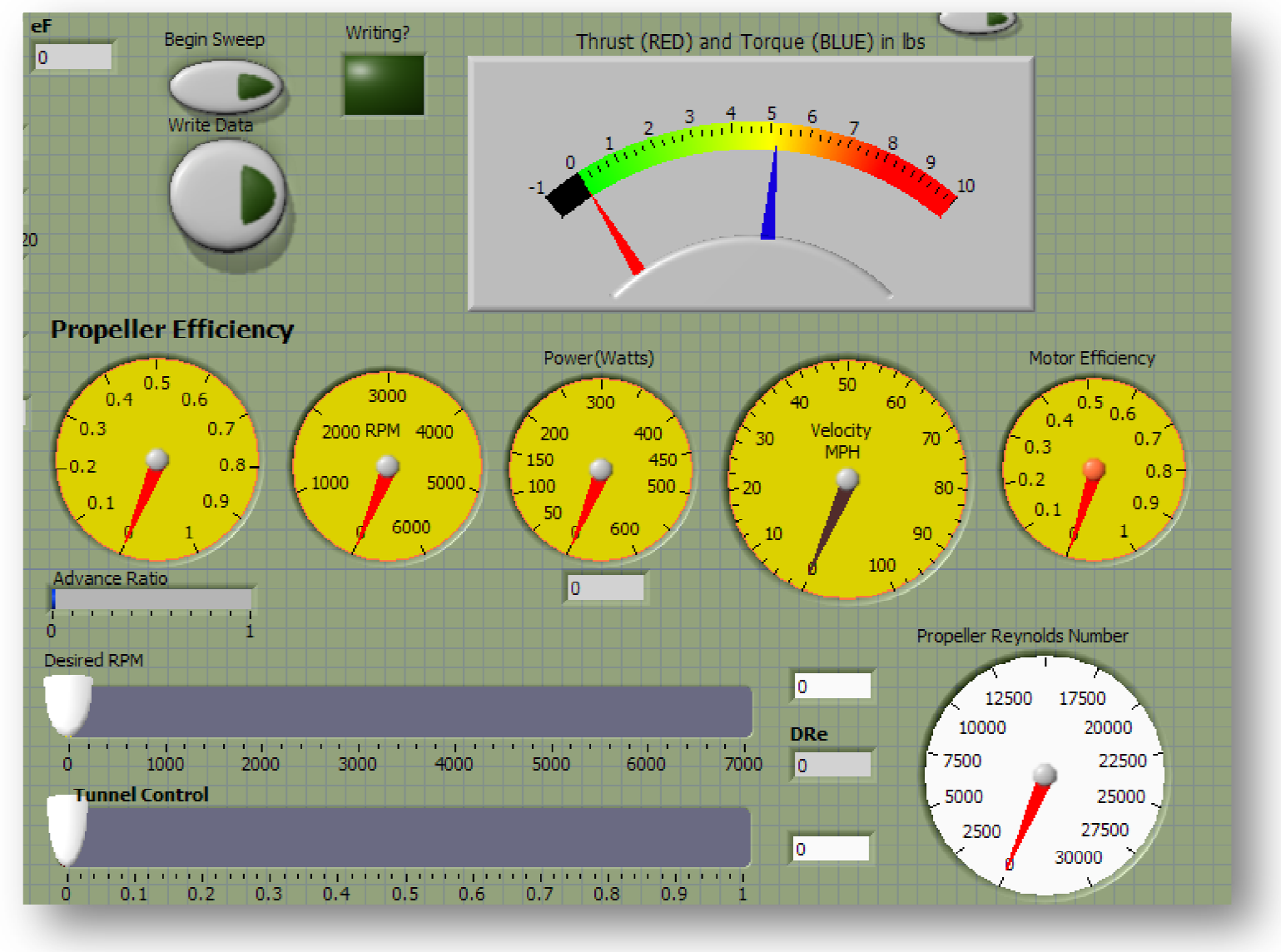

Figure 43: Overall gauges

At this point, the system is active and the computer has complete control over the motor to spin the propeller, as well as the throttle setting for the wind tunnel fan.

To check the system, turn on the main power supply to the motor and listen for the speed controller to identify that it is ready. When it is ready, it will beep three times. Next, move the RPM slider to 1000 RPM to make sure the system works. Caution should be observed over the load cell any time the propeller RPM is changed. 


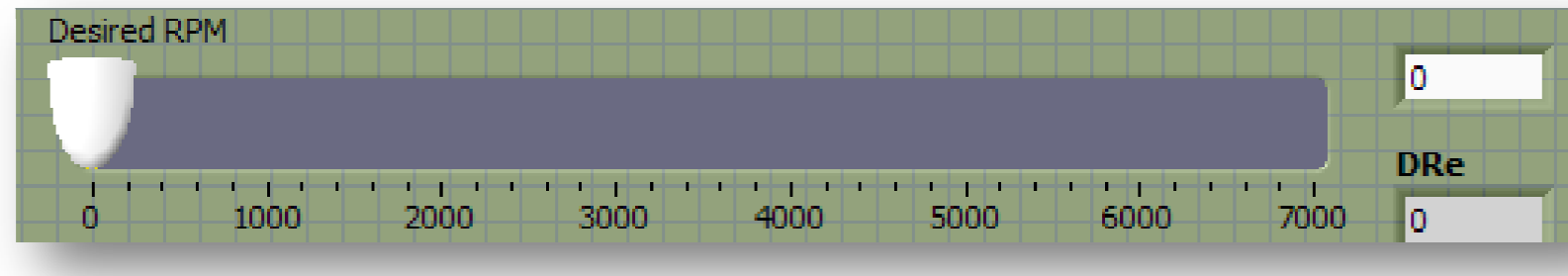

Figure 44: RPM control slider

Once it appears that the propeller is spinning, visually check the system by monitoring the RPM. At this point, the user should check the software by comparing it to the digital gauges on the dynamometer.

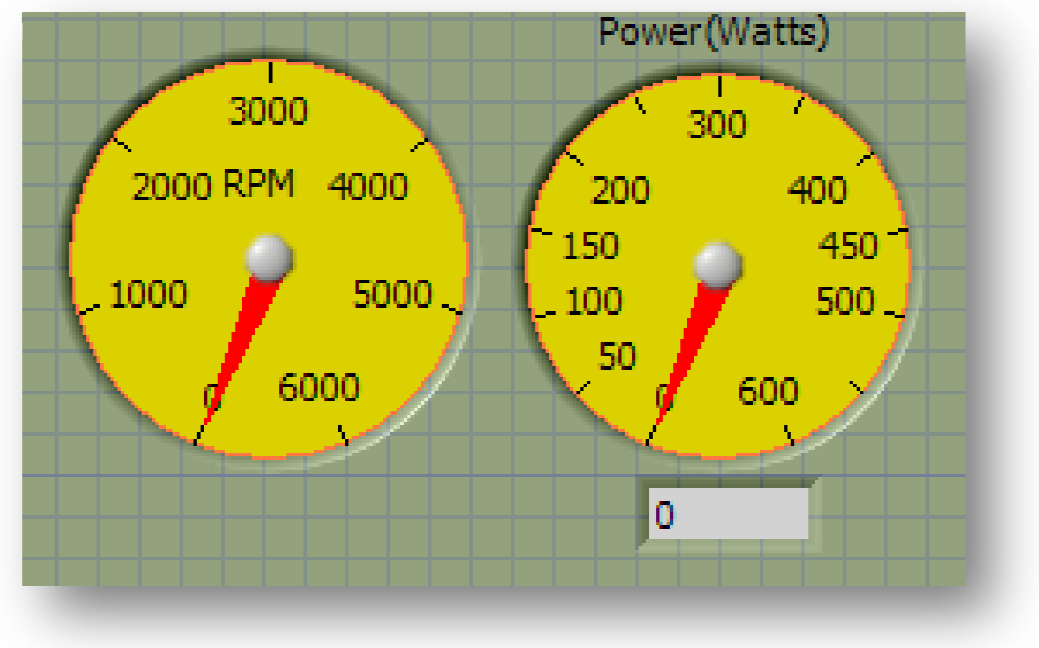

Figure 45: RPM and Power Dials

Next, slowly move up the RPM slider another 1000 RPM with a brief hesitation of 2 seconds before the next increment. This hesitation must be done because otherwise, the system will over shoot and could possibly hit the torque limit. While the RPM is being increased, attention must be kept on the torque needle to make sure it does not hit the limit, which could possibly destroy the load cell. It is dangerous when the needle reaches the $10 \mathrm{lb}$ limit.

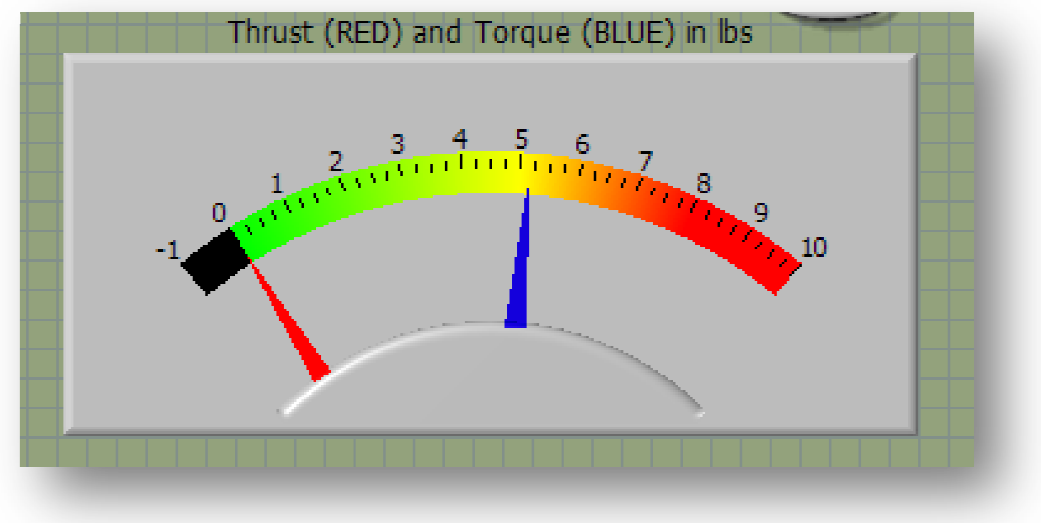

Figure 46: Thrust and Torque dials 
After the RPM is achieved successfully, the tunnel control can be used to dial in a preferred flight speed in order to take data. The tunnel control slider is below the RPM slider and it is listed in percentages. To make sure the computer can successfully control the tunnel, the slider should increase briefly.

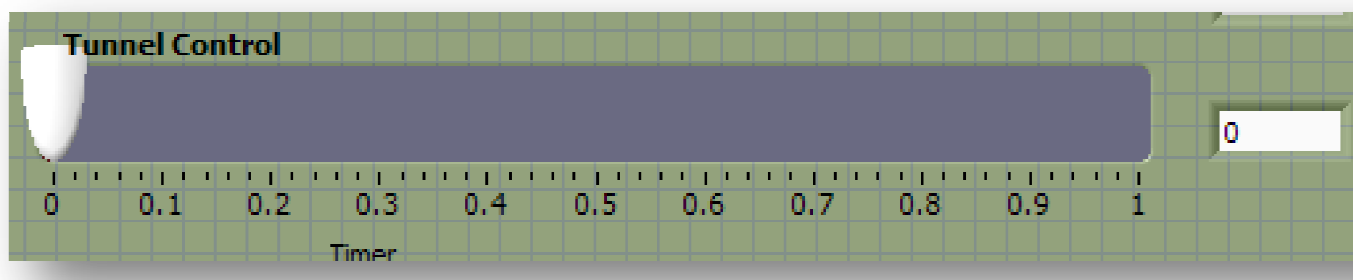

Figure 47: Tunnel control voltage slider

As the tunnel control slider increases, check the airspeed to validate that the tunnel flow is accelerating.

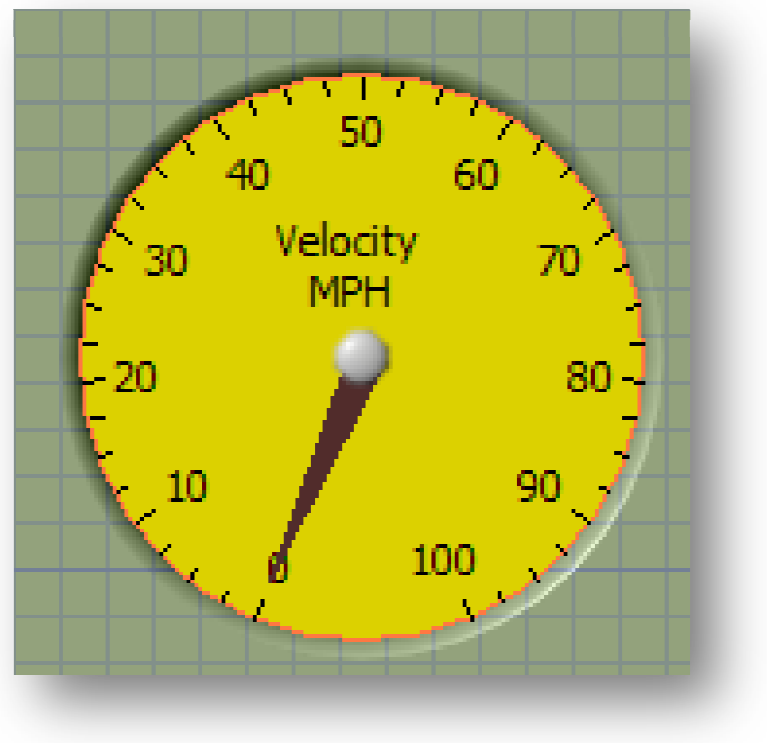

Figure 48: Tunnel velocity

The wind tunnel should never drive the propeller and propulsion system. As the tunnel velocity increases, it is important to monitor the thrust or torque values as to not allow them to go below zero.

\subsubsection{Automated Propeller Test}

After the desired RPM/Propeller Reynolds number has been set, the user can begin an experiment. There are several important sections of the screen to monitor while the test is under 
way. Continue observing while the computer is running the tests to make sure the load cells and current stay within desired limits.

For data collection the system need to be at steady state for a given amount of time. The timer for this process is positioned below the tunnel slider. The timer section includes an entry for the step sizing that the program will take when it increases the tunnel flow. The default step size is 0.01 . The clock is a 7 second timer which is used to monitor the program. The first 2 seconds of the timer are used to allow the wind tunnel flow to accelerate and RPM to stabilize. The last 5 seconds are used to obtain an average reading from the system. There is a voltage out gauge which gives the user information about the current setting that the wind tunnel is at. The sweeping light is used to monitor that the computer has active control over the tunnel.

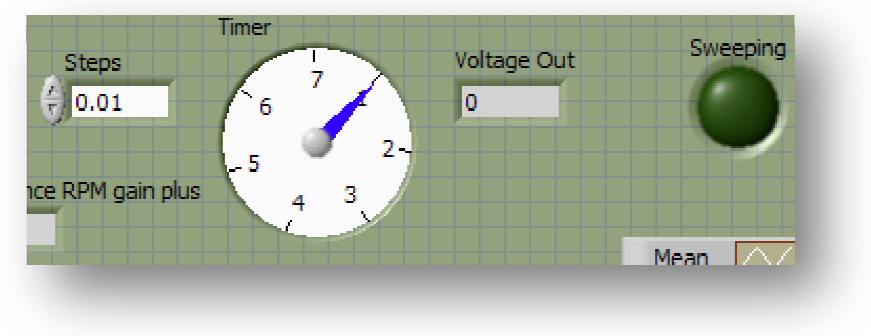

Figure 49: Timer

The next section of the screen to become familiar with are the activation buttons for the test automation. This includes a begin sweep and a write data button. The begin sweep button will start the clock and begin automatically taking data and increasing the tunnel flow based on the inputted step increments. To log all the data collected for this run make sure to simultaneously click the write data button. There is a notification light labeled "Writing?" which lights up when the system is logging the data. This light should light up only when the clock is in the last seconds of its 7 second period.

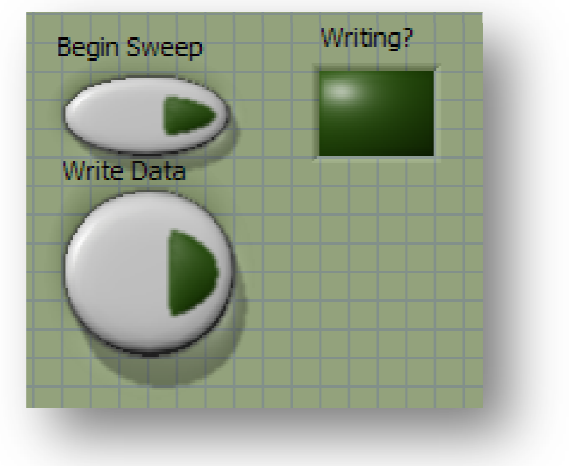

Figure 50: Automated execution buttons

While the tunnel is sweeping, an oscilloscope is used to make sure the tunnel flow has stabilized. A view of this scope is located in the upper left hand corner. 


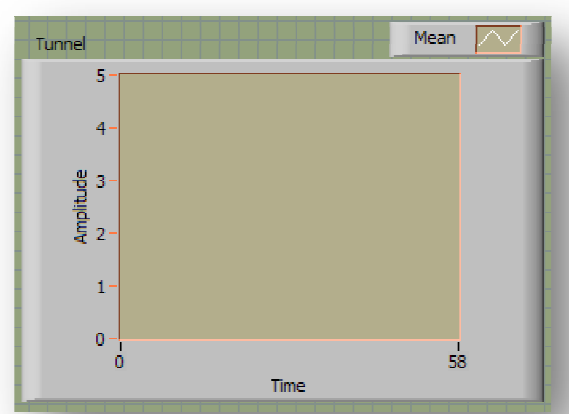

Figure 51: Wind tunnel oscilloscope

While the test is running, the user should be observing the overall system to make sure it is writing data, counting the clock, and increasing the tunnel voltage. The user should also make sure the thrust stays above zero.

The test is complete when the thrust can been driven to zero or near zero by the wind tunnel flow. At that point, the program will stop sweeping the system and the sweep light will go off. The user must then deactivate the automated sweep by pressing the begin sweep button. The user should also deactivate the write data button. Once the wind tunnel flow has reached zero RPM should be set to zero to power down the propulsion system.

Once the tunnel is off and the propeller is not spinning, the program can be deactivated by pressing the stop sign at the top of the screen.

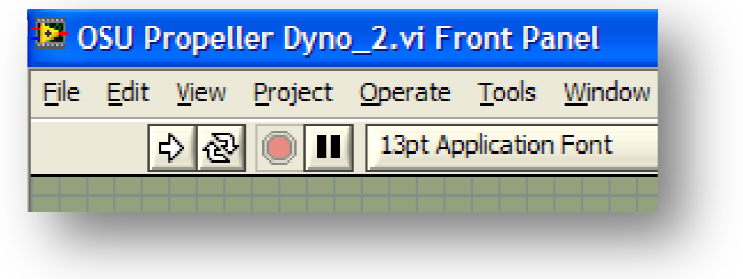

Figure 52: Deactivate program

At this point, the data from the test has been recorded and should be available to plot in excel. The data is stored in comma separated values and the description of each column is listed in the appendix of this document.

\subsubsection{Manual Propeller Test}

If the user does not want to complete a full propeller experiment, but simply wants to dynamically control and observe thrust, power, or propeller efficiency, manual mode can be used. In this mode the user can set the RPM and then sweep the tunnel flow. The gauges on the screen will read out the dimensional data, as well as the non-dimensional data, including the advance ratio and propeller efficiency. 


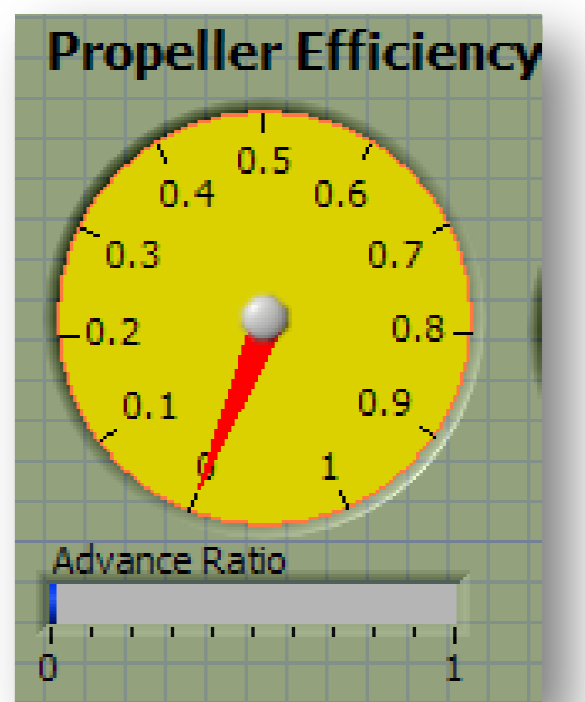

Figure 53: Propeller efficiency dial and advance ratio graph

For single point experiments, a manual writing button was created.
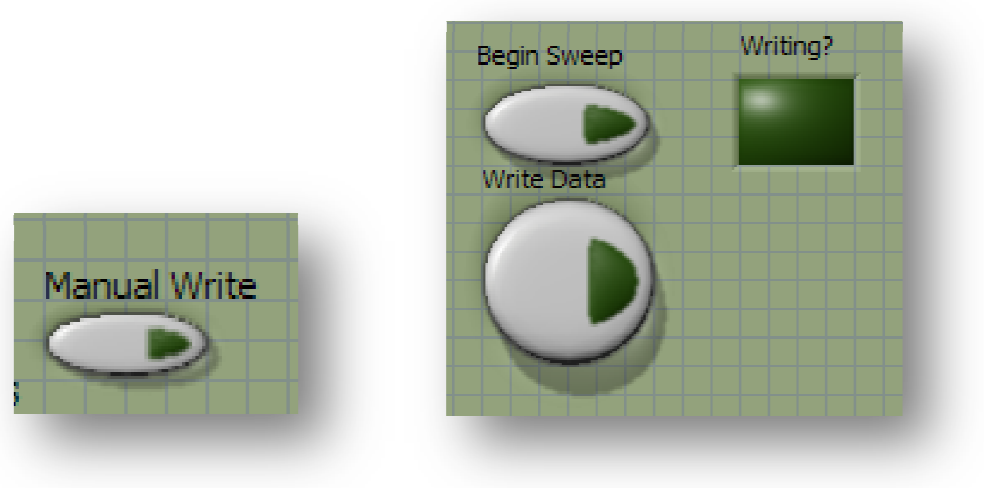

Figure 54: Manual write buttons

Once the desired tunnel velocity is achieved, the averaged data can be recorded by clicking the "Write Data" button and "Manual Write" button. Verify the data is being collected by checking that the "Writing?" light is on.

When the user has collected the desired data, the tunnel voltage and RPM should be brought to zero and the program deactivated. Data is saved in the same format as the automated section. 


\section{CHAPTER 5. RESULTS}

\subsection{Data Collected}

An 18 x 12 inch propeller was tested at 7 different RPMs. The propeller was only tested 7 times due to the uncertainty restrictions on the dynamometer. The uncertainty was the highest when the load cells were loaded the least. The maximum test RPM was determined by the limit of the load cells. The torque load would reach its maximum before the thrust load cell would, but they were both fairly close to their limits. The highest RPM tested has the lowest uncertainty.

\begin{tabular}{|c|c|c|}
\hline Test \# & RPM & $\begin{array}{c}\text { Propeller } \\
\text { Reynolds } \\
\text { Number }\end{array}$ \\
\hline 1 & 1666 & 400,000 \\
\hline 2 & 2162 & 520,000 \\
\hline 3 & 2618 & 630,000 \\
\hline 4 & 3094 & 740,000 \\
\hline 5 & 3570 & 870,000 \\
\hline 6 & 4046 & 970,000 \\
\hline 7 & 4522 & $1,080,000$ \\
\hline
\end{tabular}

Table 3: APC 18 x 12 Runs

The first run was at 1666 RPM. As shown in the figure, the torque and thrust load cell were below 1 pound. 


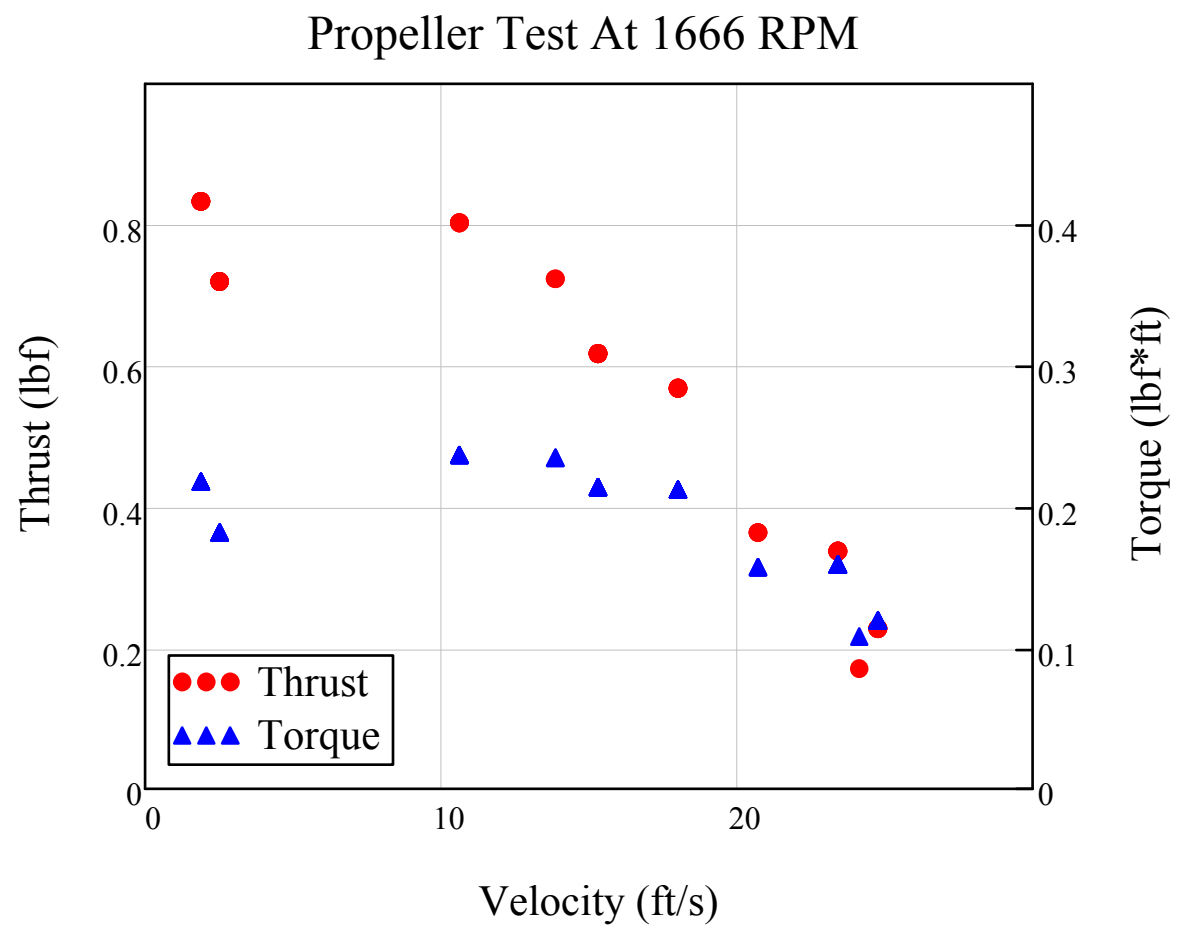

Figure 55: APC 18x12 RPM 1666

To see the uncertainty limitations, as in the lowest RPM case, a graph was created which shows the maximum calculated uncertainty. This graph shows that by the final efficiency calculation the uncertainty was $0.07 \%$. The uncertainty throughout the test grows rapidly because the load is decreasing as the test is running.

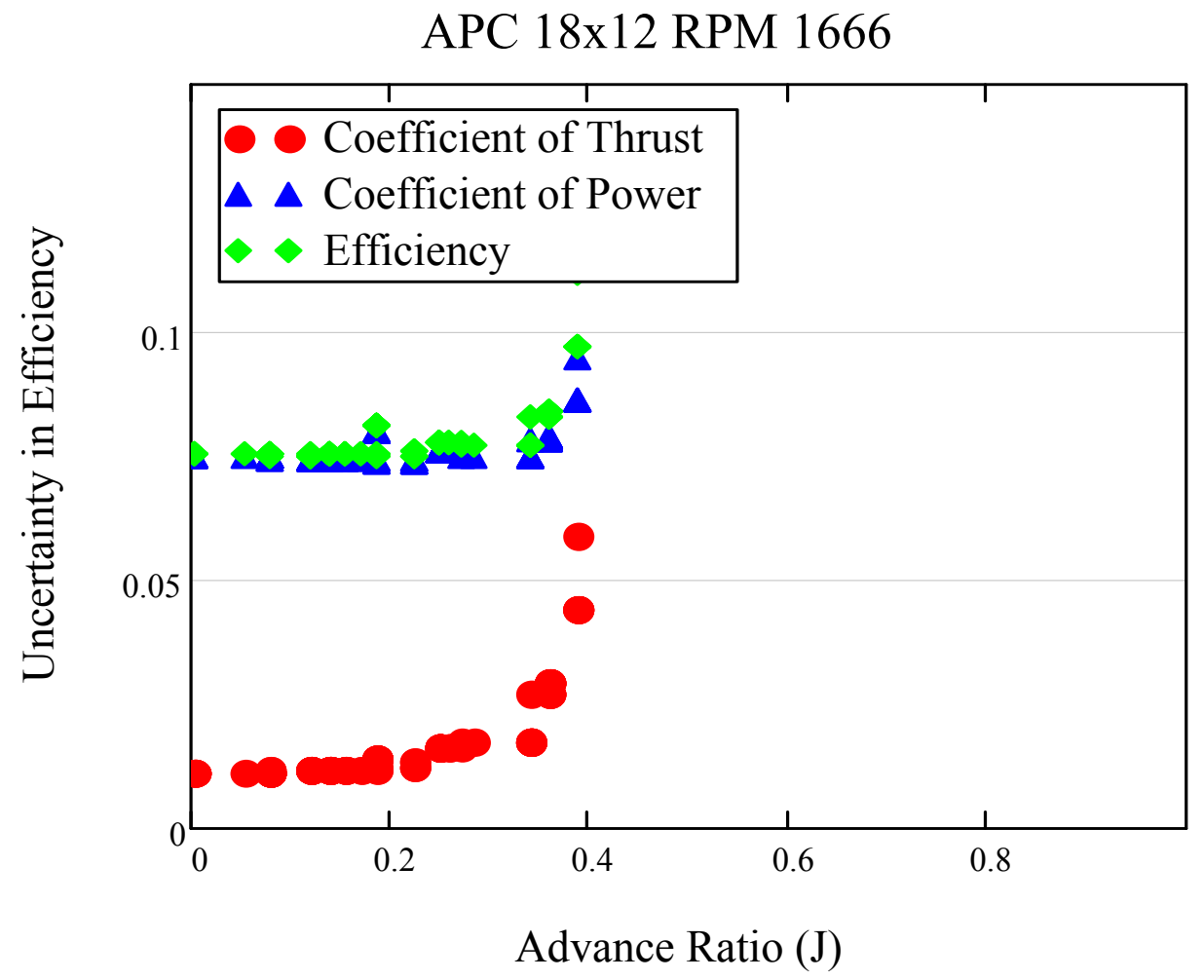


The next RPM test was at 2162 RPM. The thrust levels start at 1.5 pounds.

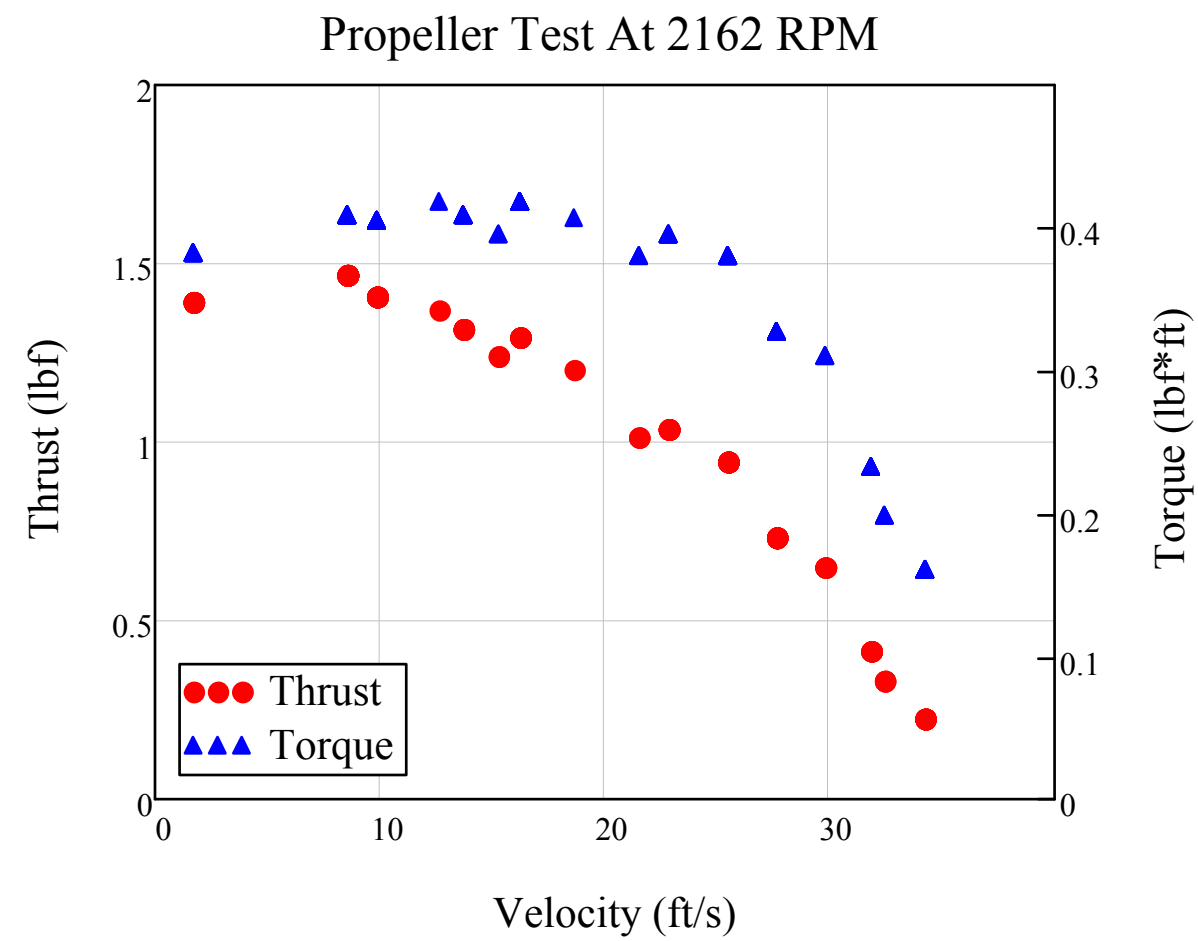

Figure 56: APC 18x12 RPM 2162

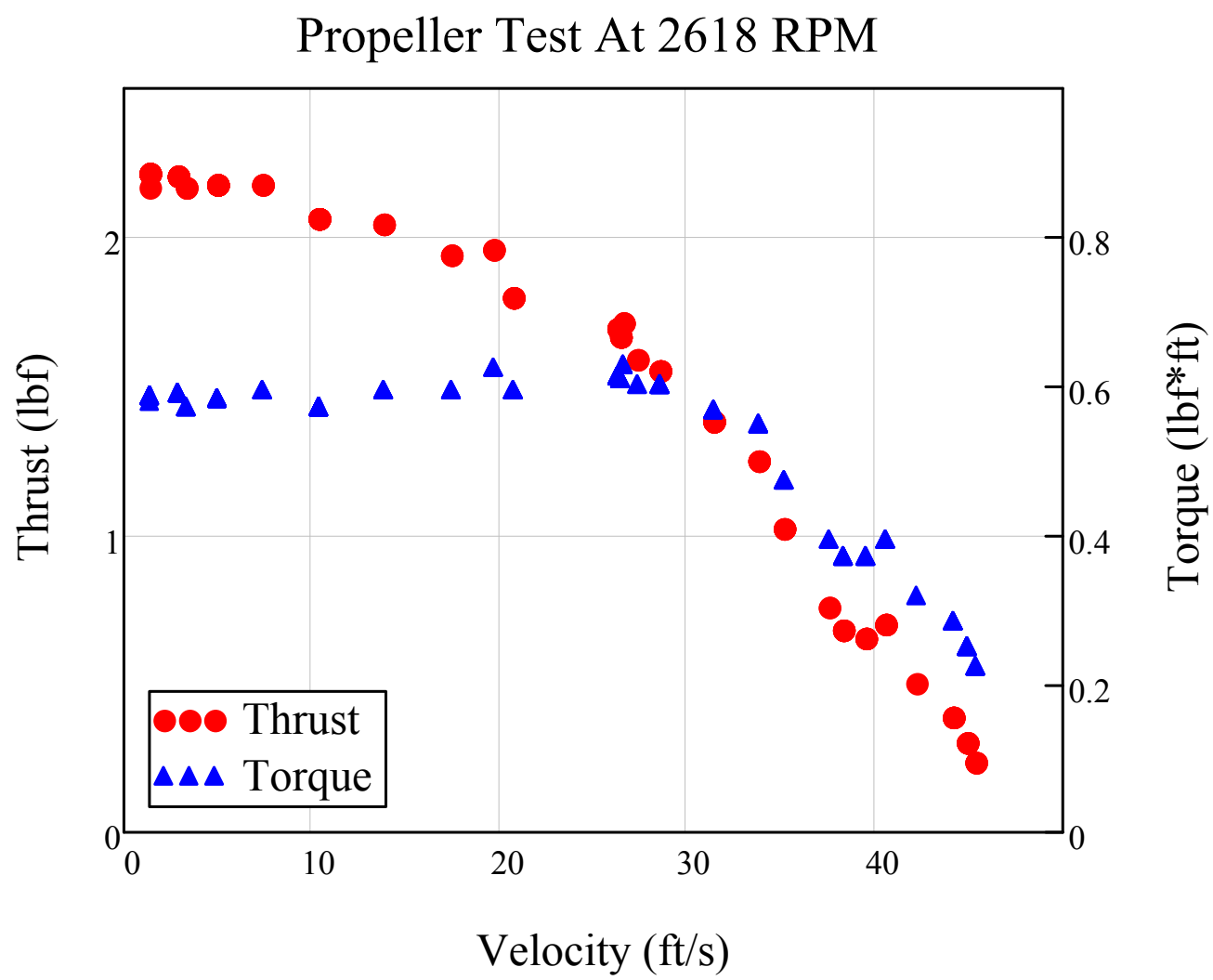

Figure 57: APC 18x12 RPM 2618 


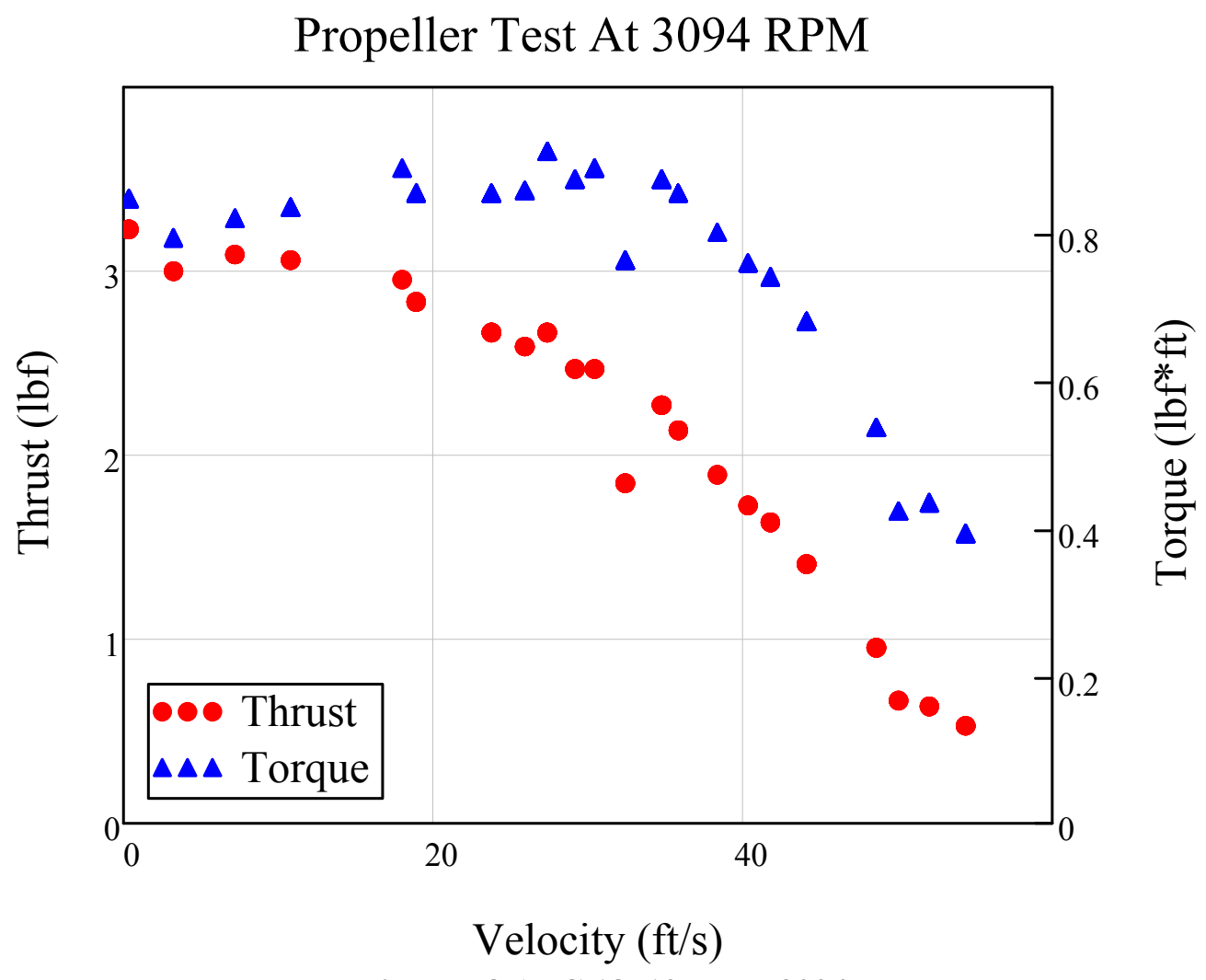

Figure 58 APC 18x12 RPM 3094

Propeller Test At 3570 RPM

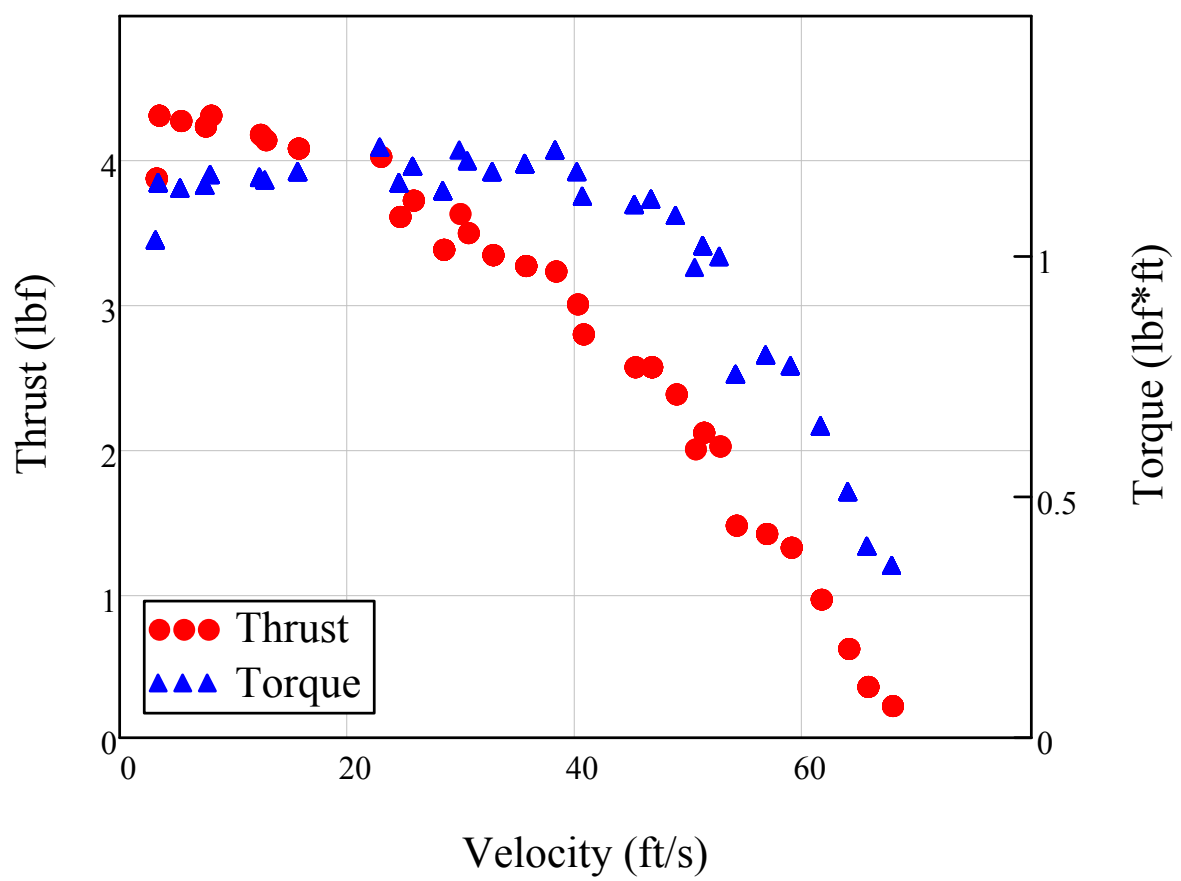

Figure 59 APC 18x12 RPM 3570 


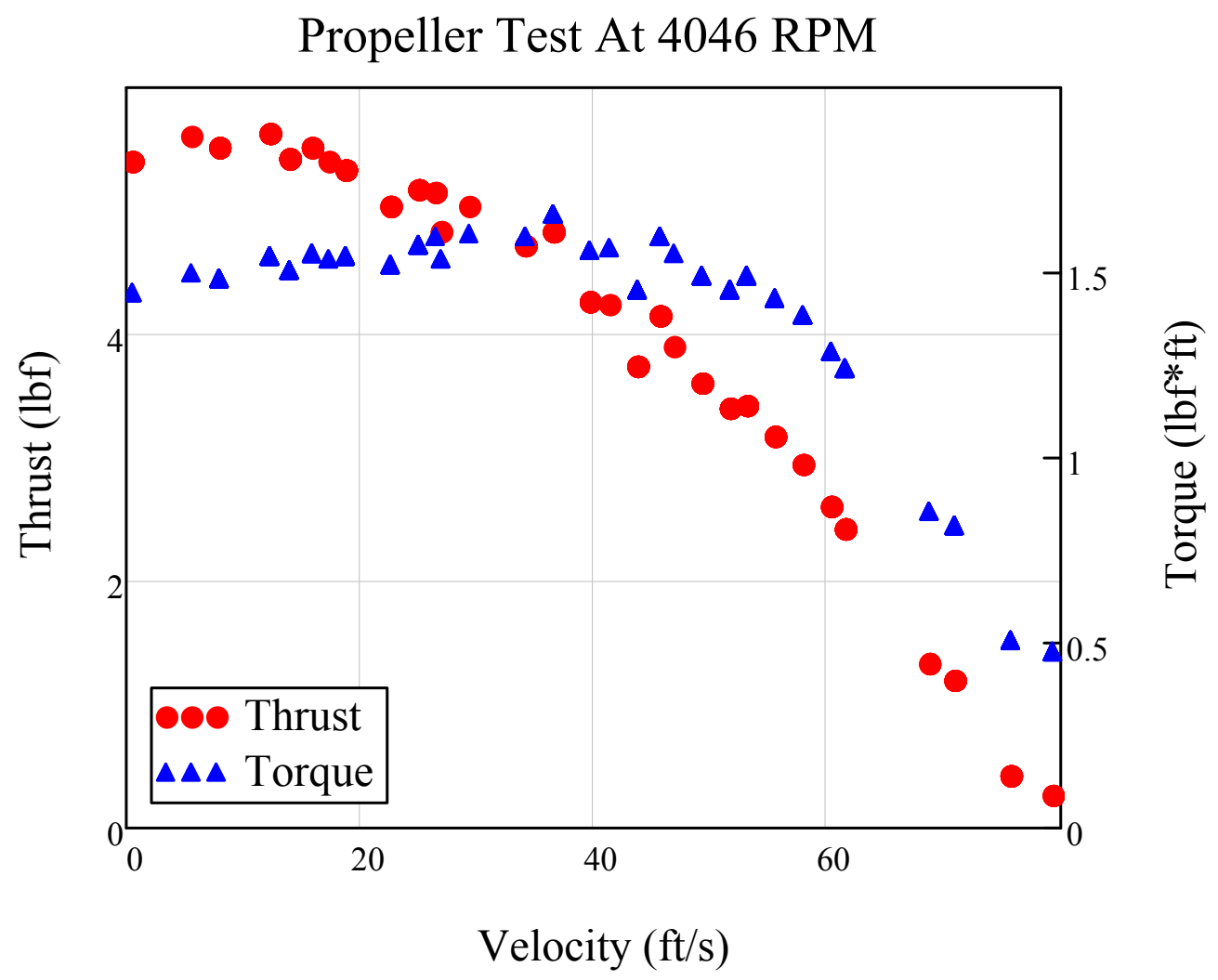

Figure 60 APC 18x12 RPM 4046

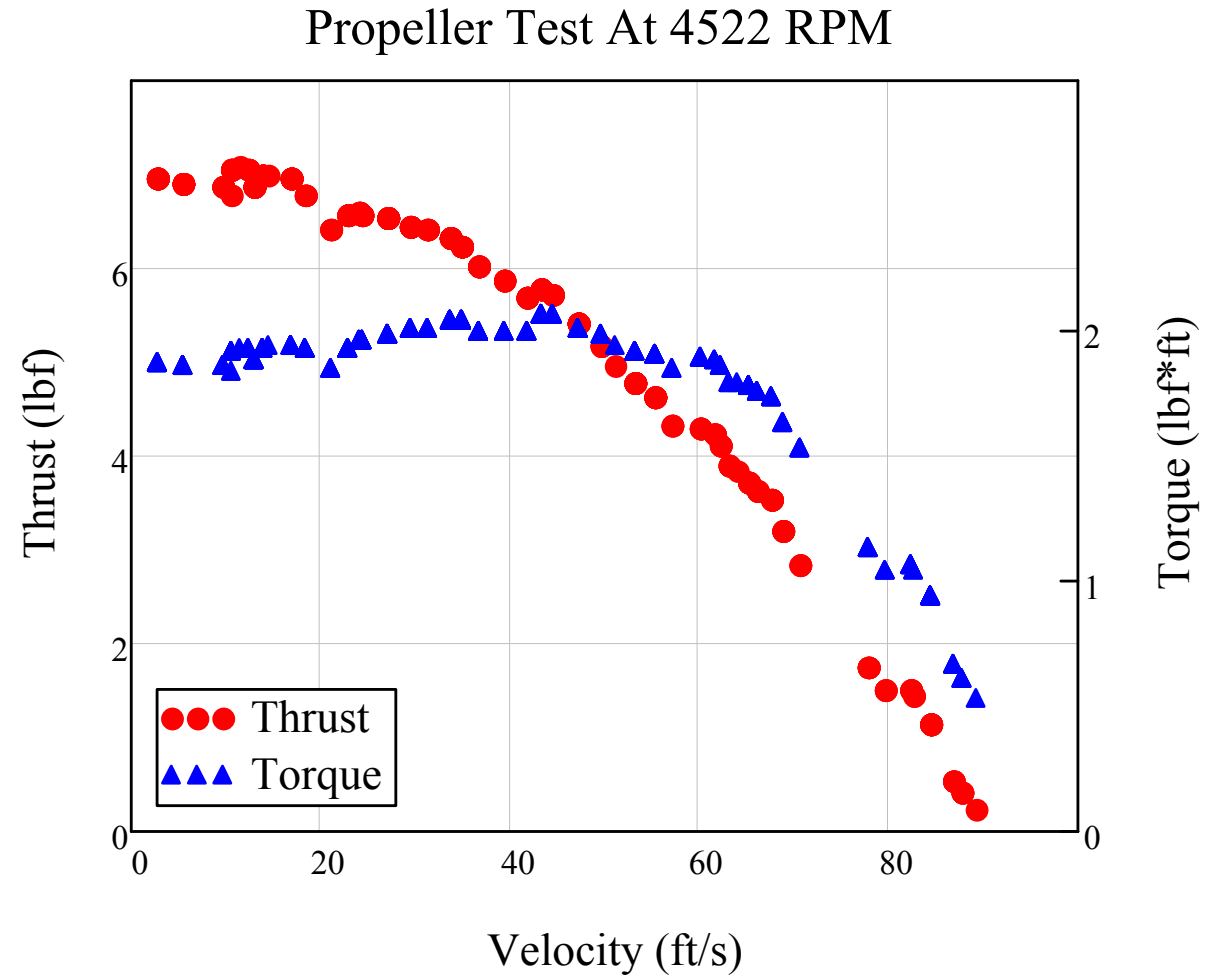

Figure 61: APC 18x12 RPM 4522 
All of the dimensional graphs are complied on one graph, which shows each respective test run and compares thrust produced to the free stream velocity.

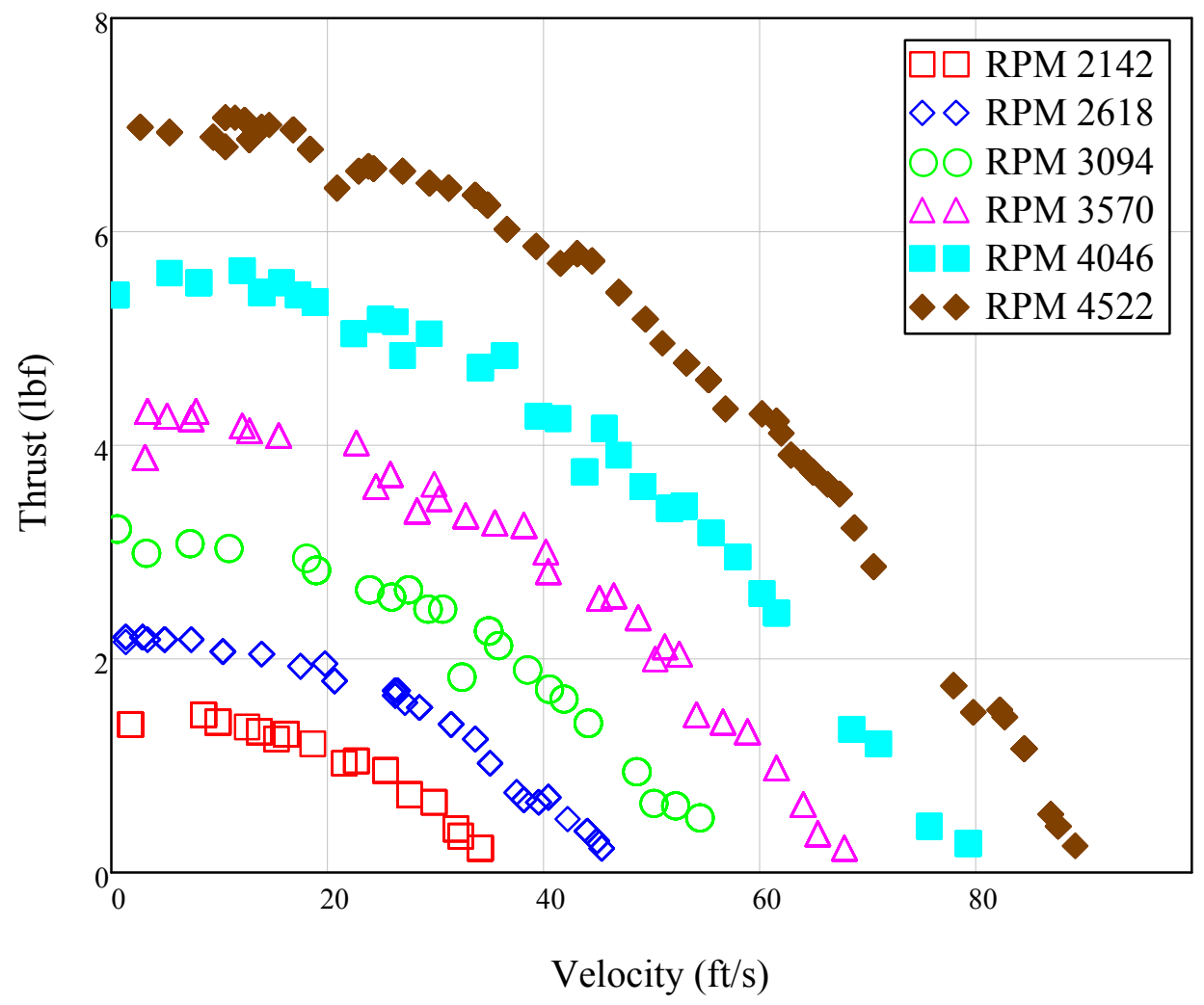

Figure 62 APC 18x12 Thrust vs. Velocity

The figure was recreated, but thrust was replaced with torque. 


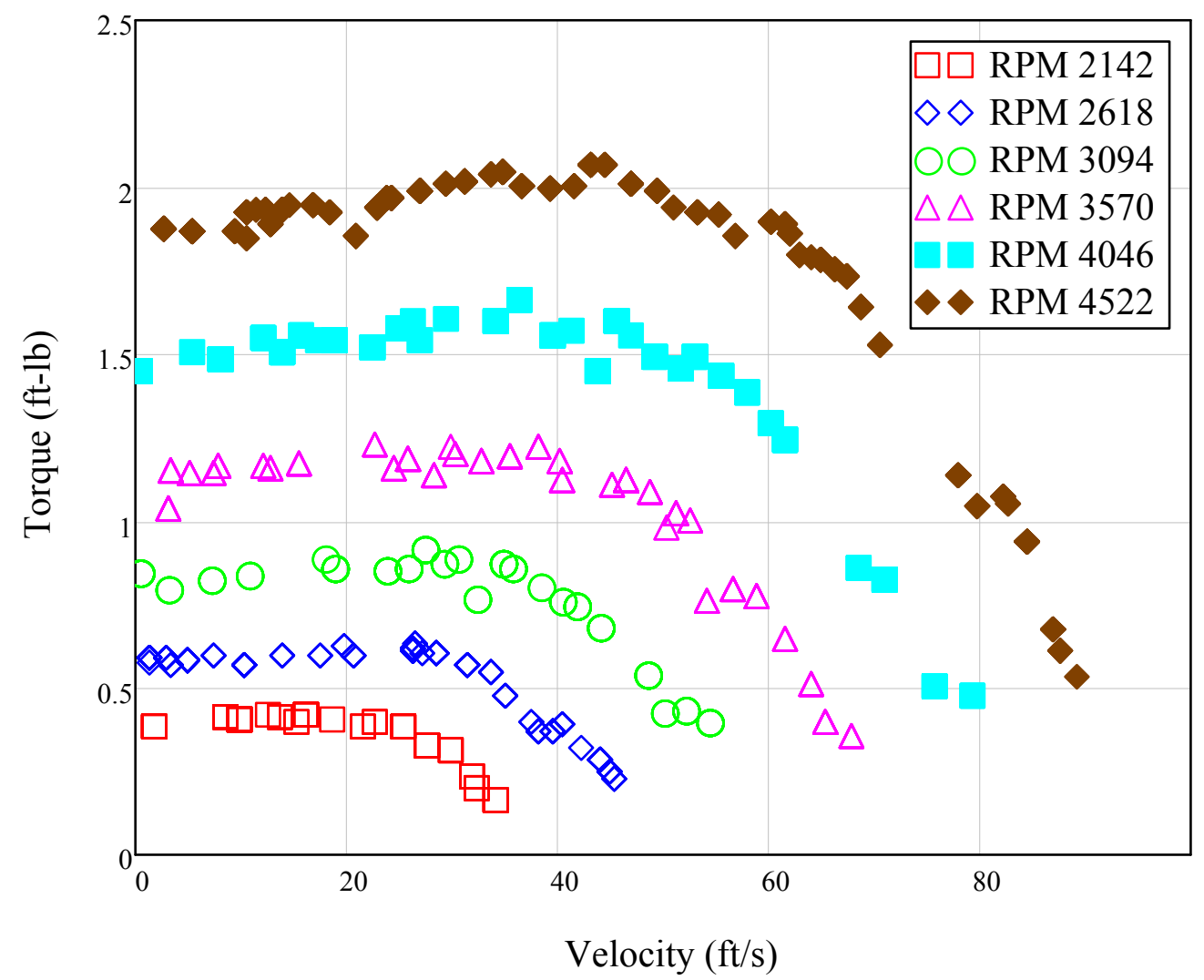

Figure 63: APC 18x12 Torque vs. Velocity 


\subsection{Low Reynolds Number Effect on Propellers}

Data recorded from the experiment showed an efficiency increase, as well as a pitch increase when the Reynolds number of the propeller area increased. With a Reynolds increase from $400,000(1,700 \mathrm{RPM})$ to $1,155,000$ (4850 RPM) on an APC $18 \times 12$ propeller, the efficiency was increased by $5 \%$.

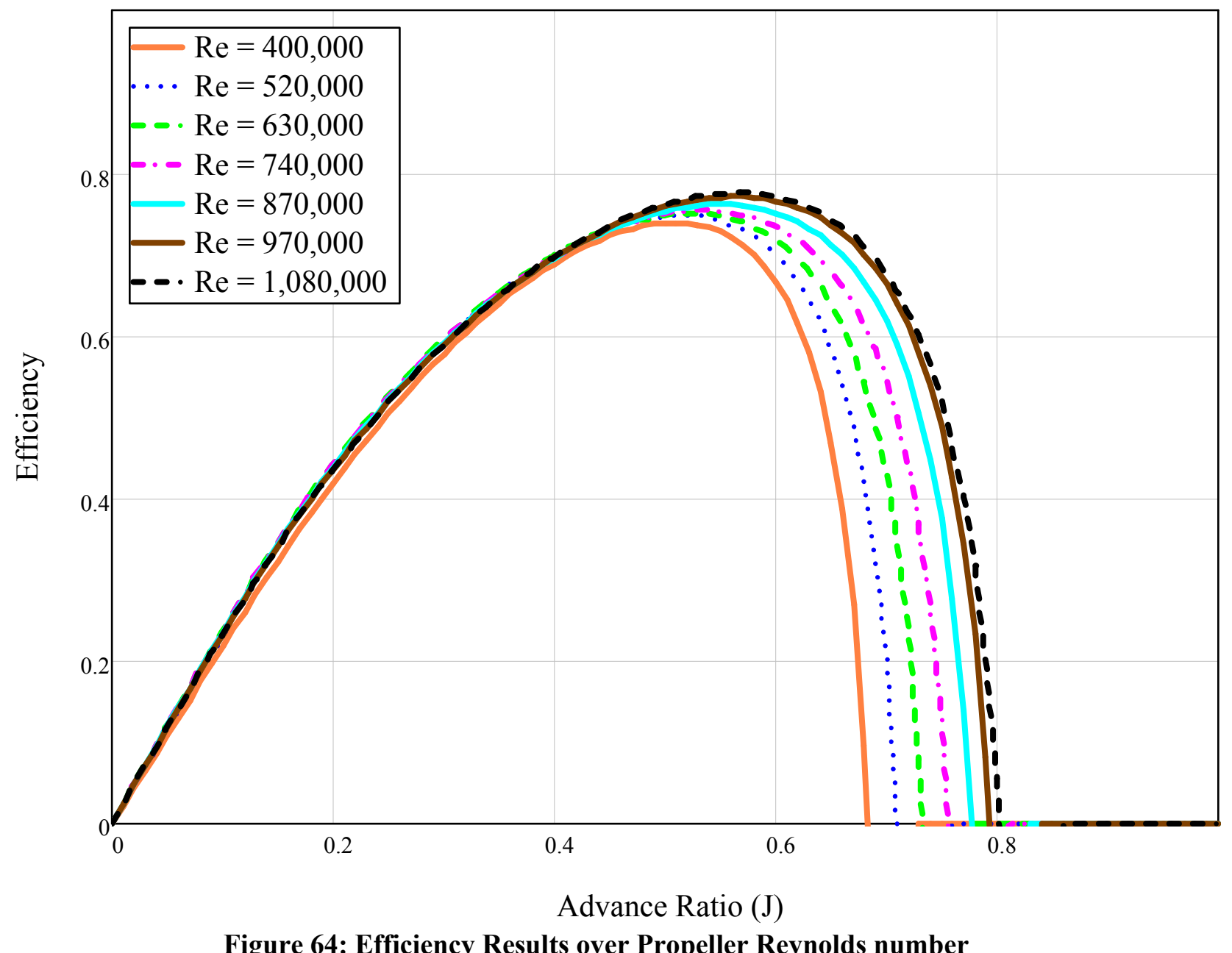

This propeller curve corresponds to the airfoil performance at low Reynolds numbers. As the Reynolds number increases, the drag decreases and the lift over drag ratio increases. On a propeller blade, this increases the propeller efficiency.

To directly see this effect of low Reynolds numbers, a plot of the coefficients of thrust and power are shown in Figure 65 and Figure 66. 


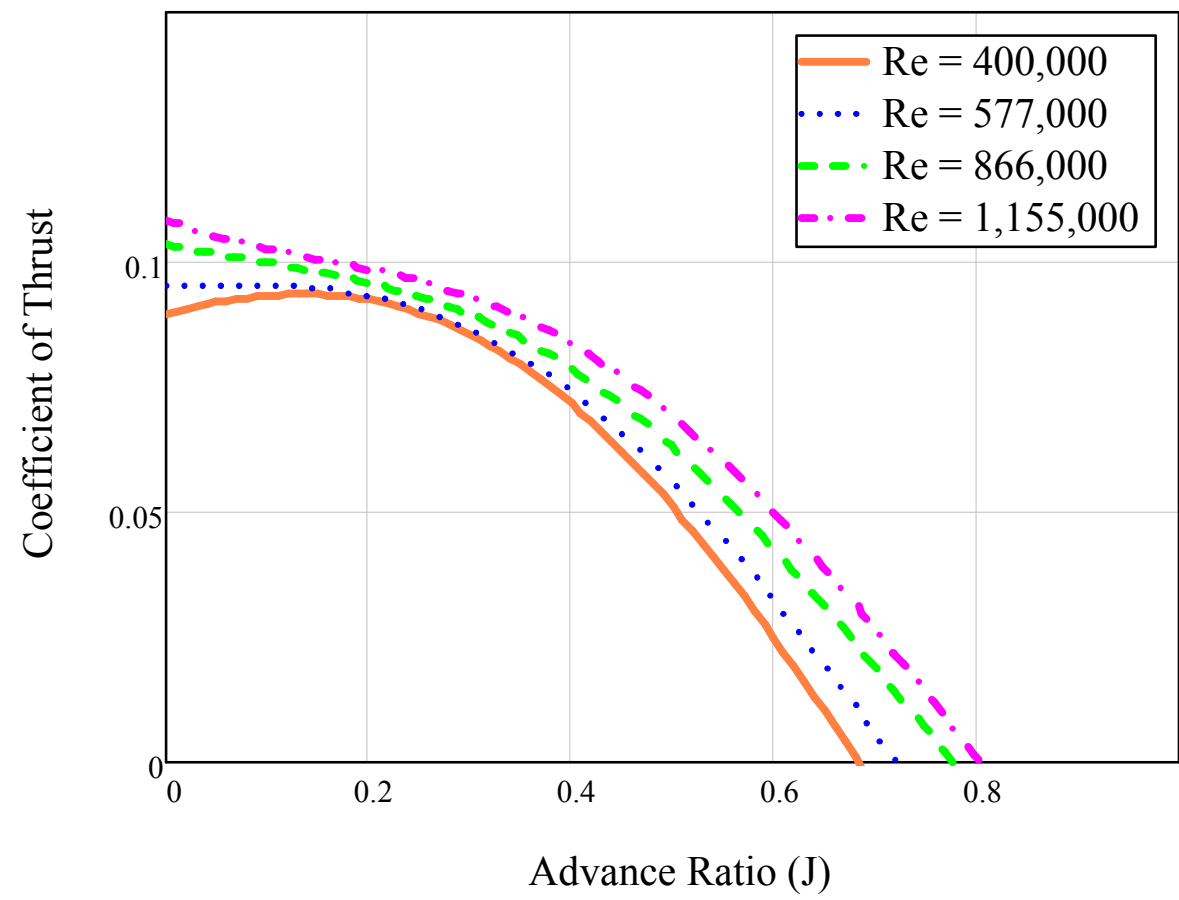

Figure 65: Coefficient of Thrust compared to Reynolds Number

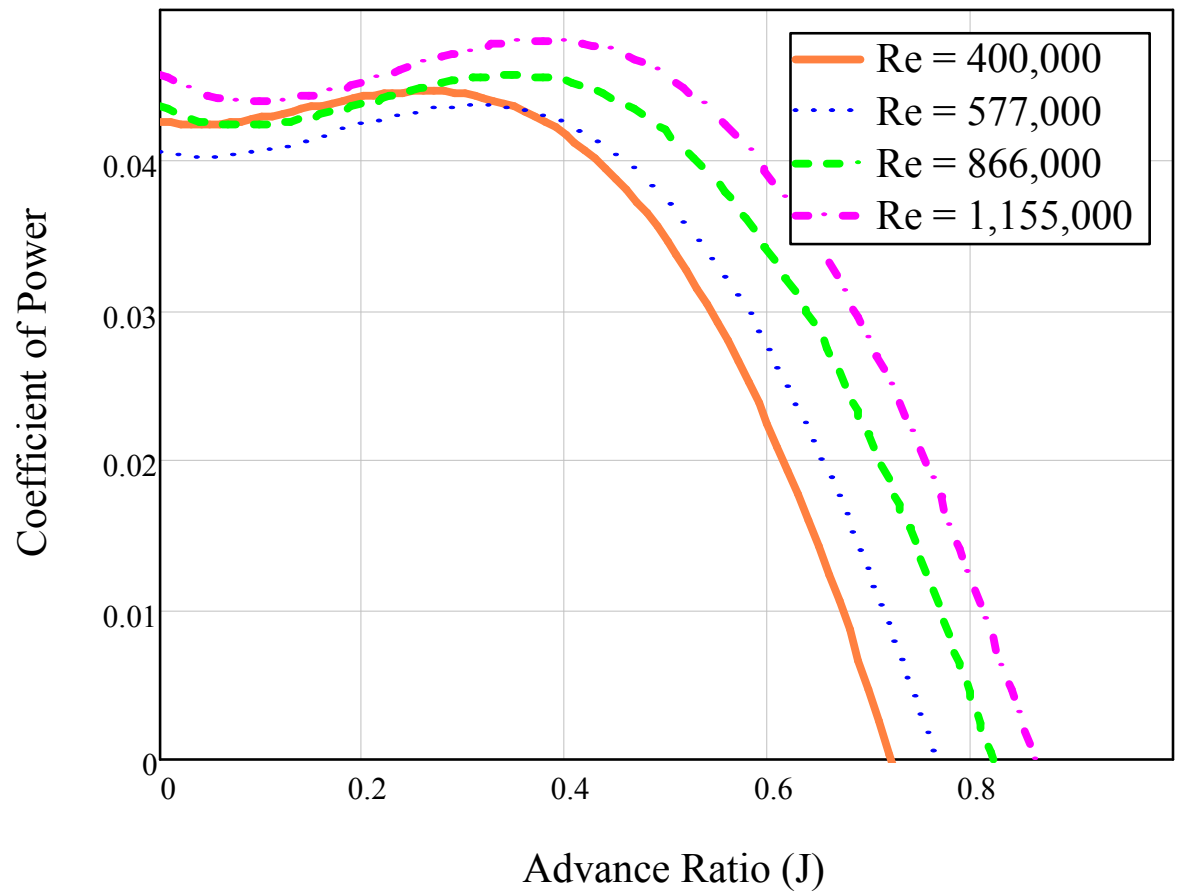

Figure 66: Coefficient of Power compared to Reynolds Number 


\subsection{Data Collected on Various pitched Propellers}

To compare the effects of different pitched propellers, an APC $18 \times 8$ and a $14 \times 12$ propeller were also tested. The APC 18x8 was tested at the same RPMs as the $18 \times 12$ number because they have the same diameter. Both also have the same Reynolds number. Seven experiments were completed for this propeller.

\begin{tabular}{|c|c|c|}
\hline Test \# & RPM & $\begin{array}{c}\text { Propeller } \\
\text { Reynolds } \\
\text { Number }\end{array}$ \\
\hline 1 & 2142 & 502,000 \\
\hline 2 & 2618 & 643,000 \\
\hline 3 & 3094 & 754,000 \\
\hline 4 & 3570 & 848,000 \\
\hline 5 & 4046 & 973,000 \\
\hline 6 & 4522 & $1,100,000$ \\
\hline 7 & 5000 & $1,213,000$ \\
\hline
\end{tabular}

Table 4: APC 18 x 8 Test Runs

The data collected was plotted similarly to the APC $18 \times 12$. 


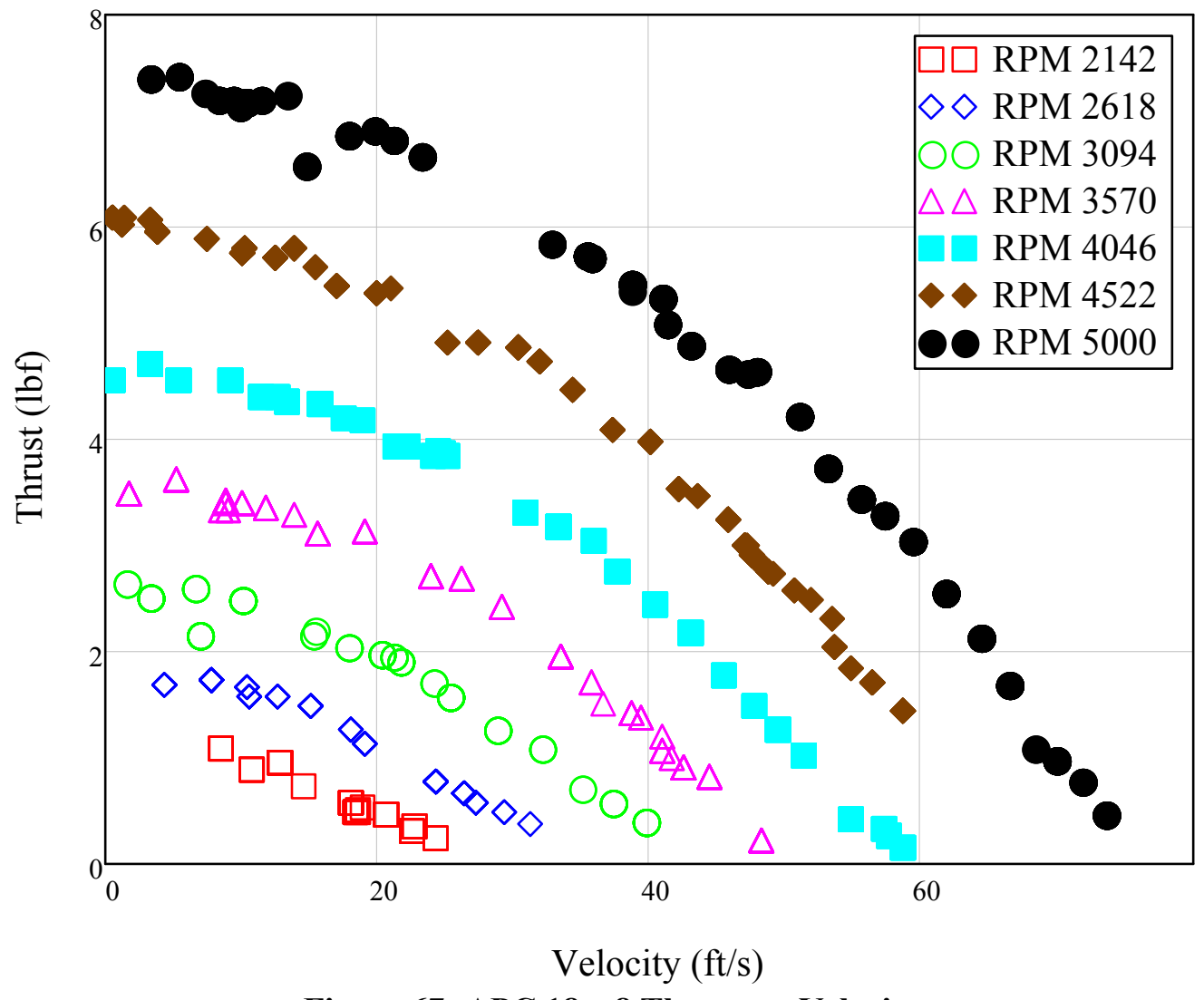

Figure 67: APC 18 x 8 Thrust vs. Velocity

Since this propeller is pitched lower than the $18 \mathrm{x} 12$, as shown on the plot, the $18 \mathrm{x} 8$ propeller does not produce thrust above $60 \mathrm{ft} / \mathrm{s}$. 


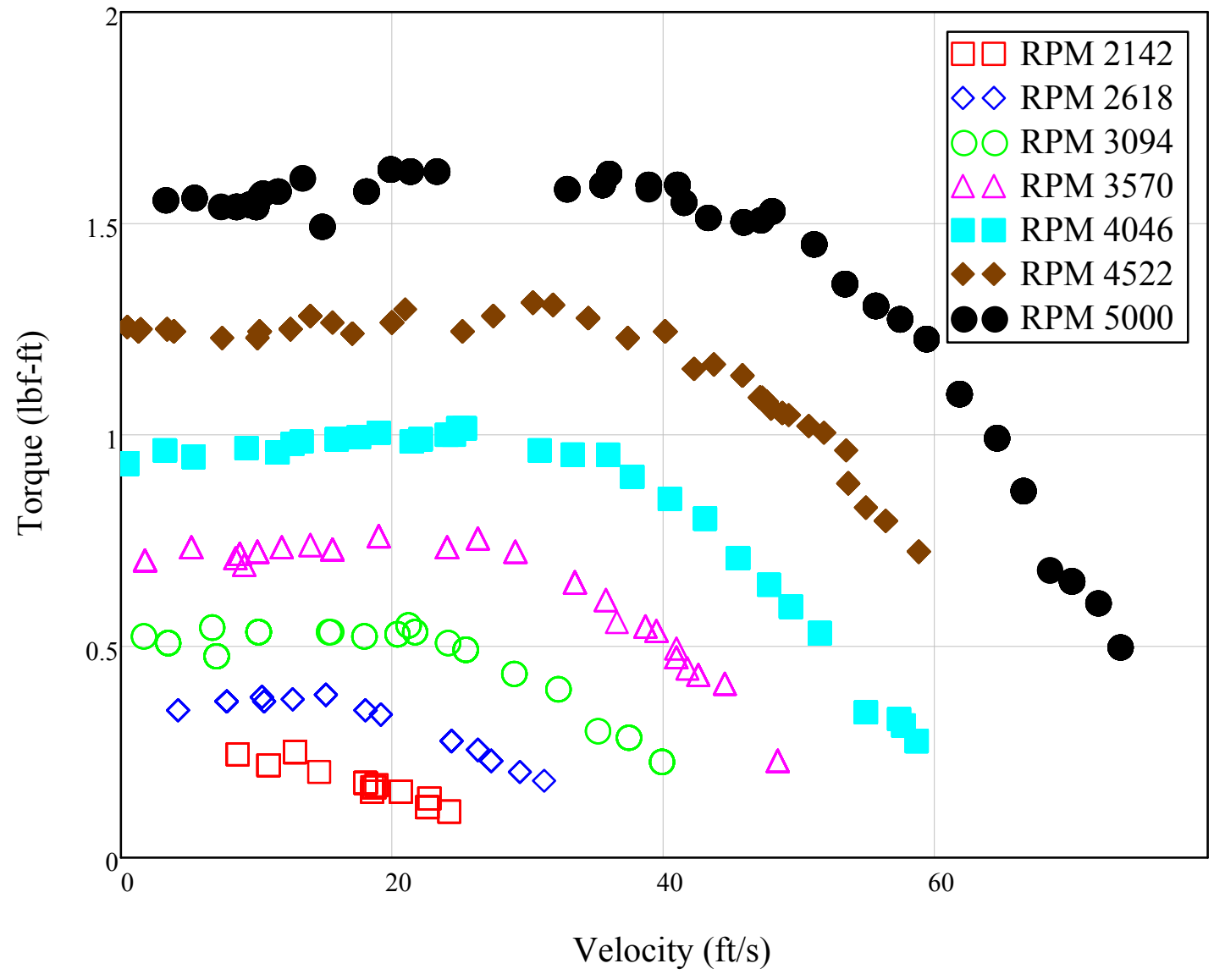

Figure 68: APC 18 x 8 Torque vs. Velocity

The APC 14x 12 propeller was run six times at RPMs similar to those of the other propellers tested.

\begin{tabular}{|c|c|c|}
\hline Test \# & RPM & $\begin{array}{c}\text { Propeller } \\
\text { Reynolds } \\
\text { Number }\end{array}$ \\
\hline 1 & 2754 & 401,000 \\
\hline 2 & 3541 & 522,000 \\
\hline 3 & 4328 & 638,000 \\
\hline 4 & 5118 & 748,000 \\
\hline 5 & 5902 & 869,000 \\
\hline 6 & 6689 & 970,000 \\
\hline
\end{tabular}

Table 5: APC $14 \times 12$ Test Runs

Since the $14 \times 12$ propeller has a lower diameter, the dynamometer load cells allowed the propeller to spin at much higher RPMs. The higher pitch ratio meant that the propeller could continue producing thrust past $60 \mathrm{ft} / \mathrm{s}$ and on to $120 \mathrm{ft} / \mathrm{s}$. 


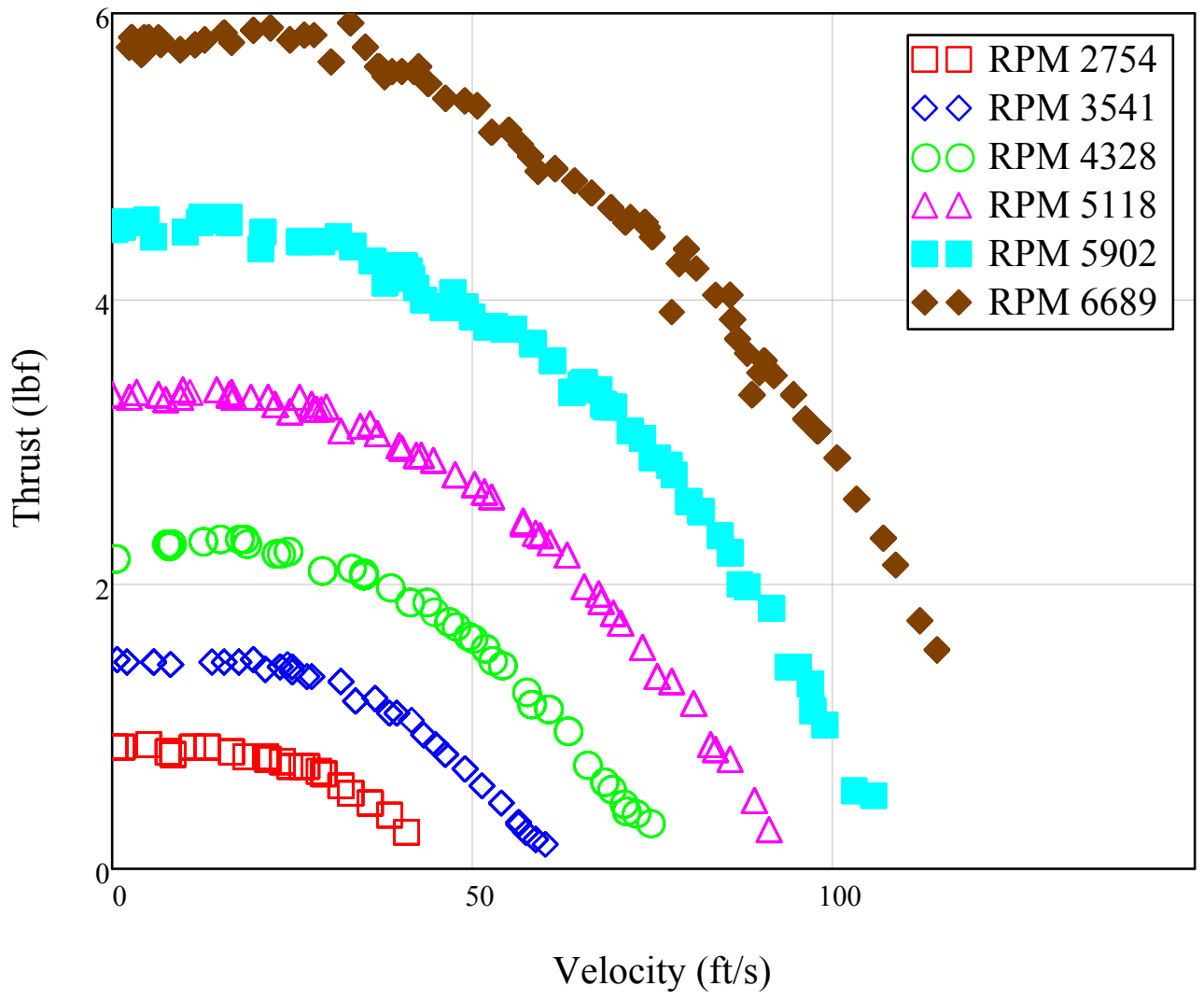

Figure 69: APC 14 x 12 Thrust vs. Velocity

The range of experiments for the APC 14x12 were at the dynamometer limitations, which were similar to the range of RPMs tested for the APC $18 \times 12$. 


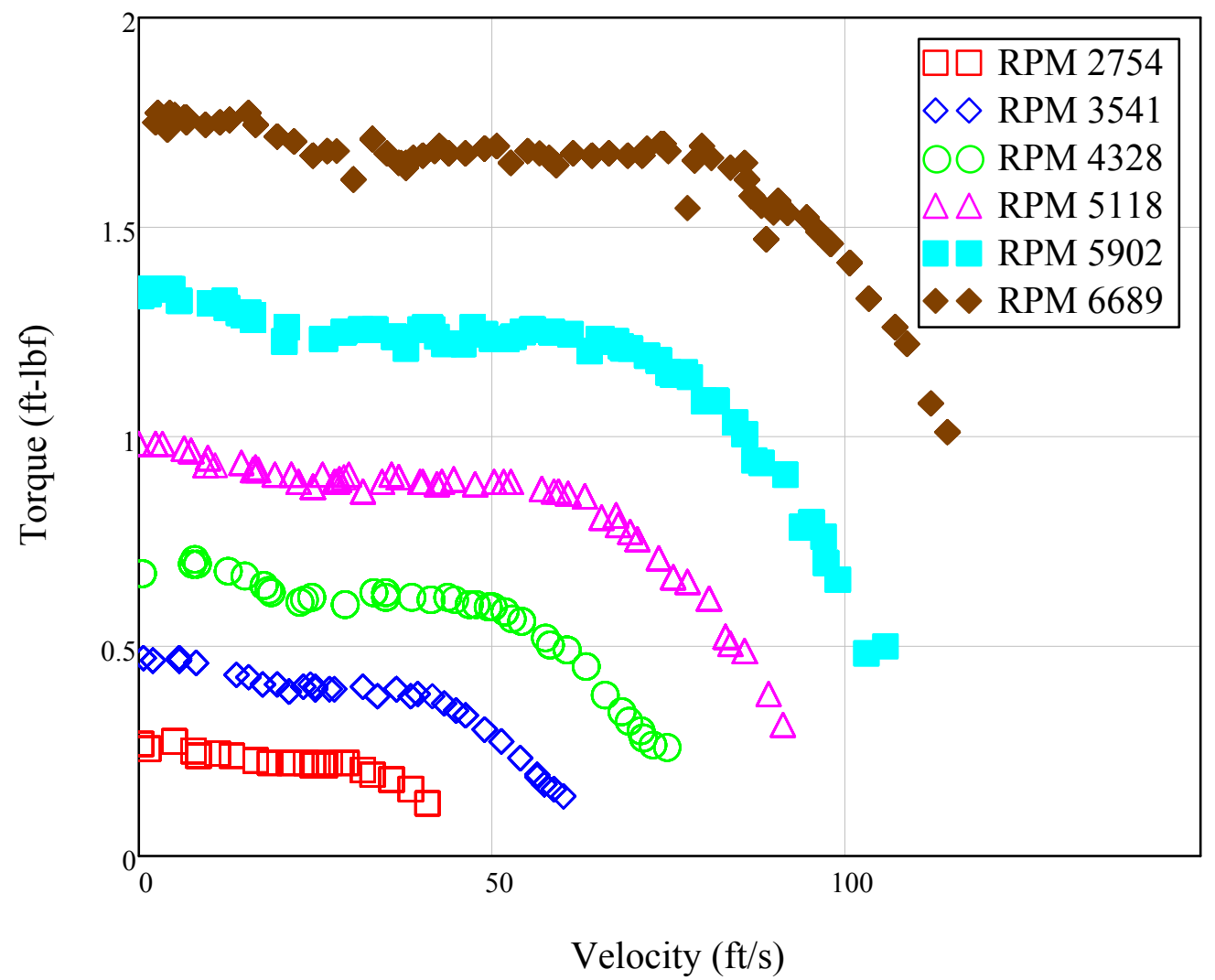

Figure 70: APC 14 x 12 Torque vs. Velocity

All of the three propellers tested were grouped together and their efficiency was calculated. At a given propeller Reynolds number, one can see the effect of changing pitch on small propellers. As the pitch increases, the efficiency increases as well as its ability to provide thrust at higher advance ratios. 


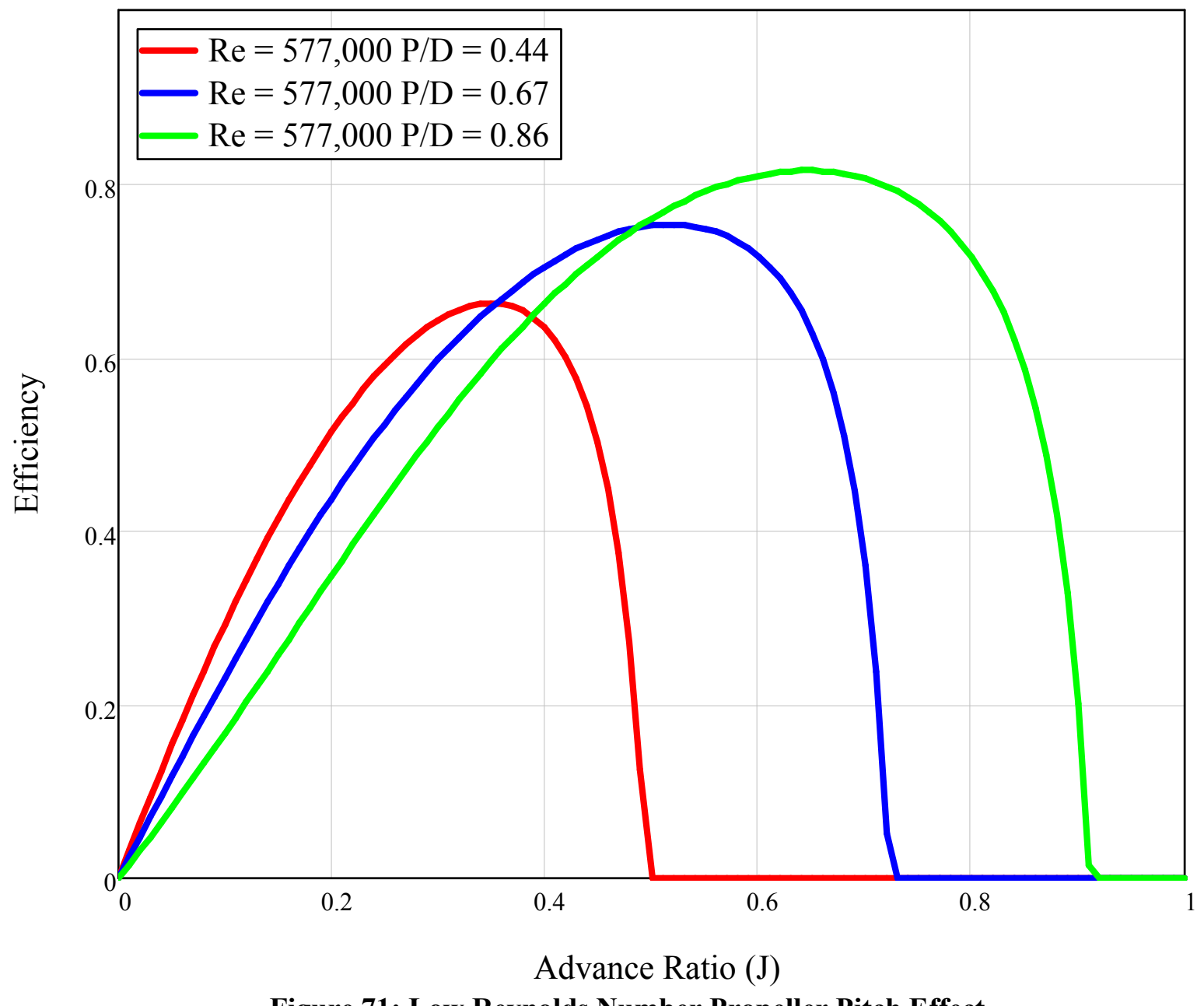

Figure 71: Low Reynolds Number Propeller Pitch Effect

Another interesting issue of the effect of low Reynolds numbers is the shift in pitch at maximum efficiency. Notice that in low Reynolds number airfoil performance, the drag of an airfoil is higher on the lower angle of attack, but the drag decreases as the Reynolds number is increased. This effect can be observed in low Reynolds number propeller performance because it reduces the drag on the high advance ratio end. APC propeller of sizes $18 \times 8,18 \times 12$, and $14 \times 12$ are used to calculate the following curves. 


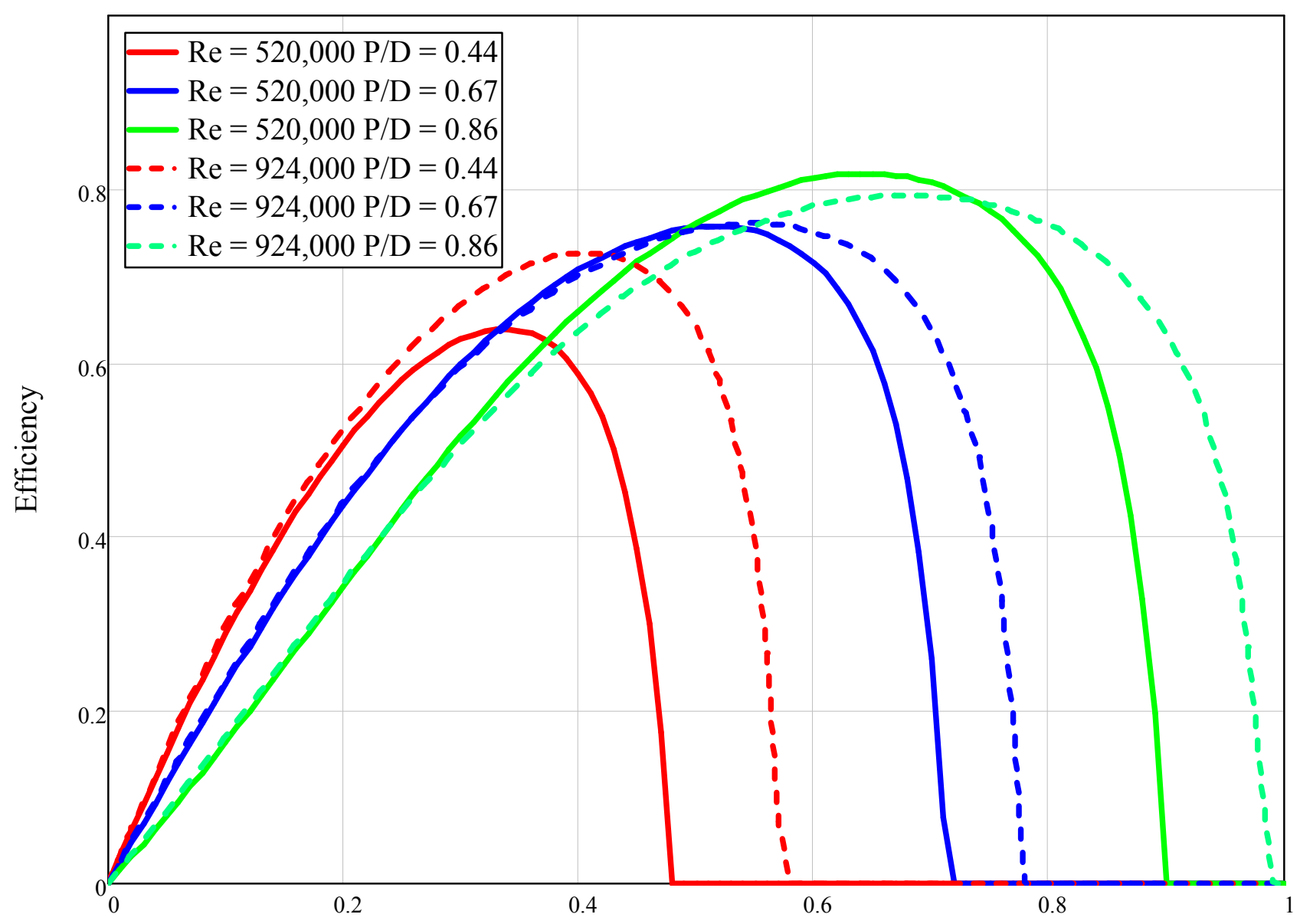

Advance Ratio (J)

Figure 72: Reynolds effect on Propeller efficiency and pitch

The problem with the shift in the pitch of efficiency is that a designer needs to take into account the Reynolds number when selecting the best propeller for cruise.

\subsection{Advance ratio using Pitch}

The advance ratio was redefined using pitch as the length value instead of diameter. The results show that the optimal ratio for any propeller diameter is a pitch ratio of 0.75 . Therefore, if one is selecting a propeller, they should select the pitch to match the flight speed, and the RPM to equal 0.75 for optimal performance. The diameter should then be selected to provide the thrust needed. 


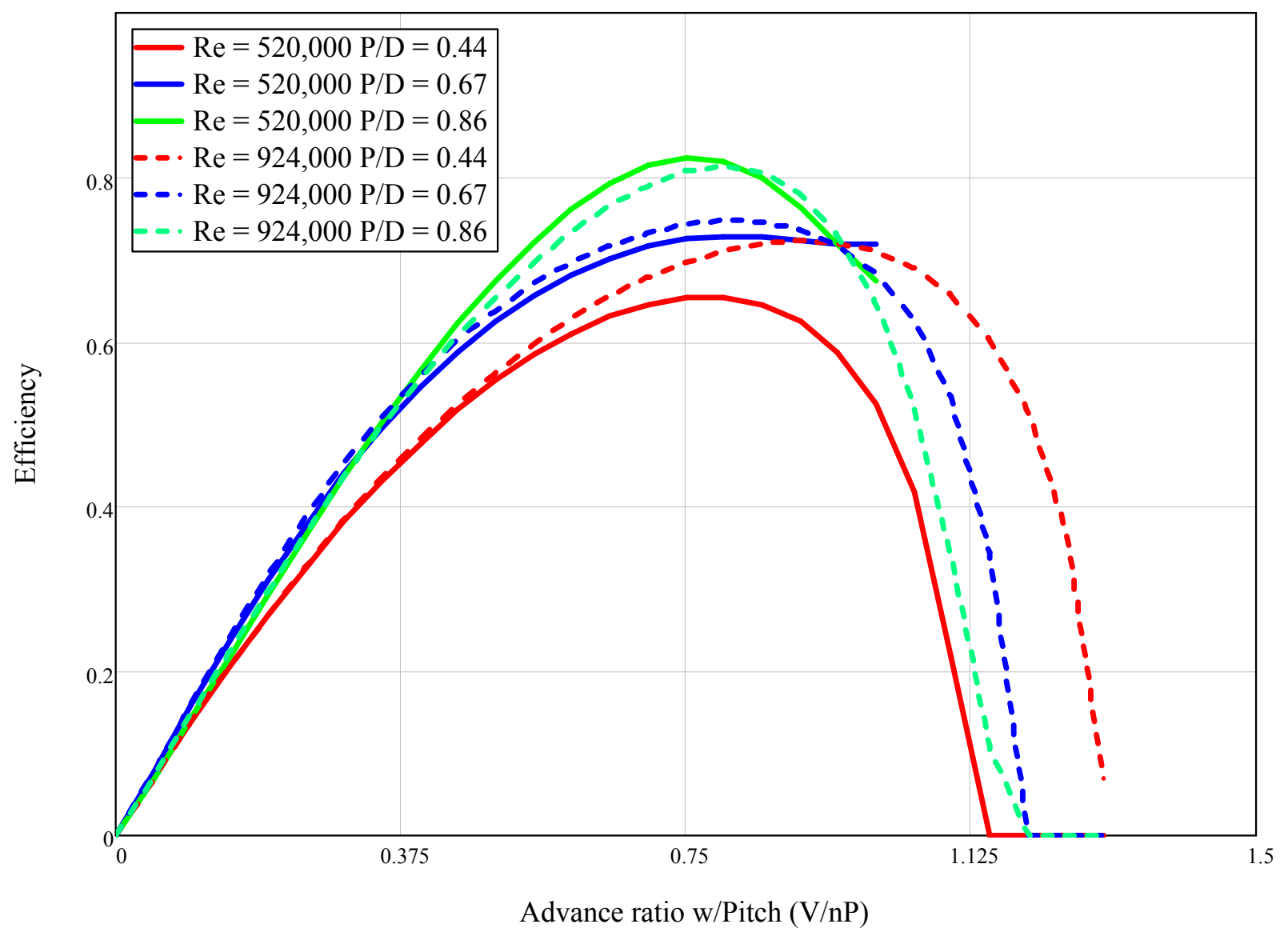

Figure 73: Propeller efficiency vs. advance ratio using pitch

Notice that the graph here shows that the efficiency reaches zero at a value of $\sim 1.2$, which is nonzero. This might be because the manufacture has defined pitch geometrically instead of using the zero lift line. Since the airfoil on the propeller blade is cambered, it does not cross the origin on a $\mathrm{Cl}$ vs. alpha graph. Instead it crosses as -4 degrees. This would shift the ideal pitch of the propeller blade.

The $75 \%$ ratio was verified with a different manufacture's propeller. A folding, 3 bladed, Feudenthaler propeller was tested using all the test methods as carried out with the APC. The results verified that the optimal pitch of any small propeller can be chosen by matching the advance ratio pitch ratio to 0.75 


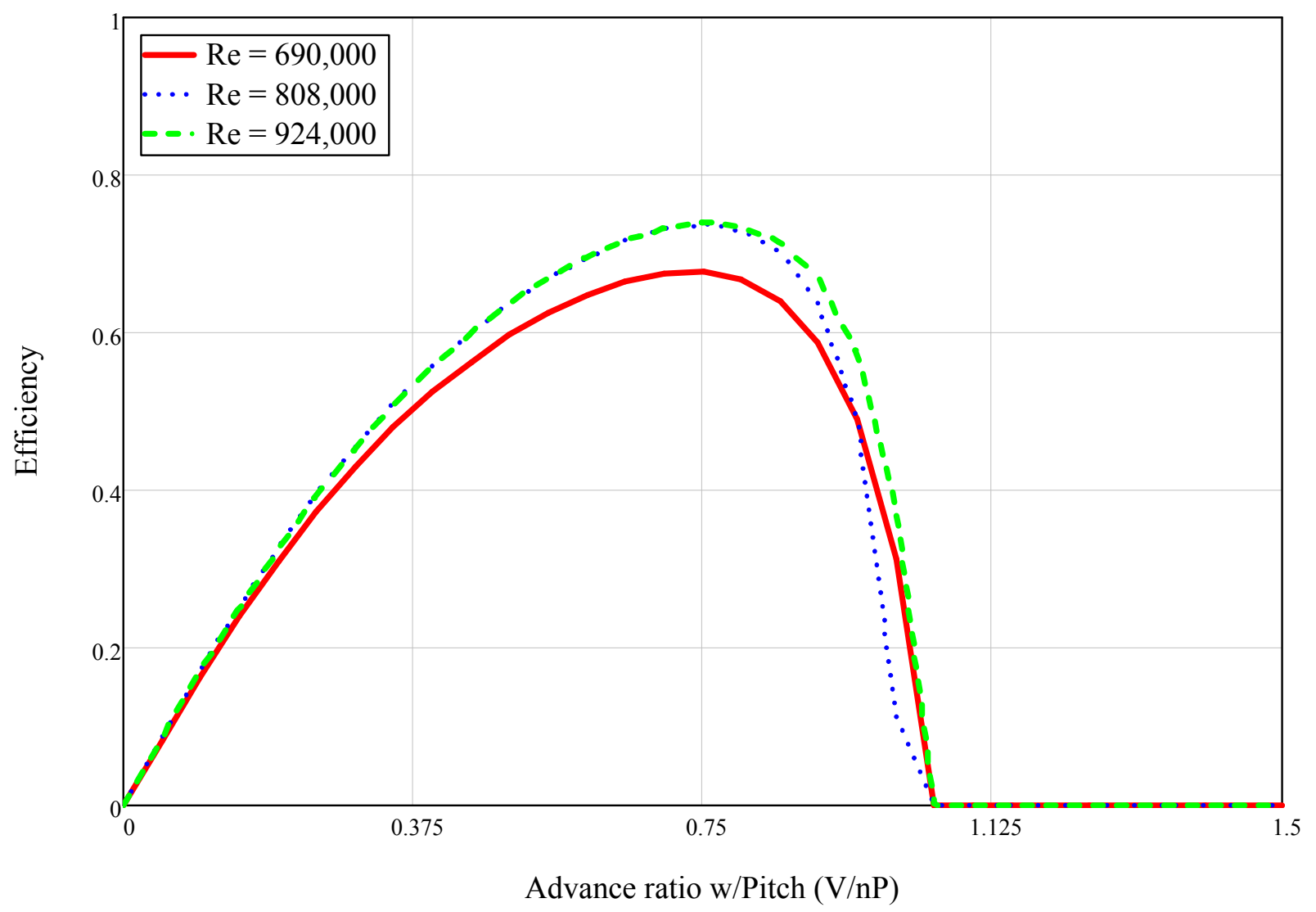

Figure 74: Propeller efficiency vs. advance ratio using pitch with 3 bladed Feudenthaler 


\section{CHAPTER 6. CONCLUSIONS AND FUTURE WORK}

The research and experimental results shown here have proven that low Reynolds numbers have a strong effect on small propellers. This effect can not only reduce the efficiency, but also affects the pitch of a propeller. Any propulsion systems' designer should take into account the Reynolds number of a propeller blade. The propeller should be tested at the RPM that it will be flying at. Data from a propeller experiment can be used if it was tested in the same RPM region.

The next step in this process is to design a propeller taking the low Reynolds number effect into account. This would mean a modified twist distribution of the blade, as well as, the selection of a low Reynolds airfoil. The chord distribution could also be modified to increase the local Reynolds number on the blade element itself. The first step of this would be to design a mathematical model that theoretically determines the performance of a propeller. Once this model matches the experimental performance of the propeller tested, a new design can be made. Optimization techniques should be implemented which can shape the blade as well as modify the diameter and pitch to obtain the most efficient propeller. 


\section{CHAPTER 7. APPENDIX}

\subsection{GUI Interface}

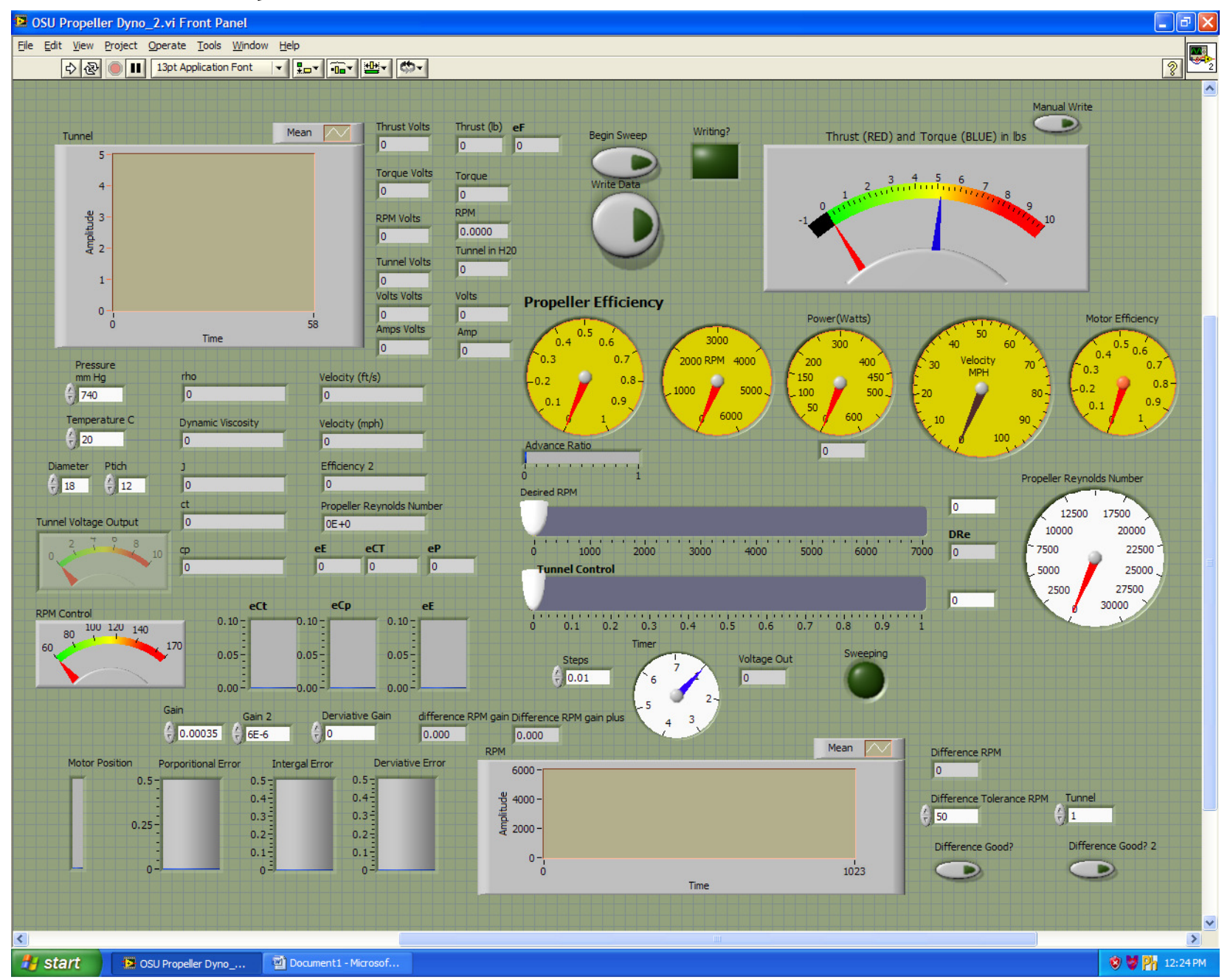




\subsection{Data Output Columns listings}
A. Time stamp
B. Thrust in pounds
C. Torque in lbs*in
D. Repeat of above
E. N/A
F. RPM
G. N/A
H. Density
I. Viscosity
J. N/A
K. Advance ratio $(\mathrm{J})$
L. Coefficient of Thrust
M. Coefficient of Power
N. Efficiency of propeller
O. Propeller Reynolds number
P. N/A
Q. N/A
R. RPM
S. Volts
T. Amps being drawn
U. Watts
V. N/A
W. N/A
X. N/A
Y. Motor Efficiency
Z. Diameter of Propeller
AA. Pitch of Propeller
BB. Pitch over Diameter ratio 


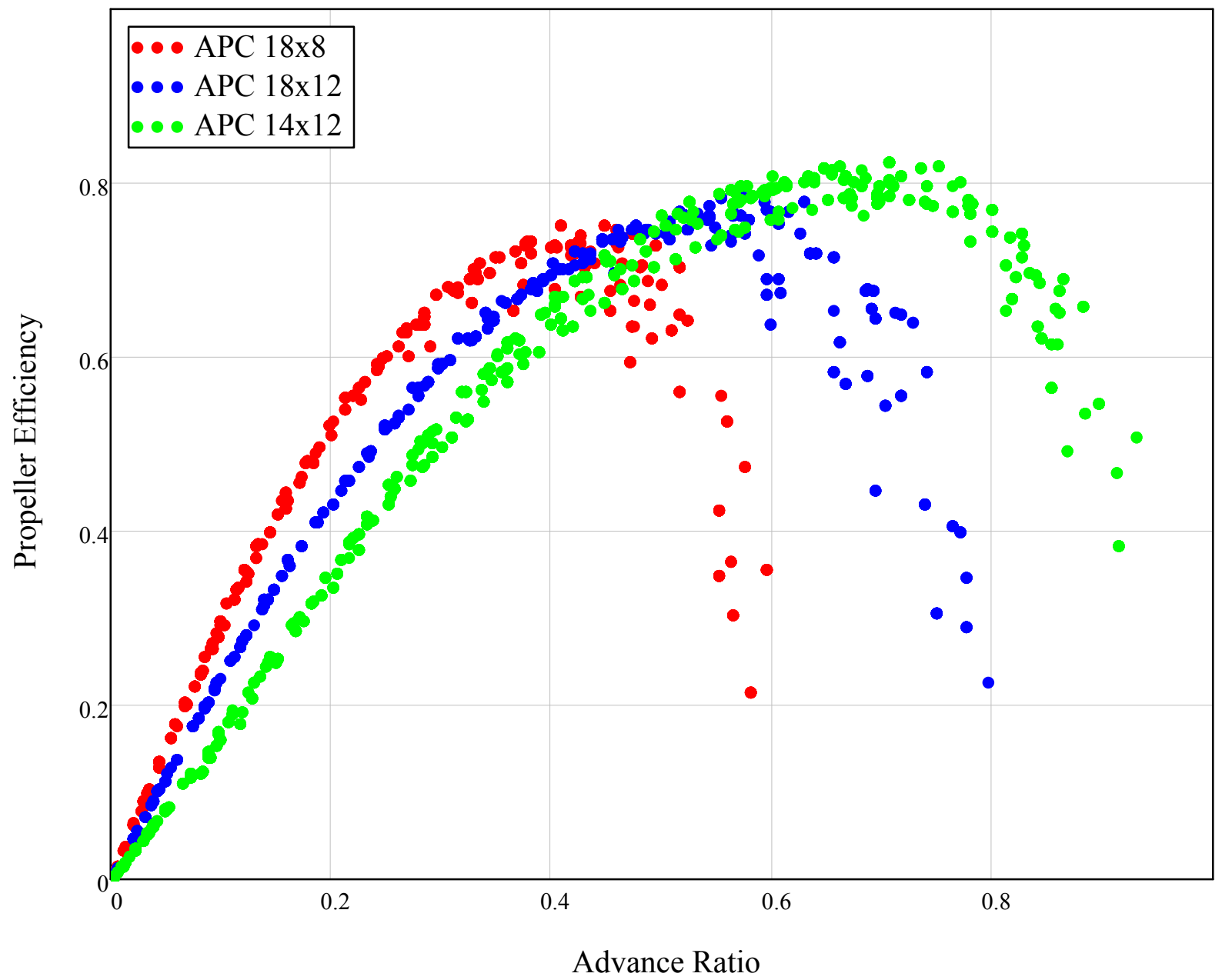

All the data collected from several experiment runs with different propellers at different Reynolds numbers 


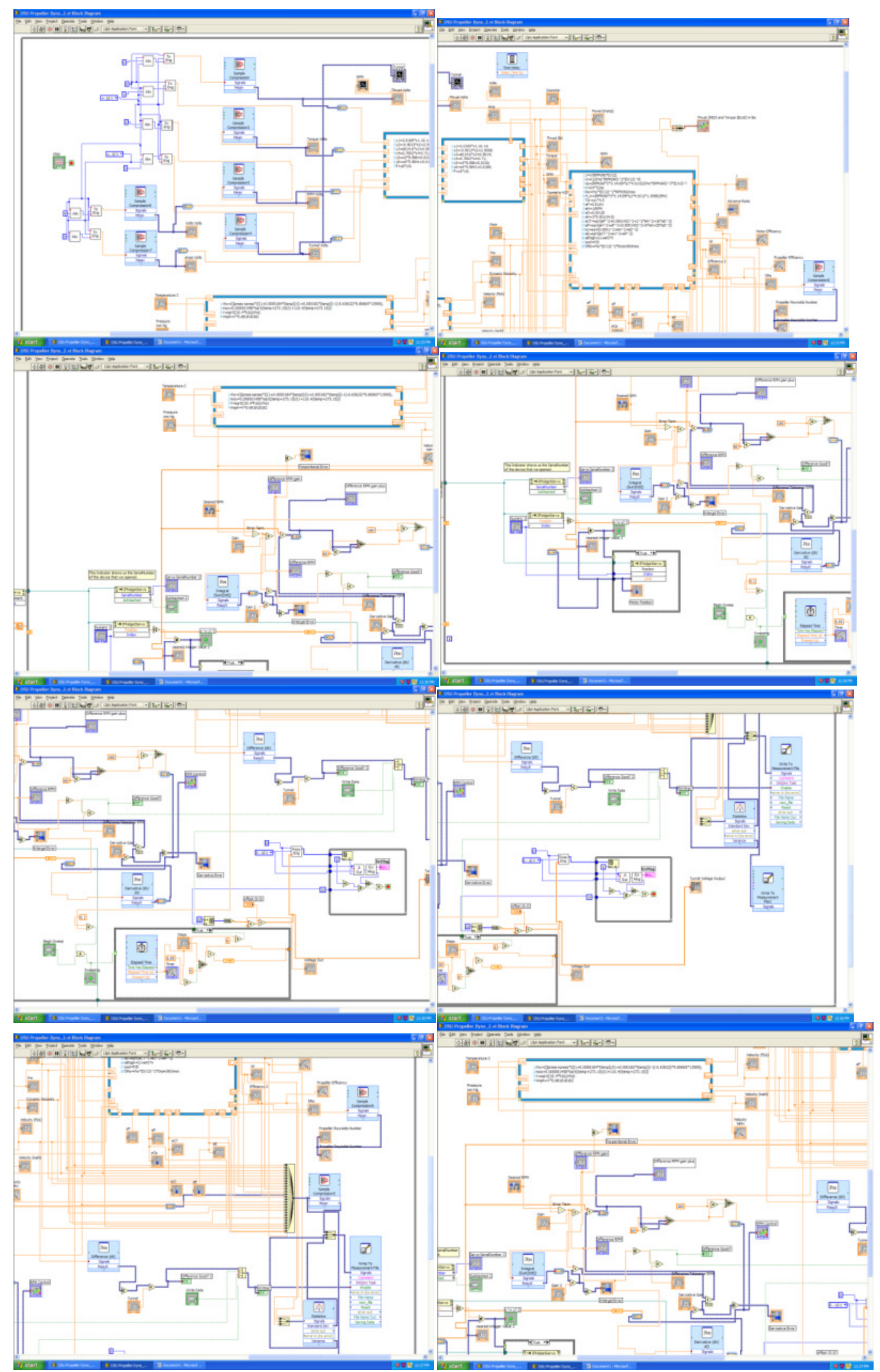

LabVIEW $^{\text {TM }}$ Code 


\section{CHAPTER 8. WORKS CITED}

APC Propellers. (n.d.). Retrieved September 4, 2009, from http://www.apcprop.com/

Ash, R. L., Miley, S. J., \& Landman, D. (2001). Evolution of Wright Flyer Propellers between 1903 and 1912. AIAA.

Borst, V. H. (1977). Design and Analysis of Propellers for Low Reynolds Number Application to Mini-RPV's. Society of Automotive Engineers, 14.

Buckingham, E. (1914). On Physically Similar Systems; Illustrations of the Use of Dimensional Equations. Bureau of Standards , 345-376.

Carroll, T. J., \& Carroll, T. R. (January-February 2005). Wright Brothers' Invention of 1903

Propeller and Genesis. JOURNAL OF AIRCRAFT .

Drela, M. (1989). XFOIL: An Analysis and Design System for Low Reynolds Number Airfoils.

Cambridge: MIT Department of Aeronautics and Astronautics.

Hoerner, S. F. (1965). Fluid-Dyanmic Drag. Bakersfield: Horner Fluid Dynamics.

Kline, S. J. (1985). The Purposes of Uncertainty Analysis. Journal of Fluids Engineering , 107, $153-160$.

Kochersberger, K., Wald, Q., \& Hyde, K. (2000). An Experimental and Analytical Evaluation of the 1911 Wright Bent End. AIAA .

Kotcherlakota, A. (2006). Small Scale Propller Experiments. Stillwater: Oklahoma State University.

McCormick, B. W. (1995). Aerodynamics Aeronautics and Flight Mechanics (2 ed.). Hoboken, NJ: John Wiley \& Sons, Inc. 
Merchant, M. P. (2004). Propeller Performance Measurements for Low Reynolds Number Unmanned Aerial Vehicle Applications. Wichita: Wichita State University. Mueller, T. J. (2001). Fixed and Flapping Wind Aerodyanmics for Micro Air Vehicle Applications. Danvers: American Institude of Aeronautics and Astronautics.

Mueller, T. J., \& Batill, S. M. (1982). Experimental Studies of Seperation on a Two-Dimensional Airfoil at Low Reynolds Number. AIAA , 457-463.

Neu, S. (n.d.). Neu Motors. Retrieved 8 23, 2009, from

http://www.neumotors.com/Site/Dyno_data.html

Pohlen, L. J., \& Mueller, T. J. (1984). Boundary Layer Characteristics of Miley Airfoil at Low Reynolds Numbers. Journal of aircraft , 21 (9), 658-664.

Reynolds, O. (1883). An experimental investigation of the circumstances which determine whether the motion of water shall be direct or sinuous, and of the law of resistance in parallel channels. Philosophical Transactions of the Royal Society, 935-982.

Roskam, J., \& Lan, C.-T. E. (1997). Airplane Aerodynamics and Performance. Lawrence, Kansas: Design, Analysis and Research Corporation.

Scharphf, F. D., \& Mueller, T. J. (1992). Experimental Study of a Low Reynolds Number Tandem Arifoil Configuration. Journal of Aircraft , 232.

Sullivan, J. M. (2005). Revolution or Evolution? The Rise of the UAVs. Technology and Society , 94-101.

Tibery, C., \& Wrench Jr., J. (1964). Tables of Goldstein factor. Washington, DC: Applie Mathematics Laboratory.

Wald, Q. R. (2006). The aerodynamics of propellers. Port Townsend: Elsevier Ltd.

Weick, F. E. (1930). Aircraft Propeller Design. New York: McGraw-Hill Book Company, Inc. 
Weick, F. E. (1926). Propeller Design A Simple System Based on Model Propeller Test DataIII. Washignton: National Avsiory Committee for Aeronautics. 
VITA

Dustin Eli Gamble

Candidate for the Degree of

Master of Science

\section{Thesis: AUTOMATED DYNAMIC PROPELLER TESTING AT LOW REYNOLDS} NUMBERS

Major Field: Aerospace and Mechanical Engineering

Biographical:

Education:

Completed the requirements for the Master of Science or Arts in Aerospace and Mechanical Engineering at Oklahoma State University, Stillwater, Oklahoma in December, 2009.

Bachelors of Aerospace and Mechanical Engineering Earned at Oklahoma State University earned in 2008

Experience:

Internships at Lockheed Martin Aeronautics during summers 2008 \& 2009 Chief Engineer of Design Build Fly OSU Orange Team 2008

World Records for Hydrogen fuel cell powered airplane "Pterosoar" 2007

World Records for electric power battery aircraft "Dragonfly" 2006

Professional Memberships: American Institute of Aeronautics and Astronautics 
Name: Dustin Eli Gamble

Institution: Oklahoma State University
Date of Degree: December, 2009

Location: Stillwater, Oklahoma

Title of Study: AUTOMATED DYNAMIC PROPELLER TESTING AT LOW REYNOLDS NUMBERS

Pages in Study: 68

Candidate for the Degree of Master of Science

Major Field: Aerospace and Mechanical Engineering

Scope and Method of Study:

Experiments were conducted on small propellers using a motor dynamometer in a wind tunnel. The effects at different Reynolds numbers were observed. To maintain the Reynolds number and consistent test procedures, the wind tunnel speed and propeller RPM was dynamically controlled using a PI controller. The propeller diameters ranged from 14 inches to 18 inches with local Reynolds numbers between 20,000 and 400,000 at advance ratios from 0 to 1 .

Findings and Conclusions:

The experiments validated that the performance of small propellers are affected by low Reynolds numbers. The efficiency of small propellers varied based on their rotational speed. The results demonstrated an efficiency dependence on non-dimensional propeller constants, including the Reynolds number. The Reynolds number also affects the design pitch of a propeller. Additionally, a pitch based advance ratio definition found that the propellers tested have a constant ratio. At this constant ratio, a propeller achieves peak efficiency. 